\title{
Regulation of CHK1 inhibitor resistance by a c-Rel and USP1 dependent pathway
}

Jill E. Hunter ${ }^{1}$, Amy E. Campbell ${ }^{2}$, Nicola L. Hannaway ${ }^{1}$, Scott Kerridge ${ }^{1}$, Saimir Luli ${ }^{3}$, Jacqueline A. Butterworth ${ }^{1}$, Helene Sellier ${ }^{1}$, Reshmi Mukherjee ${ }^{1}$, Huw D. Thomas ${ }^{3}$, Philip J. Brownridge $^{2}$, Johnathon Coxhead ${ }^{1}$, Leigh Taylor ${ }^{1}$ Peter Leary ${ }^{4}$, Megan S.R. Hasoon ${ }^{4}$ Ian Collins $^{5}$, Michelle D. Garrett ${ }^{6}$, Claire E. Eyers ${ }^{2}$ and Neil D. Perkins ${ }^{1^{*}}$

${ }^{1}$ Newcastle University Biosciences Institute Faculty of Medical Sciences

Newcastle University Newcastle Upon Tyne, NE2 4HH, UK

${ }^{2}$ Centre for Proteome Research, Department of Biochemistry and Systems Biology, Institute of Systems, Molecular and Integrative Biology,

University of Liverpool,

Liverpool L69 7ZB, U.K.

${ }^{3}$ Newcastle University Clinical and Translational Research Institute

Preclinical In Vivo Imaging (PIVI)

Faculty of Medical Sciences

Newcastle University

Newcastle Upon Tyne, NE2 4HH, UK

${ }^{4}$ Bioinformatics Support Unit,

Faculty of Medical Sciences

Newcastle University

Newcastle Upon Tyne, NE2 4HH, UK

${ }^{5}$ The Institute of Cancer Research

Sutton, SM2 5NG, UK

${ }^{6}$ School of Biosciences,

Stacey Building,

University of Kent,

Canterbury, Kent, CT2 7NJ, UK

* corresponding author

Tel. 01912088866

Fax. 01912087424

Email: neil.perkins@ncl.ac.uk 


\begin{abstract}
We previously discovered that deletion of $c-R e l$ in the E $\mu$-Myc mouse model of lymphoma results in earlier onset of disease, a finding that contrasted with the expected function of this

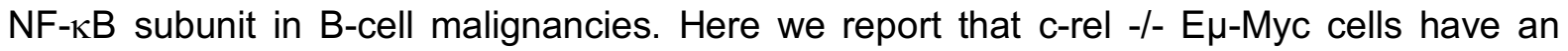
unexpected and major defect in the CHK1 pathway, with almost undetectable levels of CHK1 and CLSPN protein leading to therapeutic resistance to the highly specific CHK1 inhibitor (CHK1i) CCT244747. Similar downregulation of CHK1 levels was also seen in CCT244747 resistant U2OS osteosarcoma cells. Further investigation revealed that downregulation of the deubiquitinase USP1 is responsible, at least in part, for these effects. Importantly, we

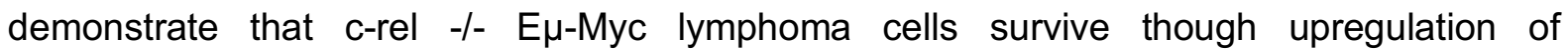
compensatory PI3K/AKT pathway activity. Moreover, targeting this pathway with Pictilisib (GDC-0941) effectively killed c-rel -/- E $\mu-M y c$ in vivo, while having no effect on wild type $E \mu-$ Myc cells. This data reveals an NF-KB regulated pathway controlling CHK1 activity in cancer cells and identifies a potential mechanism for both acquiring and overcoming $\mathrm{CHK} 1 \mathrm{i}$ resistance in cancer patients.
\end{abstract}




\section{Introduction}

The development of targeted therapies has changed the face of cancer therapeutics, and allowed for a more personalised approach to treatment based on the molecular basis of an individual's tumour. One of the oncogenic kinases identified as a 'druggable' target is the checkpoint kinase, CHK1, and for this reason, CHK1 inhibitors (CHK1i) represent a potential new class of anti-cancer therapies, and are currently in clinical trials [1].

CHK1 plays a critical role in the response to DNA replication stress, which results from stalled DNA replication forks. In cancer cells, replication stress drives both genomic instability and clonal evolution [2-4]. It can be induced by a variety of mechanisms, including DNA damaging agents and by oncogenes such as MYC driving hyper-DNA replication [2-4]. Critical regulators of the cellular response to DNA replication stress, not only include CHK1 but also the kinase Ataxia Telangiectasia and Rad3 Related, which protect against tumorigenesis through promoting DNA repair [4, 5]. However, once established, tumour cells can also become addicted to this pathway since it enables them to survive on-going, potentially lethal, genomic instability. Therefore, inhibiting key protein kinases, such as CHK1, provides a potential therapeutic strategy in order to specifically target tumours that have become dependent on their activity [6].

We, and others have shown that there is significant crosstalk, between the ATR-CHK1 and the NF-kB pathways. For example, we have shown in vitro that $\mathrm{CHK} 1$ can phosphorylate the RelA subunit in its transactivation domain at Thr 505 (T505), resulting in inhibition of tumour promoting activities of NF-kB, including resistance to apoptosis, autophagy, cell proliferation and cell migration [7-11]. Direct phosphorylation of the p50 NF-KB subunit on Ser 329 by CHK1 was demonstrated following DNA damage $[12,13]$, and in vitro phosphorylation of p50 by $\mathrm{CHK} 1$ also regulates DNA binding of the p50 homodimer through phosphorylation on Ser 242, and homodimerisation through a phosphorylation event on Ser 337 [14]. Moreover, Kenneth et al [15], found that the c-Rel NF-KB subunit controls the expression of Claspin in cancer cell lines. This is of particular relevance as Claspin is an adaptor protein 
associated with DNA replication forks that is required for ATR dependent phosphorylation of CHK1 following DNA replication stress $[16,17]$.

Resistance to kinase inhibitors is a problem that is being frequently encountered in the clinic. Resistance can be either de novo or acquired, and there may be multiple different mechanisms that contribute to the resistance to particular agents. In the case of de novo resistance, this is primarily due to tumour intrinsic factors or patient specific pharmacokinetic factors such as the absorption, distribution, metabolism and excretion of the drug (reviewed in [18]).

Acquired resistance can develop via a variety of different mechanisms, such as the mutation of the drug target or a gene within a closely related signalling pathway. Histological changes, such as epithelial to mesenchymal transition [19] and increased growth factor production have also been reported to result in acquired resistance [20,21]. However, one of the biggest contributing factors to acquired resistance is activation of compensatory signalling pathways, so that the cell can bypass the need for the inhibited target, often referred to as "bypass signalling" [18]. There are multiple strategies being successfully employed in the clinic, including the targeting of these compensatory signaling pathways, either alone or in combination with the initial targeted agent. This strategy has been used in mutant melanoma, where a combination of RAF and MEK inhibitors have shown efficacy [22].

Using an integrated 'omics-based approach we have investigated how de novo resistance to $\mathrm{CHK} 1 \mathrm{i}$ is acquired and can be overcome, revealing that this is a two-step process. Initial downregulation of the CHK1 signalling pathway can occur by multiple different mechanisms; here we show that loss or inactivation of the CHK1 pathway either via loss of Claspin, or of the CHK1 deubquitinase (DUB), USP1, contributes to the downregulation of CHK1 signalling in our cell line and animal models. Secondly, we reveal upregulation of a compensatory PI3K/AKT signalling pathway in mice that are resistant to $\mathrm{CHK} 1$ inhibition which serves to drive continued tumour growth. Targeting this compensatory PI3K/AKT signaling pathway represents a potential therapeutic opportunity in patients developing resistance to CHK1 i in the clinic. 


\section{Results}

\section{$\mathrm{E} \mu-\mathrm{Myc} / \mathrm{c}-\mathrm{Re}^{-/}$lymphoma cells are resistant to CHK1 inhibition}

Since over-expression of c-Myc is a feature of many types of cancer and results in DNA replication stress leading to genomic instability and tumorigenesis we chose the well-

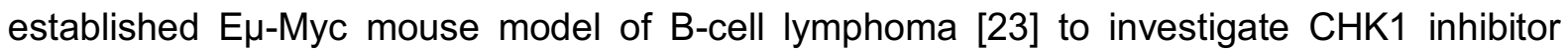
resistance mechanisms. We have previously found that knockout of the c-Rel NF-kB subunit in the E$\mu$-Myc model results in earlier onset of cancer [24]. We have also previously shown that the CHK1 inhibitor (CHK1i) SRA737, having just completed Phase I clinical trials (https://clinicaltrials.gov/ct2/show/NCT02797964), inhibits the growth of re-implanted wild type (WT) E $\mu$-Myc cells [25]. Since c-Rel has been described as an indirect regulator of CHK1 activity through inducing CLSPN gene expression [15], we were therefore curious as to

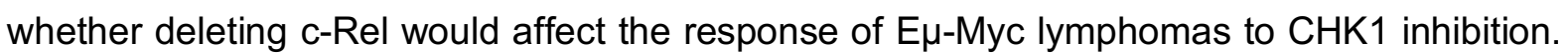
We hypothesised that less efficient activation of CHK1 by ATR in response to MYC-induced DNA replication stress in c-rel -/- E $\mu$-Myc lymphoma cells could affect $\mathrm{CHK} 1$ inhibitor sensitivity.

We therefore evaluated the effectiveness of the CHK1i CCT244747 (the precursor compound to SRA737) in vivo by analysing its effect on the growth of five transplanted WT $\mathrm{E} \mu-\mathrm{Myc}$ and $\mathrm{E} \mu-\mathrm{Myc} / \mathrm{c}-\mathrm{Re}{ }^{-}$tumours. Each tumour, which originated from an independently derived spontaneous tumour bearing mouse, was implanted via the lateral tail vein into six syngeneic C57BI/6 recipient mice and three were treated orally with CCT244747 once a day for nine days, while three received a vehicle control (Fig. 1A \& S1A). Treatment commenced at the point at which tumours in the lymphoid organs became palpable. After treatment, we observed a striking reduction in lymphoid tumour burden in all mice re-implanted with WT E $\mu$ Myc lymphomas (Figs. 1B \& C, S1B). By contrast, four of the five E $\mu-M y c / c-R e \digamma^{\digamma} / y m p h o m a s$ showed no significant reduction in lymphoid tumour burden after CCT244747 treatment, with one lymphoma only exhibiting a partial response in the thymus and cervical lymph nodes. The

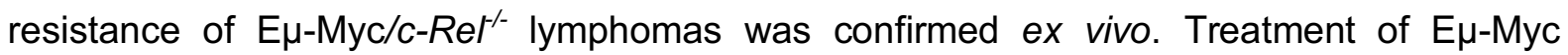


lymphoma cells with CCT244747 for 96 hours resulted in small but significant differences, with WT cells having reduced viability relative to $\mathrm{E} \mu-\mathrm{Myc} / \mathrm{c}-\mathrm{Re}^{\gamma^{-}}$or E $\mu-\mathrm{Myc} / \mathrm{Rela}^{\mathrm{T} 505 \mathrm{~A}}$ tumour cells (Fig. S1C). The reduced magnitude of the effects of CCT244747 seen here likely reflects the

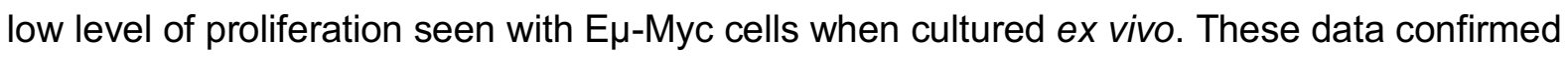
that regulation of CHK1/DNA replication stress by the c-Rel NF- $\mathrm{KB}$ subunit in vivo significantly affects the sensitivity of E $\mu-M y c$ lymphoma cells to CHK1 inhibition.

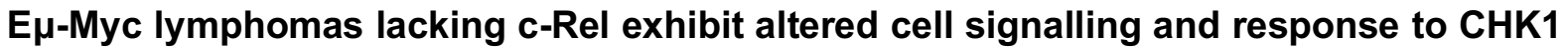 inhibition}

Since CLSPN can be an NF-kB target gene [15] we next investigated its expression

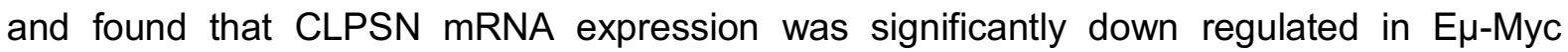
lymphoma cells lacking c-Rel (Fig 1D). By contrast, we did not observe any effect of deleting c-Rel on CLSPN expression in normal B-cells (Fig S1D). This loss of CLSPN expression in c$\mathrm{Rel}^{-/-}$E $\mu$-Myc lymphomas implied that ATR/CHK1 signalling might be compromised in these cells. We therefore decided to explore how these cells respond at an early time point to a single dose of ССТ244747 in vivo. By examining this acute response, we reasoned that we could gain insights into how signalling in these cells had been rewired, something not possible with longer ССT244747 treatment where the mixture of dead, dying and surviving lymphoma cells was likely to confound analysis.

We therefore investigated the nature of the response of re-implanted WT and c-Rel ${ }^{-/-}$ E $\mu$-Myc lymphomas following acute treatment with the CHK1i, CCT244747, using a combination of (phospho)proteomic and RNA Seq analysis. To determine the optimum timepoint to study these changes, mice re-implanted with WT E $\mu$-Myc lymphomas were culled at various timepoints following a single dose of CCT244747 (Fig S2A). We observed a significant DNA damage response, as measured by an increase in phosphorylation of $\mathrm{H} 2 \mathrm{AX}$ at Ser 139, after 8 hours of treatment that diminished at 24 and 48 hours (Fig 2A). Moreover, we observed high levels of CHK1 phosphorylation at Ser 345 at the 8-hour time point, an ATR- 
mediated phosphorylation site that typically becomes hyperphosphorylated upon CHK1 inhibition [26] 8 hours after treatment that diminished at 24 and 48 hours (Fig 2A). Hence we used this 8 hour timepoint in all further studies (Fig 2A).

To explore regulation of phosphorylation-mediated signalling pathways in these reimplanted lymphomas, we used tandem mass tag (TMT)-based isobaric labelling to quantify relative changes in both total protein levels and phosphopeptide abundance (Fig S2B). Of the $\sim 4,000$ proteins identified at a $1 \%$ false discovery rate (FDR), $\sim 2500$ were quantified in at least three biological replicates (Supp Data File 1). At the phosphopeptide level, we identified over 6,500 phosphopeptides, quantifying $\sim 3,350$ in at least three replicates $(>4,500$ in at least two bioreps; Supp Data File 1). STRING analysis (https://string-db.org/) of the phosphoproteomic data from WT E $\mu$-Myc lymphomas revealed a cluster of proteins known to be associated with CHK1, whose phosphorylation was down regulated upon CCT244747 treatment (Fig 2B, S2C, Supp Data File 2). This data confirmed effective targeting of CHK1 by CCT244747 in vivo.

Further analysis of this data demonstrated a significant number of CCT244747 effects

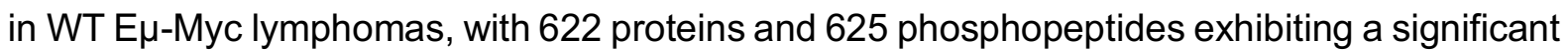
up- or down-regulation (P-value $\leq 0.05)$ (Fig 2C \& D). By contrast, relatively few effects of CHK1 inhibition were seen at the mRNA level from parallel RNA Seq data analysis (Fig S2D, Supp Data Files $3 \& 4$ ). This indicated that 8 hours after a single dose of CCT244747, the vast majority of the effects seen are post-transcriptional in nature. Strikingly, in comparison, relatively few significant changes were seen on the total and phospho proteomes following acute CCT244747 treatment of $\mathrm{c}-\mathrm{Rel}^{-{ }^{--}} \mathrm{E} \mu-\mathrm{Myc}$ lymphomas, with only 162 proteins and 89 phosphopeptides being significantly differentially regulated (P-value $\leq 0.05)$ (Fig 3A \& B, Fig. S3A). This was consistent with the lack of effectiveness on lymphoma growth seen with long term CCT244747 dosing (Fig. 1B \& C).

c-Rel -/- E $\mu-M y c$ lymphomas have intrinsically downregulated the CHK1 pathway prior to inhibitor treatment 
To better understand the underlying mechanistic basis that explains the relatively few

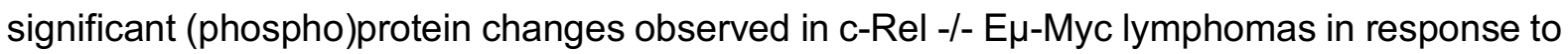
treatment with CCT244747, we compared the protein and gene expression profiles of reimplanted WT and c-Rel ${ }^{-/}$E $\mu-M y c$ lymphomas in the absence of CCT244747 treatment. The proteomic data revealed that $\mathrm{c}-\mathrm{Re}^{-/-} \mathrm{E} \mu-\mathrm{Myc}$ lymphoma cells had substantially rewired their cell signalling pathways, with a high level of both down and upregulated phosphopeptides compared to wild type (Fig. 3C, S3A). Furthermore, $\sim 75 \%$ of the protein level changes (and over $62 \%$ of the phosphorylation changes) that were induced in response to Chk $1 \mathrm{i}$ in the WT $\mathrm{E} \mu$-Myc lymphomas were also observed in the $\mathrm{c}-\mathrm{Rel}^{-1-}$ samples with no treatment, suggesting that inhibition of Chk1 with CCT244747 may be working in part by modulating c-Rel-dependent processes (Supp Fig 3B \&C, Supp Data File 5.

STRING analysis of proteins with downregulated phosphopeptides revealed that many have known connections to CHK1 (Fig 3D, Fig S3D, Supp Data File 2). Moreover, of the 284 unique downregulated phosphosites seen in wild type cells upon CCT244747 treatment, 186

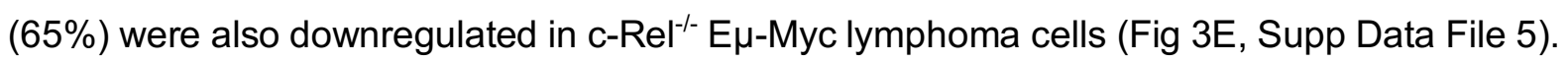
Analysis of the total protein differences between reimplanted $c-\mathrm{Re}^{-/-} \mathrm{E} \mu-\mathrm{Myc}$ lymphomas and their wild type counterparts, either with or without CCT244747 treatment revealed a similar trend. There were substantial differences between WT and $c-\mathrm{Rel}^{-{ }^{--}} \mathrm{E} \mu-\mathrm{Myc}$ lymphomas in the absence of CHK1 inhibition (Fig 3F). Moreover, there was considerable overlap between these differences and the effect observed in WT cells upon treatment with CCT244747 also being downregulated in $\mathrm{c}-\mathrm{Re}^{-/-} \mathrm{E} \mu-\mathrm{Myc}$ lymphomas (without CHK1i treatment) (Fig 3G, Supp Data File 5). Interestingly, the magnitude of the changes seen in the CCT244747 treated wild type cells was generally lower in both cases than that seen constitutively in c-Rel ${ }^{-/-} \mathrm{E \mu}-\mathrm{Myc}$ lymphomas (Fig. S4). These results demonstrated that $c-$ Rel $^{-/} \mathrm{E} \mu$-Myc lymphomas have an intrinsic defect in CHK1 kinase signalling, comparable to the effect of inhibiting CHK1 in WT

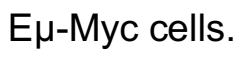

We next analysed our RNA Seq data to obtain further insights into the intrinsic transcriptional reprogramming of $c-\mathrm{Rel}^{-/} \mathrm{E} \mu-\mathrm{Myc}$ lymphoma cells that leads to these proteomic 
and cell signalling alterations (Supp Data Files $3 \& 4$ ). Functional profiling of the genes whose mRNA expression varied between WT and $c-R_{e} r^{--}$E $\mu-M y c$ cells, revealed that of the 36 genes associated with 'Activation of ATR in response to replication stress' (REAC:R-HSA-176187), $32(89 \%)$ were down regulated in $c-$ Rer $^{--}$E $\mu$-Myc cells (Fig.S5A). This included transcript levels of CHEK1, which we subsequently validated using qPCR (Fig 4A). However, of the 342 proteins whose levels were decreased in $\mathrm{c}^{-\mathrm{Re}^{-}} \mathrm{E}^{-} \mathrm{E} \mu$-Myc cells compared to their wild-type counterparts, only $163(47 \%)$ were also down regulated at the transcript level suggesting that there are very large post-transcriptional effects on protein expression (Fig S5B \& Supp Data File 5).

Western blot analysis confirmed not only that signalling through CHK1 was impaired in $c-R_{e} H^{-\alpha} E \mu-M y c$ cells, but that there was almost complete loss of CHK1, CLSPN, CDC25B and CDK2 protein (Figs 4B \& C, and S5C). Taken together, these data suggest that the de novo resistance of the $c-\mathrm{Rel}^{-/} \mathrm{E} \mu$-Myc lymphoma cells to CCT244747 arises from these cells already having downregulated the CHK1 pathway. Consequently, further attempts to inhibit CHK1 have little effect.

\section{Acquired resistance to CHK1 inhibition in U2OS cells is also associated with downregulation of CHK1 protein}

We next wished to determine if similar effects on CHK1 levels and activity were seen as a consequence of acquired CHK1 inhibitor resistance. To this end, we generated four independent isolates of the osteosarcoma cell line, U2OS, with resistance to the CHK1i, CCT244747. This was achieved through long term culture in increasing concentrations of СCT244747. Eventually, the resistant U2OS cells were able to proliferate in high CCT244747 concentrations (Fig 5A), and retain clonogenic potential (Fig 5B). As controls we also passaged U2OS cells in the absence of CCT244747 to mimic effects of long-term culture.

To determine whether CHK1 signalling was affected during the acquisition of resistance, we performed Western blotting and qPCR analyses. Western blot analysis confirmed that CHK1 levels were reduced in three out of four CCT244747 resistant isolates 
(Fig 5C \& 6E). We also observed a reduction in Claspin transcript levels in CHK1i resistant U2OS cells (Fig 5D), mirroring the observations in our resistant mice (Fig 1A). However, by contrast with our data from $c-\mathrm{Re}^{-/} \mathrm{E} \mu-\mathrm{Myc}$ lymphoma cells, there was no reduction in $\mathrm{CHK} 1$ mRNA levels as determined by RNA Seq and qPCR analysis (Fig. 5D, Supp Data Files 6 \& 7). We also failed to observe a reduction in expression of the 32 genes associated with 'Activation of ATR in response to replication stress' ( $>2$ fold change, adj $p$-value $<0.05$; REAC:R-HSA-176187) that were down regulated in the $c-\mathrm{Re}^{-/} \mathrm{E} \mu-\mathrm{Myc}$ cells. The exception to this was again CLSPN, where the RNA Seq data confirmed a 2.2 fold downregulation (adj p-value $=0.0037)$ in CCT244747 resistant U2OS cells (Fig 5E \& Supp Data Files 6 \& 7).

Taken together, the data suggest a clear and consistent mechanism of both de novo and acquired resistance, namely down regulation CHK1 levels and thus activity, thereby rendering cells insensitive to a $\mathrm{CHK} 1$ inhibitor.

\section{Deregulation of ubiquitin mediated proteolysis in $c-\mathrm{ReI}^{-/-} \mathrm{E \mu}-\mathrm{Myc}$ lymphoma cells}

Results from our E $\mu$-Myc lymphoma cell proteomic analysis above, together with the loss of CHK1 protein but not mRNA in the CCT244747 resistant U2OS cells, suggested that post-transcriptional regulation of protein levels was also a key factor in acquisition of both de novo and acquired CHK1 inhibitor resistance. We therefore further analysed our RNA Seq data from wild type and $c-\mathrm{Re}^{-/} \mathrm{E} \mu$-Myc lymphoma cells. Of the genes associated with ubiquitin dependent proteolysis we observed a number of changes. Most strikingly, there was significant down regulation of the deubiquitinases (DUBs) USP1 and USP14 (Fig. 6A, Supp Data Files 3 \& 4). USP1 has been reported as a key regulator of DNA repair and is known to play a role in stabilising members of the DNA damage response, such as FANCD2 and PCNA $[27,28]$ by removing the $K 48$ ubiquitin degradation signal. Interestingly, one report suggested that USP1 can act directly as a DUB for CHK1, by protecting it from proteasomal degradation [29], USP14 is often overexpressed in tumours and has been shown to deubiquitinate and stabilise the androgen receptor in models of breast and prostate cancer [30, 31]. Downregulation of these genes was validated by qPCR (Fig 6B), while western blot analysis 
revealed almost total loss of these proteins in extracts prepared from $c-R^{2}{ }^{-}$E $\mu-M y c$ lymphoma cells (Fig. 6C \& S6A). Moreover, both USP1 mRNA and protein were down regulated in U2OS CCT244747 resistant cells (Fig. 6D \& E). siRNA depletion of c-Rel in wild type U2OS cells, resulted in a reduction of both USP1 and USP14 mRNA and protein and this was associated with downregulation of CHK1 protein but not CHK1 mRNA (Fig. 6F). This suggests a conserved mechanism through which c-Rel can directly or indirectly control the transcription of USP1 and USP14, with the loss of one or both of these DUBs then results in CHK1 protein destabilisation.

To determine whether USP1, or USP14 were responsible for CHK1 protein stability in our model, we depleted both with siRNAs in WT U2OS cells. We found that loss of USP1 resulted in almost total loss of $\mathrm{CHK} 1$ at the protein level, suggesting that in the absence of this DUB, CHK1 is targeted by the proteasome for degradation (Fig. 6G). Depletion of USP1 also reduced USP14 levels, while the USP14 siRNA resulted in partial loss of CHK1, suggesting that the activity of these DUBs may be linked. This was confirmed by treatment of WT U2OS cells with the USP1 inhibitor ML323 [32], which also resulted in a reduction in CHK1 protein levels (Fig. 6H and S6B). Importantly, inhibition of the proteasome using MG132, restored CHK1 protein in the resistant U2OS cells (Fig 6H and S6B), and this in turn induced a DNA damage response indicated by an increase in $\mathrm{yH} 2 \mathrm{AX}$ phosphorylation, suggesting a potential restoration of $\mathrm{CHK} 1 \mathrm{i}$ sensitivity.

To determine whether loss of either USP1 or USP14, was responsible for the resistance to $\mathrm{CHK} 1$ inhibitors we performed clonogenic assays following knockdown of either USP1 or USP14 in combination with CCT244747 treatment. Although, loss of USP1 itself reduced the clonogenic potential of U2OS cells, the remaining cells now exhibited complete resistance to CHK1 inhibition (Fig. 6I). By contrast, depletion of USP14 U2OS cells had little effect on either clonogenic potential or CCT244747 sensitivity (Fig 6I). These data indicates that loss of USP1 can contribute to CHK1 inhibitor resistance in this model. 


\section{PI3K/AKT signalling is upregulated in CHK1i resistant lymphoma cells, and provides an}

\section{alternative therapeutic strategy}

The dramatic loss of CHK1 signalling we observed in the $c-\mathrm{ReF}^{--} \mathrm{E} \mu-\mathrm{Myc}$ lymphoma cells raised the question of how these cells were surviving and coping with ongoing DNA replication stress. Especially given our previous observation [24] that lymphomas in these mice arise earlier than in wild type controls. The activation of compensatory signalling pathways is a major contributing factor in the development of resistance to kinase inhibitors [33-38], and often goes hand-in-hand with the tumour cell having bypassed the need for the drug target, which we observed in our models of both de novo and acquired resistance (Figs 4 \& 5).

USP1 has also been demonstrated to be a negative regulator of AKT kinase signalling [39] We therefore further analysed our proteomic analysis following acute CHK1i treatment (Fig 2) to see if there was any evidence for altered AKT pathway activity, focusing this time on upregulated phosphosites and proteins. These analyses revealed 480 upregulated phosphosites $(p<0.05)$ and 624 upregulated proteins $(p<0.05)$ in $c-R e l^{-/-} E \mu-M y c$ lymphomas with no CCT244747 treatment compared to wild type controls (Fig. 7A \& B, S3A, Supp Data File 5). Similar to our observation with downregulated phosphosites and proteins, there was considerable overlap with those seen in wild type E $\mu$-Myc lymphomas after CCT244747

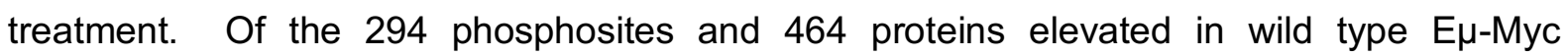
lymphomas in response to CCT244747, $51 \%$ and $74 \%$ respectively were also upregulated in $\mathrm{c}-\mathrm{Rel}^{-/-} \mathrm{E} \mu-\mathrm{Myc}$ cells (Fig. 7A \& B, Supp Data File 5). However, the magnitude of the increases seen in the CCT244747 treated wild type cells was lower in both cases than that seen constitutively in c-Rel ${ }^{--}$E $\mu-M y c$ lymphomas (Fig. S4). Nonetheless, this further confirmed the similarities between $\mathrm{c}-\mathrm{Re}^{-/-} \mathrm{E} \mu-\mathrm{Myc}$ lymphomas and their wild type equivalents following CHK1 inhibition.

Given the links between USP1 and AKT, we next examined potential links with known AKT networks. STRING analysis revealed that 71 phosphorylated proteins upregulated in c-

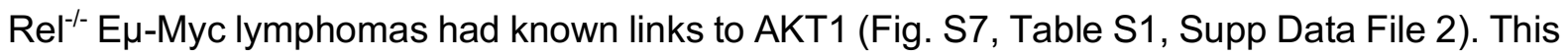
included AKT1S1, and analysis of the phosphoproteomic data (Supp Data File 1) revealed 
this was a consequence of phosphorylation at T247, a known site of AKT (Protein Kinase B) phosphorylation [40]; To determine if these upregulated phosphoproteins arose due to changes in AKT activity, we examined AKT1 phosphorylation status by western blot, revealing significant upregulation of AKT1 phosphorylation on Ser473 and Thr308 in the c-Rel ${ }^{-/-}$ lymphomas, phosphorylation sites know to be required for full AKT activity (Fig 7C, S8. Interestingly, the AKT1 activator, PI3K, also exhibited elevated levels of phosphorylation P85 (Y458) / P55 (Y199) (Fig S8). AKT phosphorylation is known to induce a pro-survival response by inducing the phosphorylation of GSK3 $\beta$ on Ser9, which inhibits its activity, and this again was upregulated in the $\mathrm{c}-\mathrm{Rel}^{-/-}$cells. We also observed an increase in ERK 1/2 phosphorylation at its activation sites T202/Y204. but not of JNK or p38 MAP kinase signalling (Fig 7C-E, S8). This result potentially explains how these tumours are surviving loss of $\mathrm{CHK} 1$, as they have hyper-activation of the PI3K/AKT and ERK pathways, which are known to inhibit apoptosis and cell cycle arrest $[41,42]$.

We hypothesised that if upregulation of the PI3K/AKT and ERK pathways allowed c$\mathrm{Rel}^{-/-} \mathrm{E} \mu-M y c$ lymphomas to survive in the absence of $\mathrm{CHK} 1$, then targeting either of these pathways would be a good therapeutic strategy. We decided to evaluate the effectiveness of the PI3K inhibitor, GDC-0941/Pictilisib [43] in vivo, by analysing its effect on the growth of

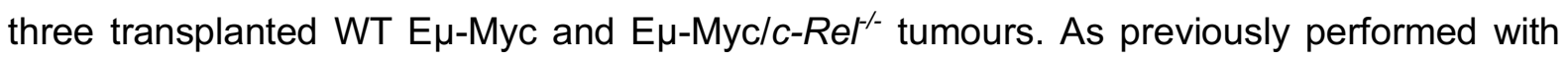
CCT244747 (Fig. S1A), each tumour was implanted into six syngeneic C57BI/6 recipient mice and three were treated orally with GDC-0941 once a day for nine days, while three received a vehicle control (Fig. 8, S9 \& 10). After treatment, we observed a striking reduction in lymphoid tumour burden in all mice re-implanted with $\mathrm{c}-\mathrm{Re}^{-/-} \mathrm{E} \mu-\mathrm{Myc}$ tumours and treated with GDC-0941 (Figs Fig. 8, S9 \& 10). By contrast, in all of the WT E $\mu$-Myc tumours, no significant reduction in lymphoid tumour burden was seen after GDC-0941 treatment. These data confirmed that elevated PI3K/AKT signalling critically compensates for loss of $\mathrm{c}-\mathrm{Re}^{-/-}$in these

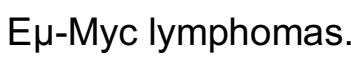




\section{Discussion}

Loss of c-Rel has many effects in the E $\mu$-Myc lymphoma model, underlining the critical role this NF-kB subunit plays in this context [24]. Indeed, our proteomic data demonstrates that these $c-\mathrm{Re}^{-/} \mathrm{E} \mu-\mathrm{Myc}$ lymphoma cells undergo a comprehensive rewiring of their cell signalling pathways. Here we have explored the basis for the resistance of $c-R e H^{--} \mathrm{E} \mu-\mathrm{Myc}$ lymphomas to $\mathrm{CHK} 1$ inhibition, and revealed a pathway regulating the response to DNA replication stress in cancer.

One dramatic finding underpinning the development of resistance to the CCT244747 $\mathrm{CHK} 1$ inhibitor in this model, is the loss of $\mathrm{CHK} 1$ protein itself, together with other components of the DNA replication stress response and cell cycle pathways. The mechanisms underlying this effect are complex but at the core of this is down regulation of the mRNA and protein of the USP1 DUB in $\mathrm{c}-\mathrm{Re}^{-/}$cells. USP1 has been previously linked to numerous components of the DNA damage response $[27,28,44]$ and implicated as a CHK1 DUB [29]. We propose that c-Rel directly, or indirectly, regulates the expression of USP1. Consequently, in the absence of c-Rel, loss of USP1 results in destabilisation of CHK1 and other pathway components (Figure 9). Contributing towards this effect, is the parallel loss of Claspin expression (Figure 1D, 4B, 5E). Whether it is the initial loss of Claspin, thus breaking the link between ATR and CHK1, that leads to subsequent effects via USP1 is not known. Nonetheless, it is probable that the parallel loss of USP1 and Claspin works synergistically to down regulate CHK1 protein levels and activity. This complexity, however, ultimately creates a simple explanation for CHK1

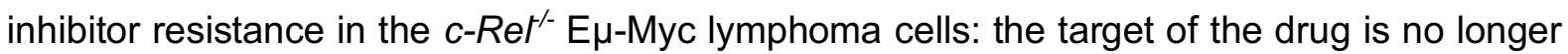
present.

Our proteomic data demonstrates that $c-R e I^{-/} \mathrm{E} \mu-M y c$ lymphomas strikingly resemble wild type $\mathrm{E} \mu-\mathrm{Myc}$ cells that had received the $\mathrm{CHK} 1$ inhibitor (Figure 3). This raised the question of why did the WT cells die when CHK1 is inhibited but the $c-R e r^{--} \mathrm{E} \mu-\mathrm{Myc}$ lymphoma do not. We observed significant upregulation of phospho and total proteins in both WT E $\mu$-Myc lymphomas treated with the CHK1 inhibitor as well as intrinsically in $c-R_{e}{ }^{-/}$cells (Figures 2, 3 \& 7). This suggested that activation of a compensatory pathway was allowing the $c-R e I^{-/} \mathrm{E} \mu-$ 
Myc lymphomas to survive and proliferate, even in the absence of CHK1 and the presence of ongoing DNA replication stress. Since USP1 has also been demonstrated to be a negative regulator of AKT pathway signalling [39, 45-47], we took a candidate approach to resolving this. Examination of the phospho proteomic data and subsequent western blot analysis of protein extracts, revealed that indeed, AKT1 pathway activity was upregulated in $c-R e H^{-} \mathrm{E} \mu-$ Myc lymphomas (Figure 7). Moreover, treatment with the PI3K inhibitor Pictilisib, selectively targeted the $c-\mathrm{Re}^{/-} \mathrm{E} \mu-\mathrm{Myc}$ lymphomas, while having no effect on their WT equivalents (Figure 8). The second component of our model therefore is that loss of c-Rel and consequently USP1, automatically results in activation of a parallel survival pathway involving PI3K and AKT. Importantly, in the phospho proteomic data, we also observed similar upregulation of AKT1 linked phospho proteins in WT EM-Myc lymphomas treated with CCT244747, albeit at a much reduced level relative to the $c-R e r^{--} \mathrm{E} \mu-\mathrm{Myc}$ lymphomas (Supp Figure 7). This implies that cotargeting of PI3K or AKT might increase the efficiency of CHK1 inhibition in cancer therapy.

This study does not address how relevant this data is to human cancer in general and the use of CHK1 inhibitors clinically. However, key components of the work from E $\mu-\mathrm{Myc}$ lymphomas, such as down regulation of CHK1 and USP1 protein, were also seen in independently derived populations of CCT244747 resistance U2OS cells (Figure 6). Moreover, down regulation of USP1 in WT U2OS cells resulted in loss of CHK1 protein and CCT244747 resistance. Nonetheless, the more widespread significance of these findings requires further study before it can be inferred that this is a common mechanism in human cancer.

Previous CHK1 inhibitor studies have shown other potential routes of drug sensitivity and resistance. An analysis of MK-8776, performed in multiple sensitive cell lines and resistant cell lines showed that cells responsive to this CHK1 inhibitor upregulated CDK2 and cyclin A after treatment, with an associated increase in double stranded DNA breaks [48]. Drug sensitivity was also associated with an increased accumulation of CDC25A [48]. By contrast, cells that were MK-8776 resistant failed to dephosphorylate and thus activate CDK2 
[48]. Another study into the MK-8776 CHK1 inhibitor found that cells deficient in MRE11 were resistant to CHK1 inhibition [49]. A study of the CHK1 inhibitor LY2603618 (Rabusertib) in head and neck cell lines also found that sensitivity to the drug was dependent on CDK activity, and highlighted CDK1 as being significant in drug response. Here, increased CDK1 levels were indicative of reduced drug sensitivity, potentially due to upregulation of origin firing and this overcoming $S$ phase replication stalling [50]. Research into the PF-00477736 CHK1 inhibitor resistant mantle cell lymphoma cell line JEKO-1, showed that resistant cells had a shorter S phase and a reduced expression of cell cycle checkpoint proteins, including cyclin D1 [51]. These studies both contrast with our analysis, where we found that $c-\operatorname{Re}^{-{ }^{-}} \mathrm{E} \mu-\mathrm{Myc}$ lymphomas exhibited reduced levels of CDK1 and CDK2.

Given these contrasting findings, it is likely that the mechanism used in the development of $\mathrm{CHK} 1$ inhibitor resistance will be dependent on the tumour context, with both the cell type and oncogene/tumour suppressor status having a key role. Nonetheless, our data suggests that down regulation or mutation of USP1 is likely to be a common feature arising in patients undergoing therapy involving a CHK1 inhibitor. Not only will loss of USP1 lead to loss of the target of the inhibitor but will also result in upregulation of AKT or ERK activity as a compensatory mechanism. We propose that should CHK1 inhibitors become commonly used cancer therapeutics that this pathway of resistance be investigated further. Our data implies that treatment with a PI3K or AKT pathway inhibitor could be a valuable strategy either in the treatment of patients whose tumours develop resistance to CHK1 inhibition or potentially as a combination therapy to enhance the effectiveness of initial treatment. 


\section{Acknowledgements}

We would like to thank Iglika Ivanova, Sonia Rocha, Laura Greaves, Niall Kenneth, Urszula McClurg, Suzanne Madgwick, Adrian Yemm, and all members of the NDP laboratory for helpful advice and assistance. JEH and AEC are funded by Cancer Research UK grant C1443/A22095. JEH previously received funding from Leukemia Lymphoma Research grant 11022 and Cancer Research UK grant C1443/A12750. NLH was funded by Cancer Research UK Clinical PhD studentship. JAB and HS were funded by Wellcome Trust grant 094409. IC and MDG receive funding from Cancer Research UK grant number C309/A11566, and MDG also from the University of Kent. This work was also supported by instrumentation funding from the Biotechnology and Biosciences Research Council (BBSRC; BB/M012557/1 and BB/R000182/1). Figure 9 was created with Biorender.com.

\section{Author contributions}

JEH: performed majority of experimental work. Contributed to design of experiments and manuscript writing.

AEC: performed all proteomics work and analyses. Contributed to manuscript writing.

PJB: supported mass spectrometry methods development and proteomics data analysis.

NLH \& SK: performed downstream analysis of mouse tissues.

SL, JAB \& HS assisted with procedures involving E $\mu-M y c$.

$\mathrm{RM}$ : contributed to in vitro experimental work.

HDT: provided training and assisted with lymphoma re-implantation studies.

JC \& LT: performed RNA-Seq analysis

PL \& MSRH: performed bioinformatics analysis of RNA-Seq data

MDG and IC: contributed to the design and analysis of experiments.

CEE: contributed to design of experiments and manuscript writing.

NDP: contributed to design of experiments, analysis of RNA Seq and proteomic data, manuscript writing. 
bioRxiv preprint doi: https://doi.org/10.1101/2021.05.26.445425; this version posted May 27, 2021. The copyright holder for this preprint (which was not certified by peer review) is the author/funder, who has granted bioRxiv a license to display the preprint in perpetuity. It is made available under aCC-BY-NC-ND 4.0 International license.

Conflict of Interest Disclosures: IC and MDG are current or former employees of The Institute of Cancer Research, which has a commercial interest in CHK1 inhibitors. The other authors disclose no conflicts of interest. 


\section{Methods}

\section{Ethics statement}

All mouse experiments were approved by Newcastle University's Animal Welfare and Ethical Review Board. All procedures, including the of breeding genetically modified mice, were carried out under project and personal licenses approved by the Secretary of State for the Home Office, under the United Kingdom's 1986 Animal (Scientific Procedures). Animals were bred in the Comparative Biology Centre, Newcastle University animal unit, according to the FELASA Guidelines.

\section{Mouse models}

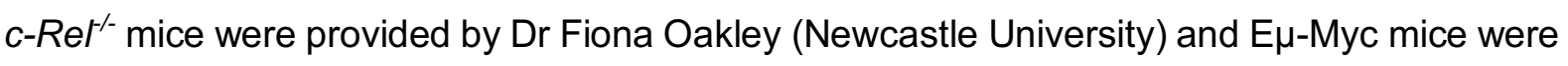
purchased from The Jackson Laboratory, Maine, USA. C57BI/6 mice used for re-implantation studies were purchased from Charles River (UK). Male E $\mu$-Myc transgenic mice that were used as breeding stock were omitted from the survival analysis. In all experiments, the relevant pure C57BI/6 (WT) strain was used as a control. No blinding of groups in mouse studies was performed. All mice were designated to an experimental group dependent on their genotype.

\section{Drugs and compounds}

CCT244747 was synthesized as described [52] by MedKoo Biosciences. GDC-0941/Pictilisib was purchased from Med Chem Express. All other compounds were purchased from Sigma Aldrich.

\section{Resistant cell line generation}

U2OS cells were cultured in increasing concentrations of CCT244747, starting with the $\mathrm{IC}_{50}$ concentration of $1 \mu \mathrm{M}$. The concentration of ССT244747 was doubled at each passage to a final concentration of $8 \mu \mathrm{M}$. WT controls were given an equivalent amount of DMSO to account for any DMSO-related toxicity. 


\section{SiRNA Knockdown transfections}

U2OS cells were transfected with $10 \mathrm{nM}$ siRNA targeting either USP1, USP14 or cRel (ONTARGET plus Smart pool, Dharmacon) or a Non-specific siRNA control using Dharmafect 4 transfection reagent, according to manufacturer's protocols. Cells were harvested, or used in downstream assays 72 hrs post-transfection, once target depletion had been confirmed.

\section{Cell viability assays}

Freshly isolated $\mathrm{E} \mu-\mathrm{Myc}$ or $\mathrm{E} \mu-\mathrm{Myc} / \mathrm{c}-\mathrm{Re} \mathrm{H}^{--}$tumour cells $\left(5 \times 10^{5}\right.$ per well), or WT or CHK1i resistant U2OS $\left(5 \times 10^{3}\right.$ per well) were seeded into 96-well plates. Increasing concentrations of CHK1 inhibitor, СCT244747, or solvent controls were added to three replicate wells. After 96hrs, viability was quantified using the PrestoBlue Cell Viability Reagent (ThermoFisher Scientific, UK), according to manufacturer's instructions.

\section{Cell survival assays}

Exponentially growing WT or CHK1i resistant U2OS were treated for $24 \mathrm{~h}$ with $1 \mu \mathrm{M}$ CHK1 inhibitor, ССТ244747 or solvent controls before re-seeding onto Petri dishes at known cell number $(1000,2500$ or 5000 cells/dish). Colonies were fixed 14 days later with methanol:acetic acid (3:1) and stained with $0.4 \%(w / v)$ Crystal Violet. Cloning efficiencies were normalized to untreated controls.

\section{Gene expression analysis using quantitative real-time PCR}

Total RNA was purified from snap frozen $\mathrm{E} \mu-\mathrm{Myc}$ or $\mathrm{E} \mu-\mathrm{Myc} / \mathrm{c}-\mathrm{Re} \mathrm{I}^{--}$tumour samples by homogenisation using Precellys 24 ceramic mix bead tubes (Stretton Scientific Ltd) in a Precellys 24 benchtop homogeniser (Stretton Scientific Ltd) at 6500 rpm for $30 \mathrm{~s}$. Following this, samples were passed through Qiashredders (Qiagen, Crawley, UK) and RNA was purified using the Qiagen RNeasy mini kit according to manufacturer's instructions. Total 
RNA from exponentially growing WT or CHK1i resistant U2OS was extracted using the PeqGold total RNA extraction kit (Peqlab), according to manufacturer's instructions.

RNA was measured for purity and concentration with the NanoDrop1000 (ThermoFisher Scientific) and reverse transcribed using the Quantitect Reverse transcription Kit (Qiagen) according to manufacturer's instructions. Quantitative real-time PCR was performed on 20ng cDNA, in triplicate, using predesigned Quanititect Primer assays (Qiagen) to the following murine genes; Clspn, Chek1, Usp1, Usp14 and human genes CLSPN, CHEK1, USP1 and USP14. These samples were run and analysed on a Rotor-gene $Q$ system (Qiagen), using murine Rp/13a or human RPL13A primers as an internal control. All CT values were normalised to Rp/13a/RPL13A levels.

\section{Western blotting}

Whole cell extracts were prepared from snap frozen pieces of $\mathrm{E} \mu-\mathrm{Myc}$, or $\mathrm{E} \mu-\mathrm{Myc} / \mathrm{c}-\mathrm{Re} \mathrm{H}^{-}$ tumour tissue. Snap frozen tumour was lysed in PhosphoSafe ${ }^{\text {TM }}$ Extraction Reagent using the Precellys24 ceramic mix bead tubes (Stretton Scientific Ltd) in a Precellys $₫ 24$ homogeniser (Stretton Scientific Ltd) at 6500 rpm for 30s, then extracted according to the PhosphoSafe ${ }^{\mathrm{TM}}$ Extraction Reagent manufacturer's instructions. In the case of cell lines samples, cell pellets were washed with ice-cold PBS, and lysed using PhosphoSafe ${ }^{\mathrm{TM}}$ Extraction Reagent (MerckMillipore, Watford, UK), according to manufacturer's protocols. Protein quantification was undertaken using the BCA protein assay, and samples resolved by standard denaturing SDSPAGE gels using the Criterion Gel System (Biorad). Samples were transferred onto PVDF membrane (Merck-Millipore) before being probed with the primary antibody. Horseradish peroxidase-conjugated secondary antibodies (anti-mouse; Sigma (UK), anti-rabbit; Sigma, UK) and enhanced chemiluminscence reagent (Thermo-scientific, UK) were used for detection.

\section{Antibodies}

Antibodies used were CHK1 (phospho S345) (2341 Cell Signaling), CHK1 (2360 Cell Signaling), USP1 (14346-1-AP Proteintech), USP14 (14517-1-AP Proteintech), yH2AX (2577 
bioRxiv preprint doi: https://doi.org/10.1101/2021.05.26.445425 - this version posted May 27, 2021. The copyright holder for this preprint (which was not certified by peer review) is the author/funder, who has granted bioRxiv a license to display the preprint in perpetuity. It is made available under aCC-BY-NC-ND 4.0 International license.

Cell Signaling), GSK3B (phospho S9) (9336 Cell Signaling), GSK3B (9315 Cell Signaling), ERK 1/2 (phospho T202, Y204) (9101 Cell Signaling), ERK 1/2 (9102 Cell Signaling), AKT (phospho S473) (9271 Cell Signaling), AKT (phospho T308) (9275 Cell Signaling), AKT (9272 Cell Signaling), JNK (phospho T183, Y195) (9251 Cell Signaling), JNK (9252 Cell Signaling), p38 (phospho T180, Y182) (9211 Cell Signaling), p38 (9212 Cell Signaling), BACTIN (A5441 Sigma), CDC25B (9525 Cell Signaling), CHK2 (3440 Cell Signaling), PEA15 (2780 Cell Signaling), PI3K (phospho Y458) (4228 Cell Signaling), PI3K (4229 Cell Signaling), Karyopherin (sc-137016 Santa Cruz), CDK2 (2546 Cell Signaling), CDK1 (phospho Y15) (4539 Cell Signaling) and CDK1 (9116 Cell Signaling). Antibodies to the murine form of Claspin was generated by Moravian Biotechnologies. Anti-rabbit IgG (A6154 Sigma and 7074 Cell Signaling) and anti-mouse IgG (7076 Cell Signaling) HRP-linked secondary antibodies were used for western blot detection.

\section{E $\mu$-Myc mice studies}

$\mathrm{E} \mu-\mathrm{Myc} / \mathrm{c}-\mathrm{Re} \mathrm{I}^{+/-}$offspring were generated by mating $c-R e H^{--}$female mice with $\mathrm{E} \mu-\mathrm{Myc}$ male mice, further $\mathrm{E} \mu-\mathrm{Myc} / \mathrm{c}-\mathrm{Rel}^{--}$mice were generated by crossing $\mathrm{E} \mu-\mathrm{Myc} / \mathrm{c}-\mathrm{ReI}^{+/-}$males with $\mathrm{c}^{-}$

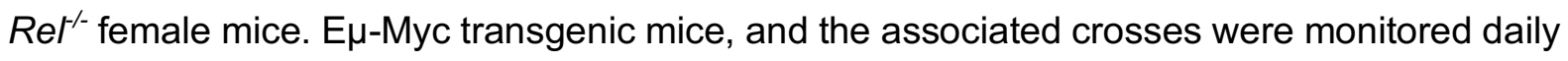
and were sacrificed at pre-determined end-points, defined as the animal becoming moribund, losing bodyweight/condition and/or having palpable tumour burden at any lymphoid organ site. Moribund mice were necropsied and single cell suspensions were prepared from tumourbearing organs. Briefly, lymph nodes, spleen or thymus were homogenised through a cell strainer, and single cell suspension collected in DMEM (Lonza) supplemented with 10\% FBS, $5 \mathrm{mM}$ L-glutamine, $5 \mathrm{mM}$ sodium pyruvate, $1 \mu \mathrm{M}$ L-asparagine and $50 \mu \mathrm{M} \beta$-mercaptoethanol (Sigma Aldrich). These cell suspensions were then frozen in 90\% FBS/10\% DMSO for longterm storage and transplantation.

\section{Reimplantation studies}


For tumour therapy studies, $2 \times 10^{6} \mathrm{E} \mu-\mathrm{Myc}$ or $\mathrm{E} \mu-\mathrm{Myc} / \mathrm{c}-\mathrm{Re} \mathrm{F}^{--}$tumour cells from male mice were transplanted intravenously (IV) via the lateral tail vein into 8-week old male C57BL/6 recipients. Mice were monitored daily using parameters such as their bodyweight and food and water consumption to assess disease progression. Mice were necropsied when they became moribund and the tumour burden assessed.

Oral administration of the CHK1 inhibitor, CCT244747, prepared as previously described [25], or vehicle control (65\% PEG-400, 20\% Tween-20, 10\% $\mathrm{H}_{2} \mathrm{O}, 5 \%$ DMSO (all Sigma Aldrich)) was initiated when tumours became palpable (approximately 10 days after inoculation of $\mathrm{E} \mu-\mathrm{Myc}$ cells, and 20 days after inoculation of $\mathrm{E} \mu-\mathrm{Myc} / \mathrm{c}-\mathrm{Rel}^{--}$cells). During efficacy studies, ССТ244747 was given as a single agent, bolus dose (100 mg/kg p.o.) for 9 consecutive days. Lymphoid tumour burden and final tumour weights were measured at necropsy 24 hours after the final dose. For acute proteomic studies, CCT244747 was given as a single agent, bolus dose (100 mg/kg p.o.) once approximately 14 days after inoculation

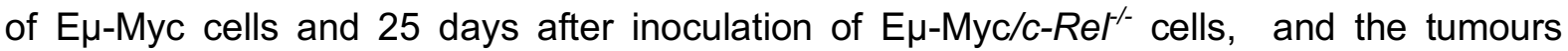
necropsied either 8,24 or 48 hours after dosing.

Oral administration of the PI3K inhibitor, GDC-0941, prepared as previously described [53], or vehicle control (0.5\% methyl cellulose, $0.2 \%$ Tween-80 (all Sigma Aldrich)) was initiated when tumours became palpable and given as a single agent, bolus dose (100 mg/kg p.o.) for 9 consecutive days. Lymphoid tumour burden and final tumour weights were measured at necropsy 24 hours after the final dose.

\section{Proteomics and analysis}

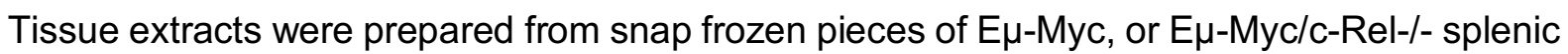
tumours. Briefly, tissue samples were suspended in $100 \mathrm{mM}$ triethylammoniumbicarbonate (TEAB) with a mixture of protease and phosphatase inhibitors (cOmplete Mini EDTA-free protease inhibitor cocktail plus PhoSTOP phosphatase inhibitor cocktail, both obtained from Roche), homogenised by bead beater, and sonicated on ice. Lysed extracts were incubated 
with $0.1 \%(\mathrm{w} / \mathrm{v})$ Rapigest SF (Waters) for $10 \mathrm{~min}$ at $80^{\circ} \mathrm{C}$, left to cool, and incubated for 10 min on ice with Benzonase endonuclease (Merck Millipore) to digest nucleic acids. Samples were centrifuged $\left(14,000 \mathrm{~g}, 10 \mathrm{~min}\right.$ at $\left.4^{\circ} \mathrm{C}\right)$ to pellet cell debris. Protein concentration of the clarified lysate was ascertained by Bradford assay. Protein $(200 \mu \mathrm{g})$ from each sample was aliquoted for protein digestion.

Disulphide bonds were reduced (4 $\mathrm{mM}$ DTT in $100 \mathrm{mM} \mathrm{TEAB}, 10 \mathrm{~min}$ at $60^{\circ} \mathrm{C}$ ) and free cysteines alkylated with iodoacetamide (14 mM in $100 \mathrm{mM}$ TEAB, for $30 \mathrm{~min}$, RT in the dark). lodoacetamide was quenched by addition of DTT to a final concentration of $7 \mathrm{mM}$. Proteins were digested with $2 \%(\mathrm{w} / \mathrm{w})$ trypsin overnight at $37^{\circ} \mathrm{C}$ with gentle agitation. Resultant peptides were labelled with TMT 6-plex reagents (Thermo Scientific) at an 8:1 tag:protein ratio as per the manufacturer's instructions, with labels assigned to samples randomly for the first biological replicate and shifted for each subsequent replicate. The labelling reaction was quenched by addition of $0.3 \%(\mathrm{v} / \mathrm{v})$ hydroxylamine (Thermo Scientific) in $100 \mathrm{mM}$ TEAB. TMT labelled peptides were mixed and dried to completion by vacuum centrifugation before resuspending in $100 \mathrm{mM}$ TEAB/ 1\% TFA to hydrolyse the Rapigest SF (RT, $10 \mathrm{~min}$ ). Insoluble Rapigest SF cleavage product was removed by centrifugation $\left(13,000 \mathrm{~g}\right.$ for $15 \mathrm{~min}$ at $\left.4^{\circ} \mathrm{C}\right)$, and the sample desalted using C18 spin columns (Pierce, \#89852) as per the manufacturers protocol, prior to strong cation exchange using stage tips (packed in-house with 5 disks per $200 \mu \mathrm{l}$ tip as described previously [54] (Empore Supelco $47 \mathrm{~mm}$ Cation Exchange disk, \#2251)). Each mixed labelled peptide sample was split across 8 tips, with peptides passed through the equilibrated stage tips twice. Bound peptides were eluted with $5 \% \mathrm{NH}_{4} \mathrm{OH}(3 \mathrm{x}$ $100 \mu \mathrm{l})$ and dried to completion using a vacuum centrifuge.

Peptides were fractionated using basic reverse-phase liquid chromatography as described [54], with 65 fractions collected, partially dried by vacuum centrifugation, and concatenated into 5 pools. For each pool, $5 \%$ was aliquoted and dried to completion prior to MS analysis. 
The remaining $95 \%$ was subjected to $\mathrm{TiO}_{2}$-based phosphopeptide enrichment, as described previously [55].

Total protein and phosphopeptide enriched fractions were analysed by LC-MS/MS using an UltiMate 3000 RSLCTM nano system (Dionex) coupled in-line with a Thermo Orbitrap Fusion Tribrid mass spectrometer (Thermo Scientific). Peptides were loaded onto the trapping column (PepMap100, C18, $300 \mu \mathrm{m} \times 5 \mathrm{~mm}$, Thermo Scientific) using partial loop injection with 2\% acetonitrile $(\mathrm{ACN}), 0.1 \%$ TFA at a flow rate of $9 \mu \mathrm{l} / \mathrm{min}$ for 7 minutes. Peptides were resolved on an analytical column (Easy-Spray C18, $75 \mu \mathrm{m} \times 500 \mathrm{~mm}, 2 \mu \mathrm{m}$ bead diameter) using a gradient from $96.2 \% \mathrm{~A}(0.1 \%$ formic acid $): 3.8 \% \mathrm{~B}(80 \% \mathrm{ACN}, 0.1 \%$ formic acid $)$ to $50 \%$ B over either 120 minutes (single injection for phosphopeptide-enriched samples and two injections for total protein samples) or 240 minutes (single injection for total protein samples only) at a flow rate of $300 \mathrm{nl} / \mathrm{min}$. Full MS1 spectra were acquired in the Orbitrap over $\mathrm{m} / \mathrm{z} 375-2000$ (60K resolution at $\mathrm{m} / \mathrm{z} 200$ ), with a maximum injection time of $50 \mathrm{~ms}$ and an ACG target of 4e5 ions. Data-dependent MS2 analysis was performed using a top speed approach (3 s cycle time) with peptides fragmented by collision-induced dissociation [56] at a normalised collision energy (NCE) of $35 \%$, with fragment ions detected in the ion trap (maximum injection time of $50 \mathrm{~ms}$, ACG target of 1e4). Following acquisition of each MS2 spectrum, a synchronous precursor selection (SPS) MS3 scan was performed on the top 10 most intense fragment ions, with SPS-MS3 precursors fragmented using higher energy collision-induced dissociation (HCD), at an NCE of $65 \%$, and analysed using the Orbitrap over $\mathrm{m} / \mathrm{z} 100-500$ (50K resolution at $\mathrm{m} / \mathrm{z} 200$ ) with a maximum injection time of $105 \mathrm{~ms}$ and an ACG target of 1 e5 $[57,58]$.

Analysis of MS data, with quantification of TMT reporter ion distributions, was performed using Proteome Discoverer 2.4 (PD 2.4) in conjunction with MASCOT (v2.6) and Percolator. For peptide identification from MS2 spectra, raw data files were converted to mzML format and searched in MASCOT against the Mouse UniProt reviewed database (Downloaded 25/04/2018; 16,966 sequences) with parameters set as follows: MS1 tolerance of $10 \mathrm{ppm}$; 
MS2 tolerance of 0.6 Da; enzyme specificity was set as trypsin with two missed cleavages allowed; carbamidomethylation of cysteine and TMT 6-plex modifications (on peptide Ntermini and lysine side chains) were set as fixed modifications; oxidation of methionine and acetylation of protein $\mathrm{N}$-termini were set as variable modifications, with the addition of phosphorylation (at serine, threonine or tyrosine residues) for phosphopeptide-enriched samples. Percolator was used for control of false discovery rates with a target FDR of 0.05 . For phosphopeptide-enriched samples, the ptmRS node, operated in phosphoRS mode, was added to the PD 2.4 workflow for phosphosite localisation. In parallel with peptide identification, relative quantification of TMT 6-plex reporter ions was performed in PD 2.4 using the 'Reporter ions quantifier' node, to quantify reporter ions from MS3 spectra with a peak integration tolerance of 20 ppm using the 'most confident centroid' integration method.

Quantitative ratios were calculated for each biological replicate to look for protein/phosphopeptide changes upon Quantitative ratios were log2 transformed and, for all proteins/phosphopeptides quantified in at least 3 out of 5 bioreps, statistical analysis was performed in $\mathrm{R}$ using the LIMMA package, using a $\mathrm{p} \leq 0.05$ significance cut off. The mass spectrometry proteomics data have been deposited to the ProteomeXchange Consortium (http://proteomecentral.proteomexchange.org) via the PRIDE partner repository [59] with the dataset identifiers Project accession: PXD026203 \& Project DOI: 10.6019/PXD026203. Access for reviewers can be obtained through: Username: reviewer_pxd026203@ebi.ac.uk Password: 5Ka35Kkf

\section{RNA-Seq and analysis}

RNA was extracted as described above and sample quality analysed using Tapestation automated electrophoresis (Aglient) according to manufacturer's instructions. Sample RNA Integrity Number (RIN) score exceeded 6 in all cases. RNA-Seq analysis was performed in the Illumina platform using TruSeq stranded mRNA-Seq at 25 million (75 bp) single reads per samples and sequencing performed on a NextSeq high-output 75 cycle run. The raw 
sequence data quality was first inspected using FastQC and MultiQC. Transcript counts were generated via Salmon [60] using Release M20 (GRCm38.p6) of the mouse genome (for the mouse samples) and Release 31 (GRCh38.p12) of the human genome (for the human samples).

The quantification files were imported into $R$ for gene-level analyses using tximport [61] and the differential gene expression analyses were carried out using DESeq2 [62]. The data has been depositied on ENA (https://www.ebi.ac.uk/ena/submit/sra/\#home) with the accession number PRJEB45284. Access for reviewers can be obtained through: Username: Webin59077, Password: 2vTrAAF0a8

\section{STRING and Venn diagram analysis}

STRING analysis was performed using version 11.0 at https://string-db.org/ [63]. Where indicated CHEK1 and AKT1 were manually added to the protein list to determine connections to phosphoproteins identified from the proteomics analysis. Details on proteins analysed and connections are in Supp Data File 2. Venn diagram analysis was performed at http://bioinformatics.psb.ugent.be/webtools/Venn/. For Venn diagrams examining phosphorylation, phosphosites identified from proteomics analysis rather than phosphopeptides were used as some phosphosites are associated with more than one phosphopeptide. Details on phosphosites analysed and are in Supp Data File 5.

\section{Statistical analysis}

GraphPad Prism software (http://www.graphpad.com, V6.0) was used for statistical analysis. Except where stated in figure legends, unpaired t-tests or One-way ANOVA were used to calculate $P$ values ( $P$ values of $p<0.05$ were considered significant). 


\section{Figure Legends}

Figure 1. Claspin expression is reduced in $\mathrm{E} \mu-\mathrm{Myc} / \mathrm{c}-\mathrm{rel-/-}$ and renders $\mathrm{E} \mu-\mathrm{Myc} / \mathrm{c}-\mathrm{rel-/-}$ lymphoma resistant to Chk1 inhibition

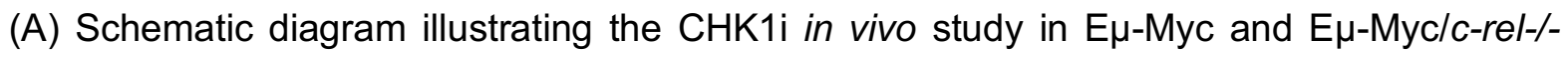

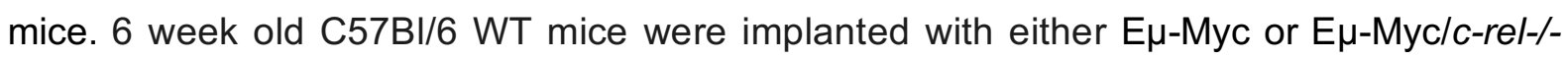
(blue arrow) and once tumours became palpable were treated with either $100 \mathrm{mg} / \mathrm{kg}$ CCT244747 p.o or vehicle control once daily for 9 days (black arrows). Mice were euthanised 24 hours after the final dose (red arrow) and tumour burden assessed.

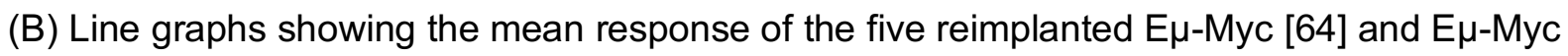
crel-/- (blue) tumours and their response to CCT244747. Each of the 5 spontaneously derived tumours was implanted into 6 syngeneic recipient C57BI/6 mice, 3 were treated with CCT244747 (100 mg/kg p.o), and 3 with vehicle control, for 9 days once lymphoid tumours became palpable. A response was defined as a significant change in tumour burden $(P<0.05)$ using unpaired Student's t-tests. The complete data set is summarised in (D). '+' indicates one experiment where treatment was stopped after 7 days and the mice were sacrificed early due to the mice becoming too ill.

(C) Table showing the response of 5 re-implanted $\mathrm{E} \mu-\mathrm{Myc}$ and $\mathrm{E} \mu-\mathrm{Myc} / \mathrm{c}-\mathrm{rel}-\mathrm{-}-$ tumours to CCT244747, in all sites where lymphoid tumour burden is anticipated in this model.

(D) Q-PCR data showing relative Claspin expression in tumorigenic spleens from E $\mu$-Myc $(n=30)$ and $E \mu-M y c / c-r e l-/-(n=11)$ mice. Data represents mean \pm SEM. $p^{* *}<0.01$ (Unpaired Student's t-test). Claspin expression is reduced in $\mathrm{c}-\mathrm{Rel}^{-{ }^{-}}$tumours. Data represents mean \pm SEM, each point is an individual mouse.

\section{Figure 2.}

(A) Western blot analysis of phospho-Ser345 CHK1, CHK1, phospho-S139 H2AX (yH2AX) or ACTIN in snap frozen tumour extracts prepared from re-implanted $\mathrm{E} \mu-\mathrm{Myc}$ and $\mathrm{E} \mu-\mathrm{Myc} / \mathrm{c}-\mathrm{rel}$ - 
/- tumours mouse inguinal lymph nodes at given timepoints (8 hours, 24 hours or 48 hours) following a single dose of CCT244747.

(B) STRING analysis showing that a cluster of proteins associated with CHK1 had downregulated phosphorylation was upon CCT244747 treatment in E $\mu$-Myc WT tumours after a single dose of the CHK1 $\mathrm{i}$.

(C \& D) Volcano plots demonstrating a significant number of CCT244747 effects in E $\mu-M y c$ WT lymphomas on both the total (C) and phospho (D) proteome, with both down- (red dots) and up-regulation (blue dots) being observed.

\section{Figure 3.}

(A \& B) Volcano plots illustrating that there was a much reduced number of CCT244747 effects

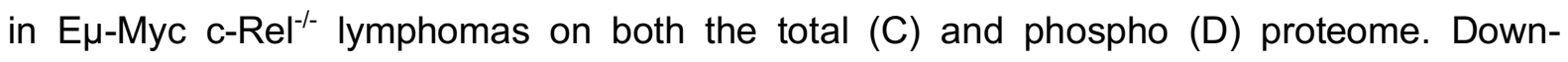
regulation is shown with the red dots and up-regulation is shown with the blue dots.

(C) Volcano plot demonstrating the significant number of phospho-proteomic differences

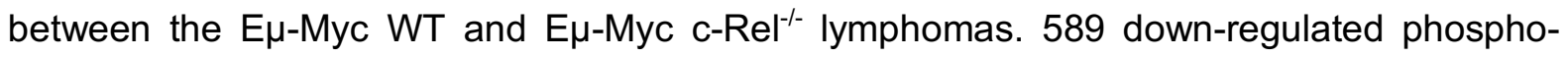
peptides (shown by the red dots were observed) and 517 up-regulated phospho-peptides (blue dots) in $\mathrm{E} \mu-\mathrm{Myc} \mathrm{c}_{\mathrm{C}} \mathrm{Re}^{-/-}$tumours when compared with $\mathrm{E} \mu-\mathrm{Myc}$ WTs.

(D) STRING analysis of the proteins associated with the 589 down-regulated phosphopeptides in the $\mathrm{E} \mu-\mathrm{Myc} \mathrm{c}_{\mathrm{C}} \mathrm{Rel}^{-/-}$lymphomas revealed that many of these had known linkages with $\mathrm{CHK} 1$ or $\mathrm{CHK} 1$ signalling.

(E) Venn diagram illustrating that of the 284 unique downregulated phosphosites seen in $\mathrm{E} \mu$ Myc WT tumours following acute CCT244747 treatment, 186 were also downregulated in c$\mathrm{Rel}^{-/-} \mathrm{E} \mu-M y c$ lymphoma cells without inhibitor treatment.

(F) Volcano plot demonstrating the significant number of total protein differences between the $\mathrm{E} \mu-\mathrm{Myc}$ WT and $\mathrm{E} \mu-\mathrm{Myc} c-\mathrm{Rel}^{-/-}$lymphomas. Down-regulated proteins are shown with red dots and up-regulated proteins are shown with blue dots. 
(G) Venn diagram illustrating that of the 158 downregulated proteins seen in E $\mu$-Myc WT tumours following acute CCT244747 treatment, 119 were also downregulated in $\mathrm{c}-\mathrm{Rel}^{-/-} \mathrm{E \mu}-$ Myc lymphoma cells without inhibitor treatment.

\section{Figure 4.}

(A) Q-PCR validation of RNA-Seq analysis. Relative CHEK1 transcript levels are significantly

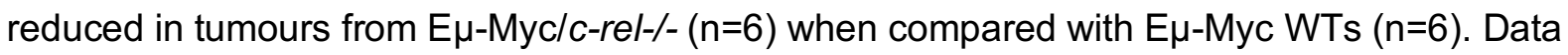
represents mean \pm SEM. $\mathrm{p}^{* *}<0.01, \mathrm{p}^{* * *}<0.001$ (One-way ANOVA with Tukey's post-hoc test). CHEK1 expression is also partially reduced in WT tumours following CCT244747 treatment. Data represents mean \pm SEM, each point is an individual mouse.

(B) Western blot analysis of CLASPIN, phospho-Ser345 CHK1, CHK1, CDK2 or ACTIN in

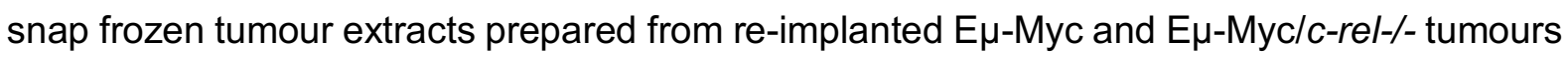
mouse inguinal lymph nodes 8 hours following a single dose of ССТ244747. The expression of $\mathrm{CHK} 1$ and related pathway components are lost in $\mathrm{E} \mu-\mathrm{Myc} / \mathrm{c}-\mathrm{rel}-/$ - tumours.

(C) Western blot analysis of CDC25B, phospho-Tyr15 CDK1, CDK1, CHK2 or KARYOPHERIN in snap frozen tumour extracts prepared from re-implanted $E \mu-M y c$ and $E \mu-$ Myc/c-rel-/- tumours mouse inguinal lymph nodes 8 hours following a single dose of CCT244747. CDC25B, phospho-Tyr15 CDK1, CDK1, expression is lost in E $\mu-M y c / c-r e l-/-$ tumours, CHK2 is unaffected.

\section{Figure 5.}

(A) Four independently derived CCT244747 resistant (CR) U20S cell lines are resistant to CHK1 inhibitor treatment. Cell viability (Prestoblue assay) in WT and CR U20S following treatment with increasing concentrations of the CHK1 inhibitor, CCT244747 for 72 hours.

(B) Increased clonogenic survival in four independently derived CCT244747 resistant (CR) U20S cell lines following CHK1 inhibitor treatment. Representative image and bar graph data showing clonogenic survival in WT and CR U20S following either treatment with $1 \mu \mathrm{M}$ 
CCT244747for 24 hours.

(C) Western blot analysis of CHK1, CDK2, or ACTIN in extracts prepared from WT and CCT244747 resistant (CR) U20S.

(D) Q-PCR data showing relative Chek1 expression in four independently derived CCT244747 resistant (CR) U20S cell lines, or their WT counterparts. Chek1 expression is unaffected in CR U20S. Data represents mean \pm SEM, each point is the mean of three independent experiments in each of the four cell lines.

(E) Q-PCR data showing relative Claspin expression in four independently derived CCT244747 resistant (CR) U20S cell lines, or their WT counterparts. Claspin expression is reduced in CR U20S. Data represents mean \pm SEM, each point is the mean of three independent experiments in each of the four cell lines $p^{*}<0.05$ (Unpaired Student's t-test).

\section{Figure 6.}

(A) Bar graph showing the relative expression of 24 DUBs that were significantly up- or downregulated in the E $\mu-\mathrm{Myc} / \mathrm{c}-\mathrm{rel} / \mathrm{-}-$ tumours by RNA-Seq analysis. The red bars show that both USP1 and USP14 were down-regulated by approximately 2 fold compared with E $\mu$-Myc WTs. (B) Q-PCR validation of RNA-Seq analysis. Relative USP1 and USP14 transcript levels are significantly reduced in tumours from $\mathrm{E} \mu-\mathrm{Myc} / \mathrm{c}-\mathrm{rel} / \mathrm{-}(\mathrm{n}=6)$ when compared with $\mathrm{E} \mu$-Myc WTs $(n=5)$. Data represents mean \pm SEM. $p^{* *}<0.01, p^{* * *}<0.001$ (Unpaired student's t-test). Data represents mean \pm SEM, each point is an individual mouse.

(C) Western blot analysis of USP1, USP14 or ACTIN in snap frozen tumour extracts prepared

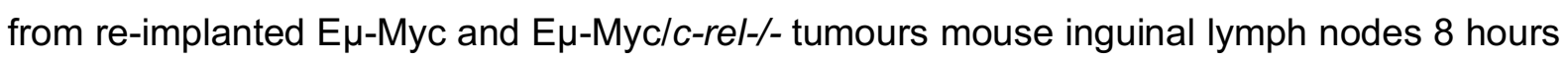
following a single dose of CCT244747. USP1 and USP14 expression is lost in E $\mu$-Myc/c-rel/- tumours.

(D) Q-PCR data showing relative USP1 and USP14 transcript levels are significantly reduced in in four independently derived CCT244747 resistant U20S cell lines, compared with WT U20S cells. Data represents mean \pm SEM. $p^{*}<0.05$ (Unpaired student's t-test). Data 
represents mean \pm SEM, each point is the mean of three independent experiments in each of the four cell lines.

(E) Western blot analysis of USP1, USP14, CHK1, or ACTIN in extracts prepared from WT and CCT244747 resistant U20S. USP1 and USP14 expression is lost in CCT244747 resistant U20S.

(F) Western blot and Q-PCR analysis from WT U2OS cells following siRNA targeting c-Rel or a Non-specific siRNA control. Western blot analysis shows that knockdown of c-Rel results in a reduction of USP1, USP14 and CHK1. ACTIN is used as a loading control. Q-PCR data shows that USP1 and USP14 transcript levels are reduced following c-Rel knockdown, but that CHEK1 transcript levels are unaffected. Data represents mean $\pm \mathrm{SEM}$, each point is the mean of three independent experiments. $\mathrm{p}^{* *}<0.01$ (Unpaired student's t-test).

(G) Western blot analysis from WT U2OS cells following siRNA targeting USP1, USP14 or a Non-specific siRNA control. Data shows that CHK1 is completely lost following USP1 knockdown and partially lost following USP14 knockdown. ACTIN is used as a loading control. (H) Western blot analysis of WT or CCT244747 resistant U2OS cells treated with CCT244747, the USP1/14 inhibitor, ML323, or the Proteasome inhibitor MG-132, alone or in combination. Blots were probed for CHK1, USP1, yH2AX or ACTIN. Inhibition of USP1/14 in WT U2OS results in the loss of CHK1. Proteasomal inhibition in the CCT244747 resistant U2OS cells results in the stabilization of $\mathrm{CHK} 1$ protein.

(I) Clonogenic survival in WT U20S cell lines following siRNA targeting USP1, USP14 or a Non-specific siRNA control. U2OS are sensitive to CCT244747 in the presence of control or USP14 siRNA, however knockdown of USP1 renders them insensitive to CCT244747 treatment. Data represents mean \pm SEM, each point is the mean of three independent experiments. $\mathrm{p}^{\star * *}<0.01$ (One-way ANOVA with Tukey's post-hoc test).

\section{Figure 7.}


(A) Venn diagram illustrating that of the 294 unique upregulated phosphosites seen in E $\mu$-Myc WT tumours following acute CCT244747 treatment, 150 were also upregulated in $\mathrm{c}-\mathrm{Re}^{-/-} \mathrm{E} \mu-$ Myc lymphoma cells without inhibitor treatment.

(B) Venn diagram illustrating that of the 464 upregulated proteins seen in E $\mu$-Myc WT tumours

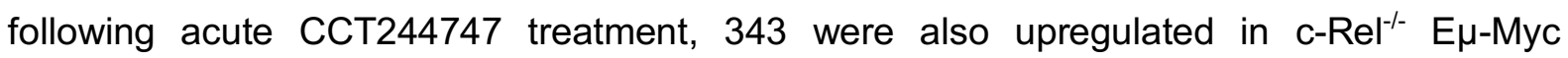
lymphoma cells without inhibitor treatment.

(C) Western blot analysis of phospho-Ser473 AKT, phospho-Thr308 AKT, AKT, phospho-Ser9 GSK3B, GSK3B or ACTIN in snap frozen tumour extracts prepared from re-implanted $\mathrm{E} \mu-\mathrm{Myc}$ and E $\mu-M y c / c-r e l-/-$ tumours mouse inguinal lymph nodes 8 hours following a single dose of

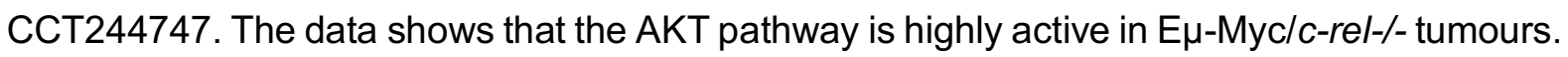
(D) Western blot analysis of phospho-Thr202/Tyr204 ERK1/2, ERK1/2 or ACTIN in snap frozen tumour extracts prepared from re-implanted $E \mu-M y c$ and $E \mu-M y c / c-r e l-/-$ tumours mouse inguinal lymph nodes 8 hours following a single dose of ССТ244747. The data shows that the ERK pathway is highly active in E $\mu-M y c / c-r e l-/-$ tumours.

(E) Western blot analysis of phospho-Thr183/Tyr185 JNK1/2, JNK1/2, phosphoThr180/Tyr182 p38, p38 or ACTIN in snap frozen tumour extracts prepared from re-implanted $\mathrm{E} \mu-\mathrm{Myc}$ and $\mathrm{E} \mu-\mathrm{Myc} / \mathrm{c}-\mathrm{rel} / \mathrm{-}-$ tumours mouse inguinal lymph nodes 8 hours following a single dose of CCT244747. The data shows that the JNK/p38 pathway signalling is reduced in E $\mu$ Myc/c-rel-/- tumours.

\section{Figure 8.}

(A) Schematic diagram illustrating the PI3Ki in vivo study in $\mathrm{E} \mu-\mathrm{Myc}$ and $\mathrm{E} \mu-\mathrm{Myc} / \mathrm{c}-\mathrm{rel} / \mathrm{-}-$ mice.

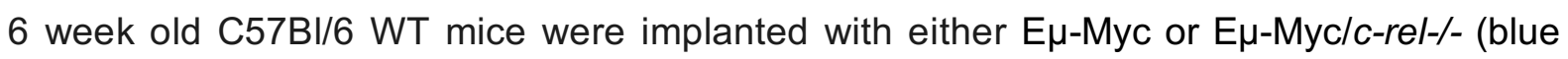
arrow) and once tumours became palpable were treated with either $100 \mathrm{mg} / \mathrm{kg}$ GDC0941/Pictilisib p.o or vehicle control once daily for 9 days (black arrows). Mice were euthanised 24 hours after the final dose (red arrow) and tumour burden assessed.

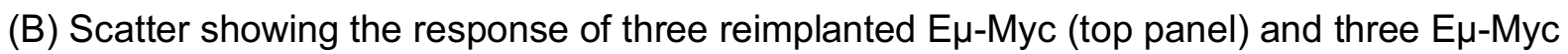


$\mathrm{CRel}^{-/-}$(bottom panel) tumours and their response to GDC-0941/Pictilisib in the cervical lymph node tumour site. Each of the 3 tumours was implanted into 6 syngeneic recipient C57BI/6 mice, 3 were treated with GDC-0941/Pictilisib (100 mg/kg p.o), and 3 with vehicle control, for 9 days once tumours became palpable. A response was defined as a significant reduction (or increase) in tumour burden $(P<0.05)$ using unpaired Student's t-tests. WT E $\mu$-Myc showed

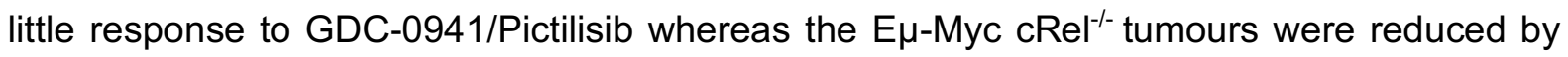
GDC-0941/Pictilisib.

\section{Figure 9.}

MYC-driven tumours, or those undergoing high levels of replication stress become addicted to ATR-CHK1 signalling. When cRel in present and controlling the levels of the adaptor protein Claspin, which facilitates the phosphorylation of CHK1 by ATR, and also the levels of USP1, the known CHK1 DUB, this addiction to CHK1 signalling renders the cell sensitive to $\mathrm{CHK} 1$ inhibition by CCT244747 or SRA737, leading to tumour cell death.

The data herein indicates that both de novo and acquired resistance to $\mathrm{CHK} 1 \mathrm{i}$ is a two-step process. First there is loss of CHK1 protein, or pathway activity, this can be due to the loss of Claspin or USP1, thus rendering the cell insensitive to CHK1 inhibition. Secondly, we observe the activation of compensatory pathways such as the PI3K/AKT and ERK pathways to allow the tumour cell to survive the loss of $\mathrm{CHK} 1$. This can be targeted with agents such as the PI3K inhibitor, GDC-0941/Pictilisib to result in tumour cell death. 


\section{Supplementary Figures}

\section{Supp Figure 1}

A) (B) Line graphs showing the mean response of the five reimplanted $\mathrm{E} \mu-\mathrm{Myc}[64]$ and $\mathrm{E} \mu$ Myc crel-/- (blue) tumours and their response to CCT244747 in further lymphoid organs. Each of the 5 tumours was implanted into 6 syngeneic recipient C57BI/6 mice, 3 were treated with CCT244747 (100 mg/kg p.o), and 3 with vehicle control, for 9 days once tumours became palpable. A response was defined as a significant reduction (or increase) in tumour burden $(P<0.05)$ using unpaired Student's t-tests.

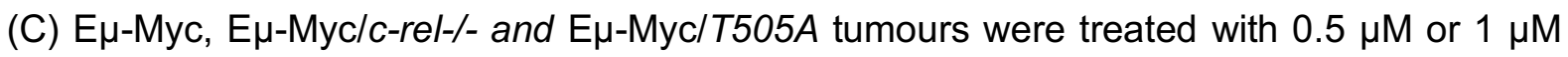

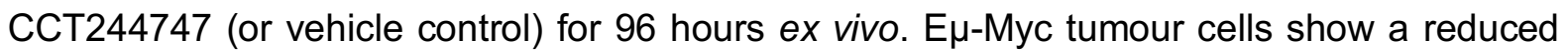

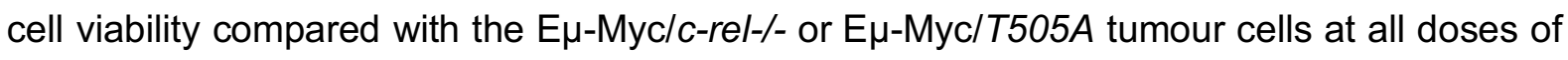
CCT244747 tested.

(D) Q-PCR showing relative Claspin expression in purified splenic B-cells from C57BI/6 $(n=6)$ and crel-/- $(n=7)$ mice. Data represents mean \pm SEM.

\section{Supp Figure 2}

(A) Schematic diagram illustrating the single dose CHK1i in vivo study in $\mathrm{E} \mu-\mathrm{Myc}$ and $\mathrm{E} \mu$ -

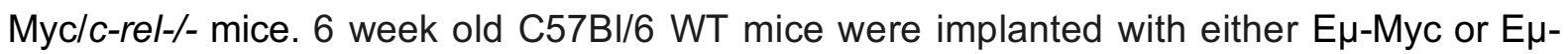
Myc/c-rel-/- (blue arrow) and once tumours became palpable were treated with either a single dose of $100 \mathrm{mg} / \mathrm{kg} \mathrm{CCT244747} \mathrm{p.o} \mathrm{or} \mathrm{vehicle} \mathrm{control} \mathrm{(black} \mathrm{arrows),} \mathrm{and} \mathrm{then} \mathrm{mice} \mathrm{were} \mathrm{then}$ euthanised at either 8 hours, 24 hours or 48 hours later (red arrow). The star $\left(^{*}\right)$ denotes the 8 hour timepoint which was taken forward for use in future RNA-Seq and proteomic studies.

(B) Schematic illustrating the workflow for proteomics experiments. Splenic tumours from $\mathrm{E} \mu-\mathrm{Myc}$ or E $\mu-\mathrm{Myc} / \mathrm{c}-\mathrm{Rel}-/-$ mice were necropsied 8 hours post-treatment with either $\mathrm{CHK} 1$ inhibitor CCT244747 or vehicle control. Proteins were extracted and digested with trypsin 
prior to peptide labelling with tandem mass tags (TMT). Differentially labelled peptides from each treatment condition were mixed then fractionated via basic reverse-phase liquid chromatography, initially into 65 fractions which were concatenated into 5 pools. For each pool, $5 \%$ of the material was analysed by LC-MS/MS to obtain relative-quantification of total protein levels whilst the remaining $95 \%$ was subject to titanium dioxide $\left(\mathrm{TiO}_{2}\right)$-based phosphopeptide enrichment prior to LC-MS/MS analysis for phosphoproteomic analysis.

(C) Wider STRING analysis showing that a cluster of proteins associated with CHK1 had

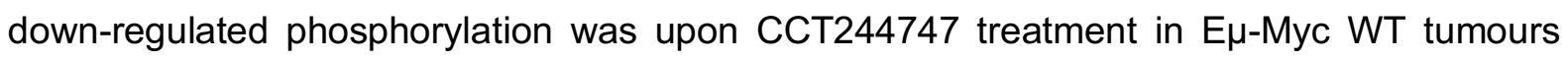
after a single dose of the CHK1i, as shown in Fig 2B.

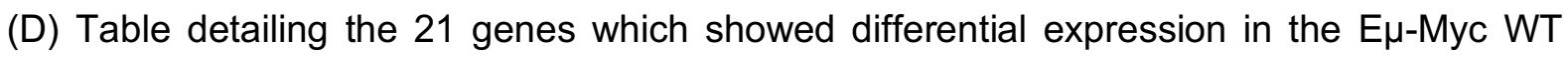
tumours following acute CCT244747 treatment by RNA-Seq analysis.

\section{Supp Figure 3}

(A) Table detailing the number of phosphopeptides (orange column) and proteins (blue column) that were significantly different when the genotypes and/or treatment arms were compared after proteomic analysis in the acute ССT244747 study. A significant different was defined as an adjusted $p$ value of $<0.05$

(B) Venn diagram illustrating that there is a high number of phosphosite changes in the c-Rel'

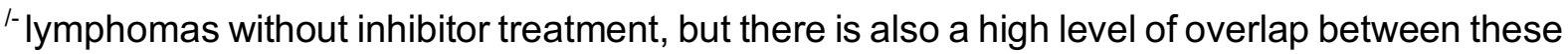
and the WT lymphomas following CCT244747 treatment.

(C) Venn diagram illustrating that there is a high number of total protein changes in the c-Rel' ${ }^{1}$ - Iymphomas without inhibitor treatment, but there is also a high level of overlap between these and the WT lymphomas following CCT244747 treatment.

(D) Wider STRING analysis of the proteins associated with the 589 down-regulated phosphopeptides in the $\mathrm{E} \mu-\mathrm{Myc} \mathrm{c}_{\mathrm{C}} \mathrm{Rel}^{-/-}$lymphomas revealed that many of these had known linkages with $\mathrm{CHK} 1$ or $\mathrm{CHK} 1$ signalling, as shown in Fig 3D. 


\section{Supp Figure 4}

Correlation between phospho peptides and proteins up or down regulated in REL-/- vs WT and WT CHK1i vs WT

\section{Supp Figure 5}

(A) Table showing the 32 genes associated with the 'Activation of ATR in response to

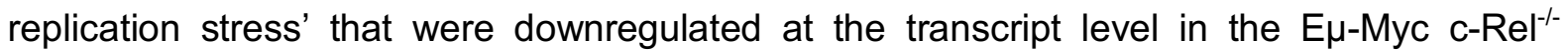
tumours when compared with E $\mu$-Myc WT tumours. A significant different was defined as an adjusted $p$ value of $<0.05$

(B) Venn diagram showing the overlap between proteins down-regulated in the E $\mu$-Myc c-Rel'

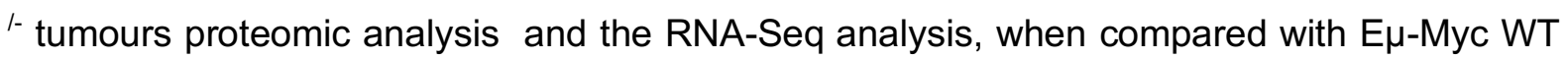
tumours.

(C) Western blot analysis of CLASPIN, phospho-Ser345 CHK1, CHK1, CDK2 or ACTIN in snap frozen tumour extracts prepared from more re-implanted $\mathrm{E} \mu-\mathrm{Myc}$ and $\mathrm{E} \mu-\mathrm{Myc} / \mathrm{c}-\mathrm{rel}-/-$ tumours mouse inguinal lymph nodes 8 hours following a single dose of CCT244747. The expression of $\mathrm{CHK} 1$ and related pathway components are lost in $\mathrm{E} \mu-\mathrm{Myc} / \mathrm{c}-\mathrm{rel} / \mathrm{/}-$ tumours.

\section{Supp Figure 6}

(A) Western blot analysis of USP1, USP14 or ACTIN in snap frozen tumour extracts prepared from more re-implanted $\mathrm{E} \mu-\mathrm{Myc}$ and $\mathrm{E} \mu-\mathrm{Myc} / \mathrm{c}-\mathrm{rel} / \mathrm{-}-$ tumours mouse inguinal lymph nodes 8 hours following a single dose of CCT244747. USP1 and USP14 expression is lost in E $\mu$ Myc/c-rel-/- tumours.

(B) Further western blot analysis of independent isolates of WT or CCT244747 resistant (CR) U2OS cells treated with CCT244747, the USP1/14 inhibitor, ML323, or the Proteasome inhibitor MG-132, alone or in combination. Blots were probed for CHK1, USP1, yH2AX or ACTIN. Inhibition of USP1/14 in WT U2OS results in the loss of CHK1. Proteasomal inhibition in the CCT244747 resistant U2OS cells results in the stabilization of CHK1 protein. 


\section{Supp Figure 7}

(A) STRING analysis showing that a cluster of proteins associated with AKT signalling is up-

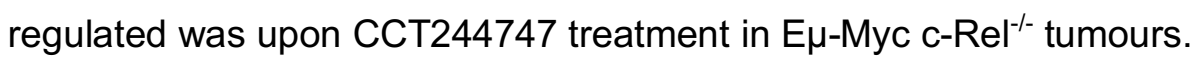

\section{Supp Table 1}

(A) Table detailing proteins in the AKT, ERK1, JNK and p38 pathways that had up-regulated phosphorylation when assessed by STRING analysis. The AKT1 pathway had the greatest number of links with a total of 71 proteins associated with AKT signaling showing increased phosphorylation

\section{Supp Figure 8}

(A) Western blot analysis of phospho-Ser473 AKT, AKT, or ACTIN in snap frozen tumour extracts prepared from more re-implanted $E \mu-M y c$ and $E \mu-M y c / c-r e l-/-$ tumours mouse inguinal lymph nodes 8 hours following a single dose of CCT244747. The data shows that the AKT pathway is highly in E $\mu$-Myc/c-rel-/- tumours.

(B) Western blot analysis of phospho-Tyr458 PI3K, PI3K, or ACTIN in snap frozen tumour extracts prepared from re-implanted $\mathrm{E} \mu-\mathrm{Myc}$ and $\mathrm{E} \mu-\mathrm{Myc} / \mathrm{c}-\mathrm{rel}-\mathrm{-}-$ tumours mouse inguinal lymph nodes 8 hours following a single dose of CCT244747. The data shows that the PI3K/AKT pathway is highly in E $\mu-M y c / c-r e l-/-$ tumours.

(C) Western blot analysis of phospho-Thr202/Tyr204 ERK1/2, ERK1/2 or ACTIN in snap frozen tumour extracts prepared from more re-implanted $\mathrm{E} \mu$-Myc and $\mathrm{E} \mu$-Myc/c-rel-/- tumours mouse inguinal lymph nodes 8 hours following a single dose of CCT244747. The data shows that the ERK pathway is highly in E $\mu-M y c / c-r e l-/-$ tumours.

(D) Western blot analysis of PEA15, or ACTIN in snap frozen tumour extracts prepared from re-implanted $\mathrm{E} \mu-\mathrm{Myc}$ and $\mathrm{E} \mu-\mathrm{Myc} / \mathrm{c}-\mathrm{rel}-\mathrm{-}$ - tumours mouse inguinal lymph nodes 8 hours following a single dose of CCT244747. (E) Western blot analysis of phospho-Thr183/Tyr185 JNK1/2, JNK1/2, phospho-Thr180/Tyr182 p38, p38 or ACTIN in snap frozen tumour extracts prepared from re-implanted $\mathrm{E} \mu-\mathrm{Myc}$ and $\mathrm{E} \mu-\mathrm{Myc} / \mathrm{c}-\mathrm{rel} / /$ - tumours mouse inguinal lymph nodes 
8 hours following a single dose of CCT244747. The data shows that the JNK/p38 pathway signalling is reduced in E $\mu$-Myc/c-rel-/- tumours.

\section{Supp Figure 9}

(A and B) Scatter showing the response of three reimplanted E $\mu$-Myc (top panel) and three E $\mu-M y c \mathrm{cRel}^{-/-}$(bottom panel) tumours and their response to GDC-0941/Pictilisib in the inguinal lymph node (A) and brachial lymph node (B) tumour sites. Each of the 3 tumours was implanted into 6 syngeneic recipient C57BI/6 mice, 3 were treated with GDC-0941/Pictilisib (100 mg/kg p.o), and 3 with vehicle control, for 9 days once tumours became palpable. A response was defined as a significant reduction (or increase) in tumour burden $(P<0.05)$ using unpaired Student's t-tests. WT E $\mu$-Myc showed little response to GDC-0941/Pictilisib whereas

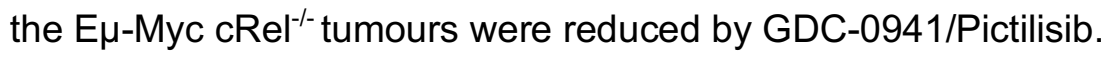

\section{Supp Figure 10}

(A and B) Scatter showing the response of three reimplanted E $\mu$-Myc (top panel) and three E $\mu-M y c \mathrm{cRel}^{-/-}$(bottom panel) tumours and their response to GDC-0941/Pictilisib in the mesenteric lymph node $(A)$ and spleen $(B)$ tumour sites. Each of the 3 tumours was implanted into 6 syngeneic recipient C57BI/6 mice, 3 were treated with GDC-0941/Pictilisib (100 mg/kg p.o), and 3 with vehicle control, for 9 days once tumours became palpable. A response was defined as a significant reduction (or increase) in tumour burden $(P<0.05)$ using unpaired

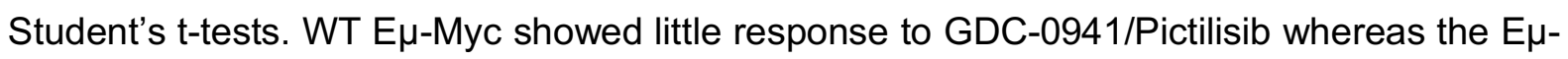
Myc $\mathrm{cRel}^{-/-}$tumours were reduced by GDC-0941/Pictilisib. 


\section{Supplementary data files}

\section{Supp Data File 1 Proteomics.xIsx}

Data from proteomics analysis of reimplanted $\mathrm{E} \mu$-Myc lymphoma cells with either vehicle of CHK1i (CCT244747) treatment for 8 hours.

Tab1: Total protein data

Tab 2: Phosphopeptide data

\section{Supp Data File 2 STRING interactions.xIsx}

STRING interactions data based phosphorylated proteins identified from phospho proteomics analysis.

Tab 1: Analysis of STRING interactions between phospho proteins down regulated in WT E $\mu$-Myc lymphoma cells after CHK1i (CCT244747) treatment. Note CHK1 (Chek1) was manually added into the protein list in order to identify potential interactions with the target of the CCT244747.

Tab 2: Analysis of STRING interactions between phospho proteins down regulated in c-Rel null versus WT $\mathrm{E} \mu-\mathrm{Myc}$ lymphomas. Note CHK1 (Chek1) was manually added into the protein list in order to identify potential interactions with the target of the CCT244747.

Tab 3: Analysis of STRING interactions between phospho proteins up regulated in c-Rel null versus $\mathrm{WT} \mathrm{E} \mu$-Myc lymphomas. Note AKT1 was manually added into the protein list in order to identify potential interactions with this kinase.

\section{Supp Data File 3 RNASeq_all_genes_list_EuMyc.xlsx}

Gene lists from RNA Seq analysis of reimplanted $\mathrm{E} \mu$-Myc lymphoma cells with either vehicle of CHK1i (CCT244747) treatment for 8 hours.

Tab 1: Comparison of gene expression changes in WT E $\mu$-Myc lymphoma cells with either vehicle or after after CHK1i (CCT244747) treatment

Tab 2: Comparison of gene expression changes between WT and c-Rel null $\mathrm{E} \mu-\mathrm{Myc}$ lymphoma cells after CHK1i (CCT244747) treatment

Tab 3: Comparison of gene expression changes between WT and c-Rel null E $\mu-M y c$ lymphoma cells with no CHK1i (CCT244747) treatment

\section{Supp Data File 4 RNASeq_counts_tximport_EuMyc.csv}

Data for all genes and samples from RNA Seq analysis of reimplanted E $\mu$-Myc lymphoma cells

\section{Supp Data File 5 Venn diagrams.xlsx}

Data files from Venn analysis of $E \mu-M y c$ lymphoma cell proteomics and RNA Seq data 
Tab1: Comparison between phosphosites downregulated in untreated c-Rel null relative to untreated wild type with those down regulated in WT cells treated with CHK1i (CCT244747) versus untreated WT.

Tab 2: Comparison between total proteins downregulated in untreated c-Rel null relative to untreated wild type with those down regulated in WT cells treated with CHK1i (CCT244747) versus untreated WT.

Tab3: Comparison between all phosphosite changed in untreated c-Rel null relative to untreated wild type with those down regulated in WT cells treated with CHK1i (CCT244747) versus untreated WT.

Tab 4: Comparison between all total changesin untreated c-Rel null relative to untreated wild type with those down regulated in WT cells treated with CHK1i (CCT244747) versus untreated WT.

Tab 5: Comparison between mRNAs and proteins down regulated in untreated c-Rel null relative to untreated wild type

Tab6: Comparison between phosphosites upregulated in untreated c-Rel null relative to untreated wild type with those down regulated in WT cells treated with CHK1i (CCT244747) versus untreated WT.

Tab 7: Comparison between total proteins upregulated in untreated c-Rel null relative to untreated wild type with those down regulated in WT cells treated with CHK1i (CCT244747) versus untreated WT.

\section{Supp Data File 6 RNASeq all_genes_list_U2OS.xIsx}

Gene lists from RNA Seq analysis of wild type control and CHK1i (CCT244747) resistant U2OS cells with or without CCT244747 treatment for 24 hours.

Tab 1: Comparison of gene expression changes in between WT untreated U2OS cells (WT.Not) and untreated CHK1i resistant U2OS cells (CR.Not)

Tab 2: Comparison of gene expression changes in between WT untreated U2OS cells (WT.Not) and WT CHK1i treated U2OS cells (WT.CHK1i)

Tab 3: Comparison of gene expression changes in between untreated $\mathrm{CHK} 1 \mathrm{i}$ resistant U2OS cells (CR.Not) and CHK1i treated resistant U2OS cells U2OS cells (CR.CHK1i)

Tab 4: Comparison of gene expression changes in between CHK1i treated WT U2OS cells (WT.CHK1i) and CHK1i treated CHK1i resistant U2OS cells (CR.CHK1i)

Tab 5: Comparison of gene expression changes in between untreated WT U2OS cells (WT.Not) and CHK1i treated CHK1i resistant U2OS cells (CR.CHK1i)

Tab 6: Comparison of gene expression changes in between CHK1i treated WT U2OS cells (WT.CHK1i) and untreated CHK1i resistant U2OS cells (CR.CHK1i)

\section{Supp Data File 7 RNA Seq counts_tximport_U2OS.csv}

Data for all genes and samples from RNA Seq analysis of U2OS cells. 
bioRxiv preprint doi: https://doi org/10.1101/2021.05.26.445425: this version posted May 27,2021 . The copyright holder for this preprint

\section{References}

1. Carrassa, L. and G. Damia, DNA damage response inhibitors: Mechanisms and potential applications in cancer therapy. Cancer Treat Rev, 2017. 60: p. 139-151.

2. Burhans, W.C. and M. Weinberger, DNA replication stress, genome instability and aging. Nucleic Acids Res, 2007. 35(22): p. 7545-56.

3. Campaner, S. and B. Amati, Two sides of the Myc-induced DNA damage response: from tumor suppression to tumor maintenance. Cell division, 2012. 7(1): p. 6.

4. Rohban, S. and S. Campaner, Myc induced replicative stress response: How to cope with it and exploit it. Biochim Biophys Acta, 2015. 1849(5): p. 517-24.

5. Maya-Mendoza, A., et al., Myc and Ras oncogenes engage different energy metabolism programs and evoke distinct patterns of oxidative and DNA replication stress. Mol Oncol, 2015. 9(3): p. 601-16.

6. Garrett, M.D. and I. Collins, Anticancer therapy with checkpoint inhibitors: what, where and when? Trends in pharmacological sciences, 2011. 32(5): p. 308-16.

7. Campbell, K.J., et al., Cisplatin mimics ARF tumor suppressor regulation of RelA (p65) nuclear factor-kappaB transactivation. Cancer research, 2006. 66(2): p. 929-35.

8. Moles, A., et al., A RelA(p65) Thr505 phospho-site mutation reveals an important mechanism regulating NF-kappaB-dependent liver regeneration and cancer. Oncogene, 2016. 35(35): p. 4623-32.

9. Msaki, A., et al., The role of RelA (p65) threonine 505 phosphorylation in the regulation of cell growth, survival, and migration. Molecular biology of the cell, 2011. 22(17): p. 3032-40.

10. Rocha, S., K.J. Campbell, and N.D. Perkins, p53- and Mdm2-independent repression of NF-kappa B transactivation by the ARF tumor suppressor. Molecular cell, 2003. 12(1): p. 15-25.

11. Rocha, S., et al., Regulation of NF-kappaB and p53 through activation of ATR and Chk1 by the ARF tumour suppressor. The EMBO journal, 2005. 24(6): p. 1157-69.

12. Crawley, C.D., et al., S-phase-dependent p50/NF-small ka, CyrillicB 1 phosphorylation in response to ATR and replication stress acts to maintain genomic stability. Cell Cycle, 2015. 14(4): p. 566-76.

13. Schmitt, A.M., et al., p50 (NF-kappaB1) is an effector protein in the cytotoxic response to DNA methylation damage. Mol Cell, 2011. 44(5): p. 785-96.

14. Vonderach, M., et al., DNA Binding and Phosphorylation Regulate the Core Structure of the NF- $\kappa B$ p50 Transcription Factor. Journal of the American Society for Mass Spectrometry, 2019.30(1): p. 128-138.

15. Kenneth, N.S., S. Mudie, and S. Rocha, IKK and NF-kappaB-mediated regulation of Claspin impacts on ATR checkpoint function. The EMBO journal, 2010. 29(17): p. 2966-78.

16. Errico, A. and V. Costanzo, Mechanisms of replication fork protection: a safeguard for genome stability. Crit Rev Biochem Mol Biol, 2012. 47(3): p. 222-35.

17. Smits, V.A.J., et al., Claspin - checkpoint adaptor and DNA replication factor. FEBS J, 2018.

18. Lovly, C.M. and A.T. Shaw, Molecular Pathways: Resistance to Kinase Inhibitors and Implications for Therapeutic Strategies. Clinical Cancer Research, 2014. 20(9): p. 2249-2256.

19. Sequist, L.V., et al., Genotypic and Histological Evolution of Lung Cancers Acquiring Resistance to EGFR Inhibitors. Science Translational Medicine, 2011. 3: p. 75ra26$75 \mathrm{ra} 26$. 
bioRxiv preprint doi: https://doi org/10.1101/2021 05.26.445425; this version posted May 27,2021 . The copyright holder for this preprint

20. Straussman, R., et al., Tumour micro-environment elicits innate resistance to RAF inhibitors through HGF secretion. Nature, 2012. 487(7408): p. 500-504.

21. Yano, S., et al., Hepatocyte Growth Factor Induces Gefitinib Resistance of Lung Adenocarcinoma with Epidermal Growth Factor Receptor-Activating Mutations. Cancer Research, 2008. 68: p. 9479-9487.

22. Sale, M.J., et al., Targeting melanoma's MCL1 bias unleashes the apoptotic potential of BRAF and ERK1/2 pathway inhibitors. Nature Communications, 2019. 10(1).

23. Harris, A.W., et al., The E mu-myc transgenic mouse. A model for high-incidence spontaneous lymphoma and leukemia of early $B$ cells. The Journal of experimental medicine, 1988. 167(2): p. 353-71.

24. Hunter, J.E., et al., The NF-kappaB subunit c-Rel regulates Bach2 tumour suppressor expression in B-cell lymphoma. Oncogene, 2016. 35(26): p. 3476-84.

25. Walton, M.I., et al., The clinical development candidate CCT245737 is an orally active CHK1 inhibitor with preclinical activity in RAS mutant NSCLC and Emicro-MYC driven B-cell lymphoma. Oncotarget, 2015.

26. Leung-Pineda, V., C.E. Ryan, and H. Piwnica-Worms, Phosphorylation of Chk1 by ATR is antagonized by a Chkl-regulated protein phosphatase $2 \mathrm{~A}$ circuit. Molecular and cellular biology, 2006. 26(20): p. 7529-7538.

27. Huang, T.T. and A.D. D'Andrea, Regulation of DNA repair by ubiquitylation. Nature Reviews Molecular Cell Biology, 2006. 7(5): p. 323-334.

28. Kim, H. and A.D. D'Andrea, Regulation of DNA cross-link repair by the Fanconi anemia/BRCA pathway. Genes \& Development, 2012. 26(13): p. 1393-1408.

29. Guervilly, J.-H., et al., USP1 deubiquitinase maintains phosphorylated CHK1 by limiting its DDB1-dependent degradation. Human Molecular Genetics, 2011. 20(11): p. 2171-2181.

30. Liao, Y., et al., Proteasome-associated deubiquitinase ubiquitin-specific protease 14 regulates prostate cancer proliferation by deubiquitinating and stabilizing androgen receptor. Cell Death \& Disease, 2017. 8(2): p. e2585-e2585.

31. Liao, Y., et al., Growth arrest and apoptosis induction in androgen receptor-positive human breast cancer cells by inhibition of USP14-mediated androgen receptor deubiquitination. Oncogene, 2018. 37(14): p. 1896-1910.

32. Dexheimer, T.S., et al., Synthesis and Structure-Activity Relationship Studies of NBenzyl-2-phenylpyrimidin-4-amine Derivatives as Potent USP1/UAF1 Deubiquitinase Inhibitors with Anticancer Activity against Nonsmall Cell Lung Cancer. Journal of Medicinal Chemistry, 2014. 57(19): p. 8099-8110.

33. Engelman, J.A., et al., \&lt;em\&gt;MET\&lt;/em\&gt; Amplification Leads to Gefitinib Resistance in Lung Cancer by Activating ERBB3 Signaling. Science, 2007. 316(5827): p. 1039.

34. Katayama, R., et al., Mechanisms of Acquired Crizotinib Resistance in ALKRearranged Lung Cancers. Science Translational Medicine, 2012. 4(120): p. 120ra17.

35. Nazarian, R., et al., Melanomas acquire resistance to B-RAF(V600E) inhibition by RTK or N-RAS upregulation. Nature, 2010. 468(7326): p. 973-977.

36. Shah, N.P. and C.L. Sawyers, Mechanisms of resistance to STI571 in Philadelphia chromosome-associated leukemias. Oncogene, 2003. 22(47): p. 7389-7395.

37. Takezawa, K., et al., \&lt;em\&gt;HER2\&lt;/em\&gt; Amplification: A Potential Mechanism of Acquired Resistance to EGFR Inhibition in $\& l t ; e m \& g t ; E G F R \& l t ; /$ em\&gt;-Mutant Lung Cancers That Lack the Second-Site $\& l t ;$ em\&gt;EGFR\&lt;/em\&gt;\&lt;sup\&gt;T790M\&lt;/sup\&gt; Mutation. Cancer Discovery, 2012. 2(10): p. 922. 
bioRxiv preprint doi: https://doi org/10.1101/2021.05.26.445425; this version posted May 27, 2021. The copyright holder for this preprint

38. Villanueva, J., et al., Acquired Resistance to BRAF Inhibitors Mediated by a RAF Kinase Switch in Melanoma Can Be Overcome by Cotargeting MEK and IGF-1R/PI3K. Cancer Cell, 2010. 18(6): p. 683-695.

39. Zhang, X., et al., FANCI is a negative regulator of Akt activation. Cell Cycle, 2016. 15(8): p. 1134-1143.

40. Nascimento, E.B.M., et al., Phosphorylation of PRAS40 on Thr246 by PKB/AKT facilitates efficient phosphorylation of Ser183 by mTORC1. Cellular Signalling, 2010. 22(6): p. 961-967.

41. Guo, Y.J., et al., ERK/MAPK signalling pathway and tumorigenesis (Review). Experimental and Therapeutic Medicine, 2020.

42. Porta, C., C. Paglino, and A. Mosca, Targeting PI3K/Akt/mTOR Signaling in Cancer. Frontiers in Oncology, 2014. 4(64).

43. Raynaud, F.I., et al., Biological properties of potent inhibitors of class I phosphatidylinositide 3-kinases: from PI-103 through PI-540, PI-620 to the oral agent GDC-0941. Molecular Cancer Therapeutics, 2009. 8(7): p. 1725-1738.

44. Lim, K.S., et al., USP1 Is Required for Replication Fork Protection in BRCA1-Deficient Tumors. Molecular Cell, 2018. 72(6): p. 925-941.e4.

45. Goldbraikh, D., et al., USP

1 deubiquitinates Akt to inhibit

$P I$

$3 K$-Akt-FoxO signaling in muscle during prolonged starvation. EMBO reports, 2020. 21(4).

46. Kuang, X., et al., Inhibition of USP1 induces apoptosis via IDI/AKT pathway in B-cell acute lymphoblastic leukemia cells. International Journal of Medical Sciences, 2021. 18(1): p. 245-255.

47. Zhiqiang, Z., et al., USP1 regulates AKT phosphorylation by modulating the stability of PHLPP1 in lung cancer cells. Journal of Cancer Research and Clinical Oncology, 2012. 138(7): p. 1231-1238.

48. Sakurikar, N., et al., A subset of cancer cell lines is acutely sensitive to the Chk1 inhibitor MK-8776 as monotherapy due to CDK2 activation in $S$ phase. Oncotarget; Vol 7, No 2, 2015.

49. Thompson, R., R. Montano, and A. Eastman, The Mre11 Nuclease Is Critical for the Sensitivity of Cells to Chk1 Inhibition. PLOS ONE, 2012. 7(8): p. e44021.

50. van Harten, A.M., et al., Targeting the cell cycle in head and neck cancer by Chk1 inhibition: a novel concept of bimodal cell death. Oncogenesis, 2019. 8(7): p. 38.

51. Restelli, V., et al., Characterization of a mantle cell lymphoma cell line resistant to the Chk1 inhibitor PF-00477736. Oncotarget, 2015. 6(35): p. 37229-37240.

52. Walton, M.I., et al., CCT244747 is a novel potent and selective CHK1 inhibitor with oral efficacy alone and in combination with genotoxic anticancer drugs. Clinical cancer research : an official journal of the American Association for Cancer Research, 2012. 18(20): p. 5650-61.

53. Beale, G., et al., Combined PI3K and CDK2 inhibition induces cell death and enhances in vivo antitumour activity in colorectal cancer. British Journal of Cancer, 2016. 115(6): p. 682-690.

54. Byrne, D.P., et al., Use of the Polo-like kinase 4 (PLK4) inhibitor centrinone to investigate intracellular signalling networks using SILAC-based phosphoproteomics. Biochemical Journal, 2020. 477(13): p. 2451-2475.

55. Ferries, S., et al., Evaluation of Parameters for Confident Phosphorylation Site Localization Using an Orbitrap Fusion Tribrid Mass Spectrometer. Journal of Proteome Research, 2017. 16(9): p. 3448-3459. 
bioRxiv preprint doi: https://doi org/10.1101/2021.05.26.445425: this version posted May 27. 2021. The copyriaht holder for this preprint (which was not certified by peer review) is the author/funder, who has granted bioRxiv a license to display the preprint in perpetuity. It is made available under aCC-BY-NC-ND 4.0 International license.

56. Murga, M., et al., Exploiting oncogene-induced replicative stress for the selective killing of Myc-driven tumors. Nature structural \& molecular biology, 2011. 18(12): p. 1331-5.

57. $\quad$ Erickson, B.K., et al., Evaluating Multiplexed Quantitative Phosphopeptide Analysis on a Hybrid Quadrupole Mass Filter/Linear Ion Trap/Orbitrap Mass Spectrometer. Analytical Chemistry, 2015. 87(2): p. 1241-1249.

58. Ting, L., et al., MS3 eliminates ratio distortion in isobaric multiplexed quantitative proteomics. Nature Methods, 2011. 8(11): p. 937-940.

59. Vizcaíno, J.A., et al., The Proteomics Identifications (PRIDE) database and associated tools: status in 2013. Nucleic Acids Research, 2013. 41(D1): p. D1063-D1069.

60. Patro, R., et al., Salmon provides fast and bias-aware quantification of transcript expression. Nature Methods, 2017. 14(4): p. 417-419.

61. Soneson, C., M.I. Love, and M.D. Robinson, Differential analyses for RNA-seq: transcript-level estimates improve gene-level inferences. F1000Research, 2015. 4: p. 1521.

62. Love, M.I., W. Huber, and S. Anders, Moderated estimation of fold change and dispersion for RNA-seq data with DESeq2. Genome Biology, 2014. 15(12): p. 550.

63. Szklarczyk, D., et al., STRING v11: protein-protein association networks with increased coverage, supporting functional discovery in genome-wide experimental datasets. Nucleic Acids Research, 2019. 47(D1): p. D607-D613.

64. Pereira, L., et al., Inhibition of p38 MAPK sensitizes tumour cells to cisplatin-induced apoptosis mediated by reactive oxygen species and JNK. EMBO Mol Med, 2013. 5(11): p. 1759-74. 
bioRxiv preprint doi: https://doi org/10.1101/2021.05.26 445425: this version posted May 27 2021. The copyriaht holder for this preprint (which was not certified by peer review) is the author/funder, who has granted bioRxiv a license to display the preprint in perpetuity. It is made available under aCC-BY-NC-ND 4.0 International license.

\section{Hunter et al., Figure 1}

A

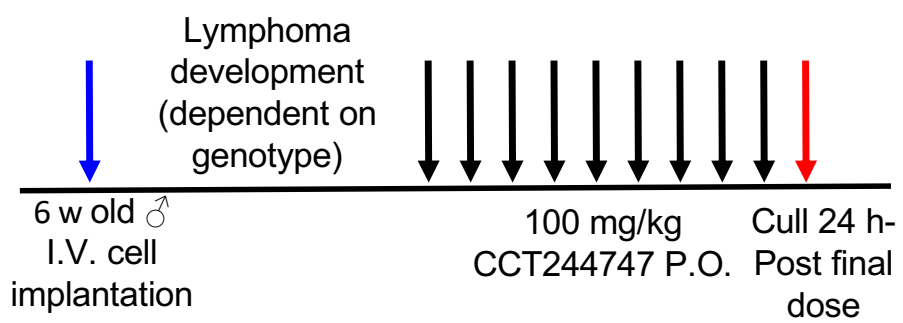

B
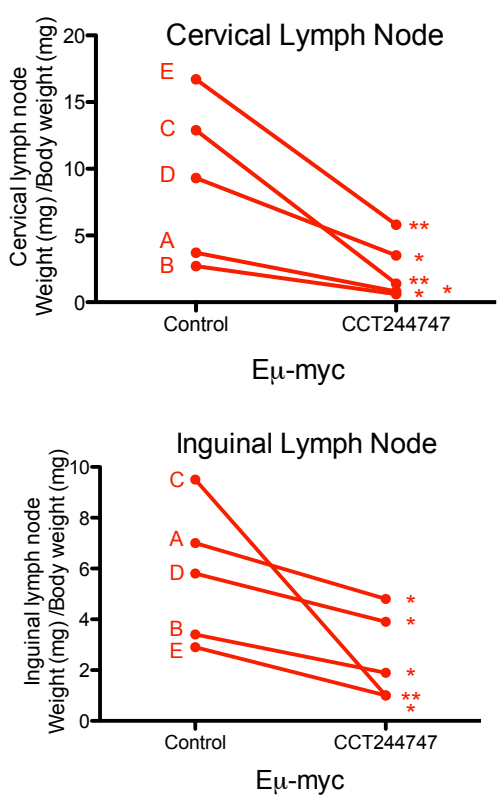

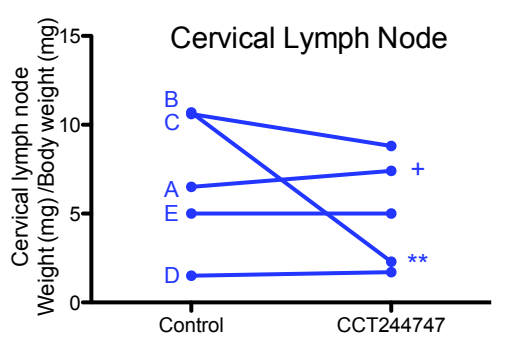

Eu-myc crel-/-

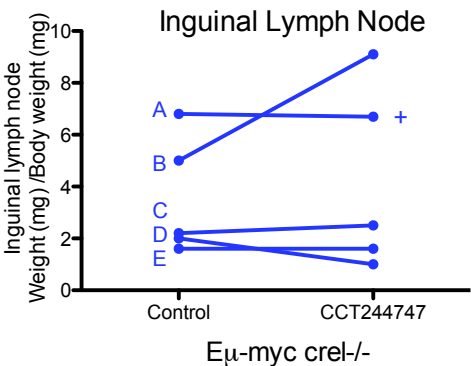

C

\begin{tabular}{|c|c|c|c|}
\hline & \multicolumn{3}{|c|}{ Eu-myc } \\
\hline Organ & $\begin{array}{c}\text { Decrease } \\
\text { tumour } \\
\text { burden }\end{array}$ & $\begin{array}{c}\text { No } \\
\text { response }\end{array}$ & $\begin{array}{c}\text { Increase } \\
\text { tumour } \\
\text { burden }\end{array}$ \\
\hline Inguinal LN & $5 / 5$ & $0 / 5$ & $0 / 5$ \\
\hline Brachial LN & $5 / 5$ & $0 / 5$ & $0 / 5$ \\
\hline $\begin{array}{c}\text { Mesenteric } \\
\text { LN }\end{array}$ & $5 / 5$ & $0 / 5$ & $0 / 5$ \\
\hline Spleen & $0 / 5$ & $4 / 5$ & $1 / 5$ \\
\hline Thymus & $5 / 5$ & $0 / 5$ & $0 / 5$ \\
\hline Cervical LN & $5 / 5$ & $0 / 5$ & $0 / 5$ \\
\hline & \multicolumn{3}{|c|}{ Eि-myc crel--/- } \\
\hline Inguinal LN & $0 / 5$ & $4 / 5$ & $1 / 5$ \\
\hline Brachial LN & $0 / 5$ & $4 / 5$ & $1 / 5$ \\
\hline $\begin{array}{c}\text { Mesenteric } \\
\text { LN }\end{array}$ & $0 / 5$ & $5 / 5$ & $0 / 5$ \\
\hline Spleen & $1 / 5$ & $4 / 5$ & $0 / 5$ \\
\hline Thymus & $1 / 5$ & $4 / 5$ & $0 / 5$ \\
\hline Cervical LN & $1 / 5$ & $4 / 5$ & $0 / 5$ \\
\hline
\end{tabular}

D

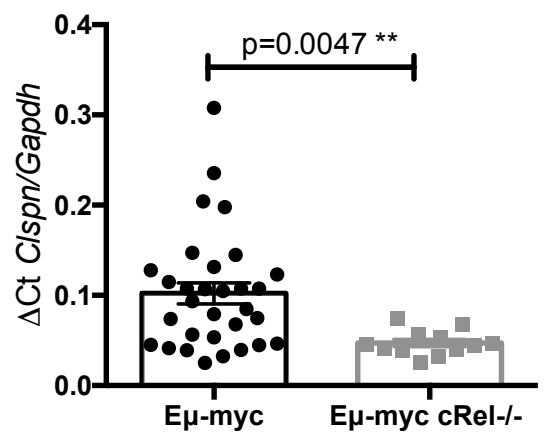


bioRxiv preprint doi: https://doi.org/10.1101/2021.05.26.445425; this version posted May 27, 2021. The copyright holder for this preprint (which was not certified by peer review) is the author/funder, who has granted bioRxiv a license to display the preprint in perpetuity. It is made available under aCC-BY-NC-ND 4.0 International license.

\section{Hunter et al., Figure 2}

\section{A}

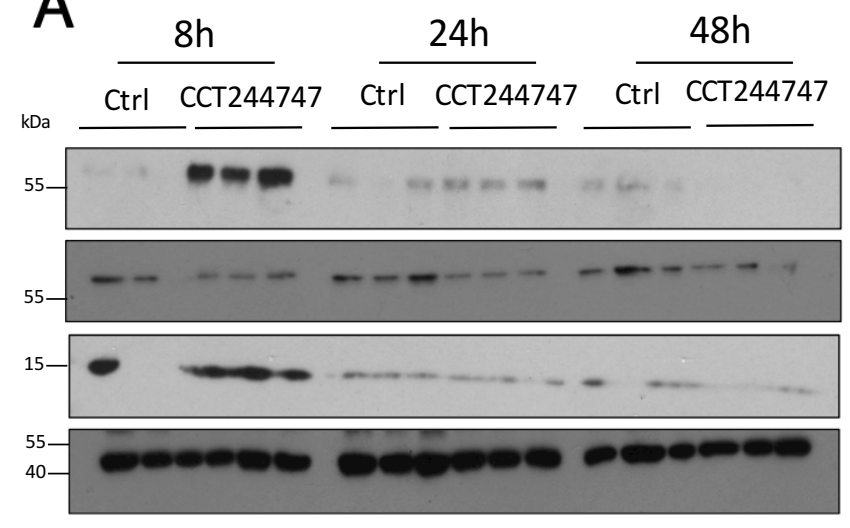

pCHK1 S345

CHK1

pH2AX S139

ACTIN
B

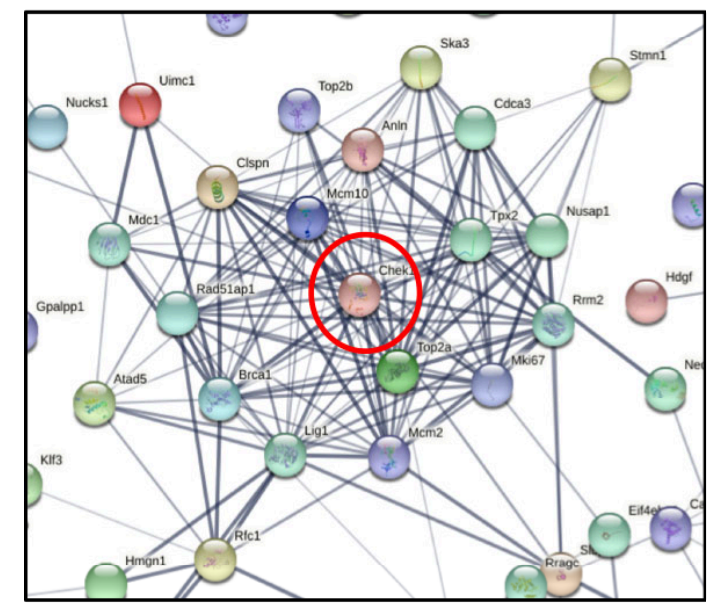

Phospho proteome: WT vs WT CHK1i

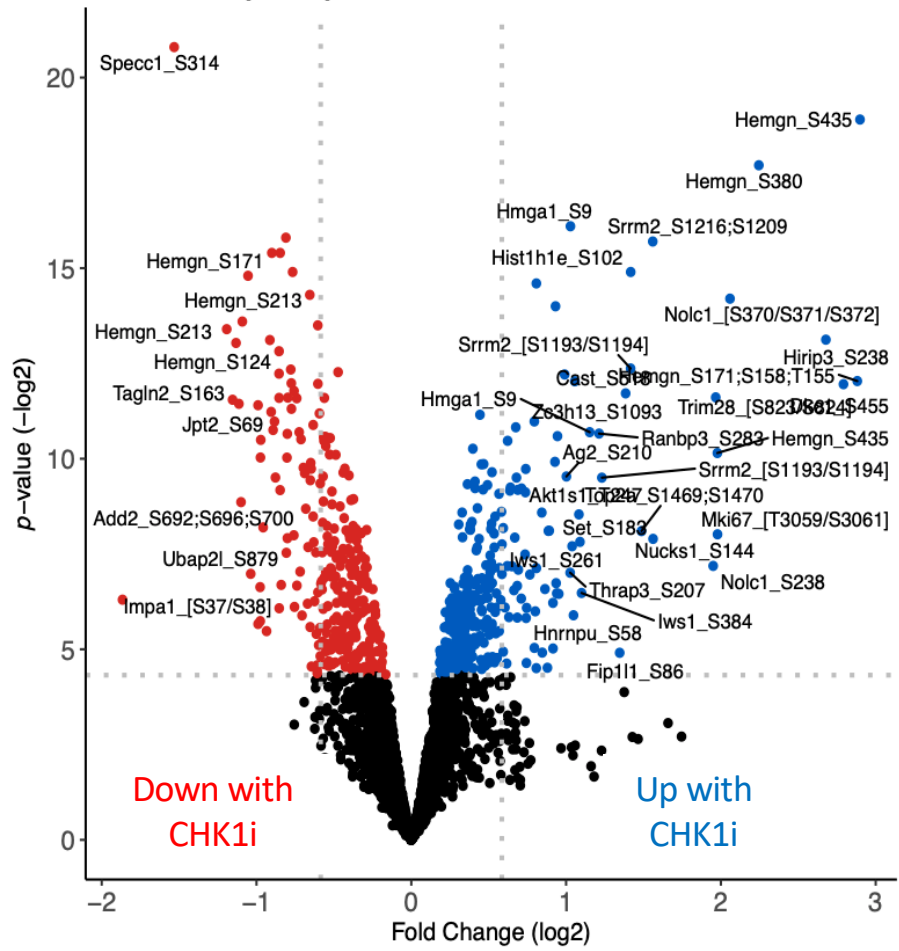

C

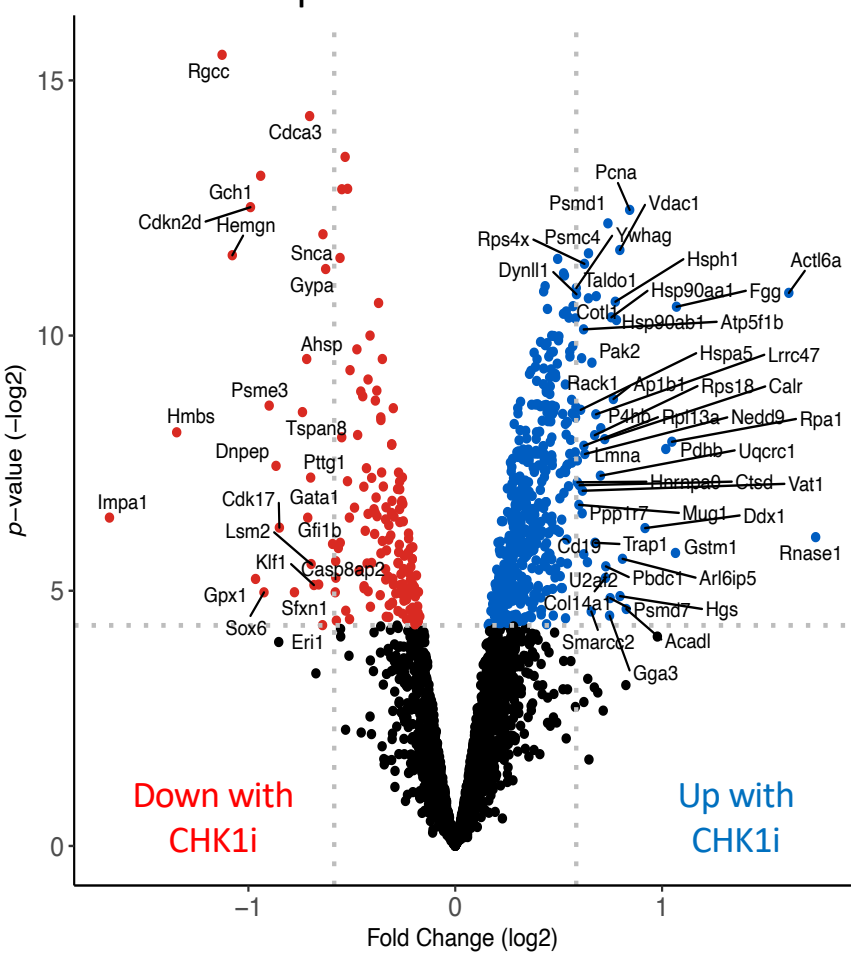

D 
bioRxiv preprint doi: https://doi.org/10.1101/2021.05.26.445425; this version posted May 27, 2021. The copyright holder for this preprint (which was not certified by peer review) is the author/funder, who has granted bioRxiv a license to display the preprint in perpetuity. It is made available under aCC-BY-NC-ND 4.0 International license.

\section{Hunter et al., Figure 3}

A

Total proteome: REL-/- vs REL-/- CHK1i

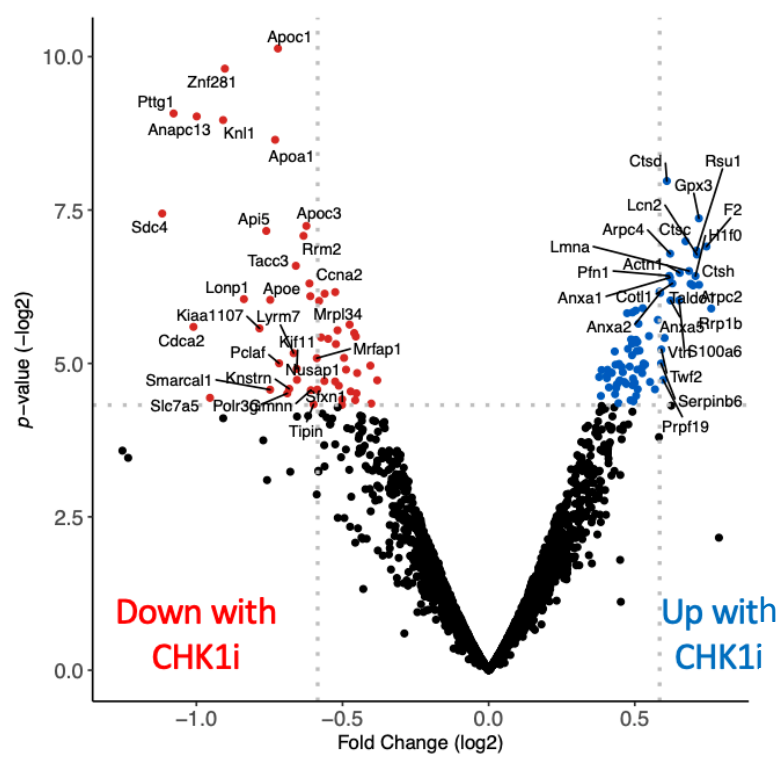

C

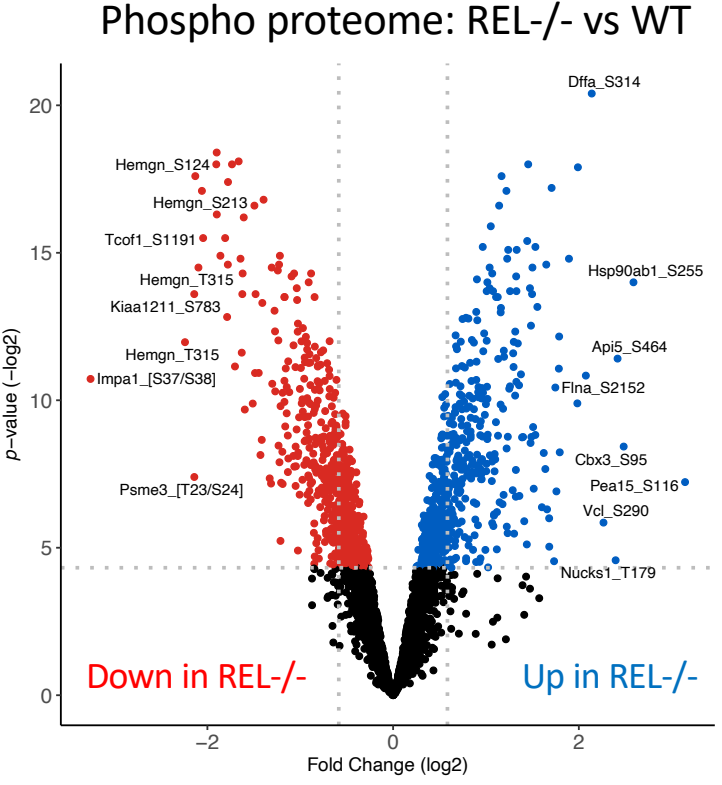

$\mathrm{F}$

Total proteome: REL-/- vs WT

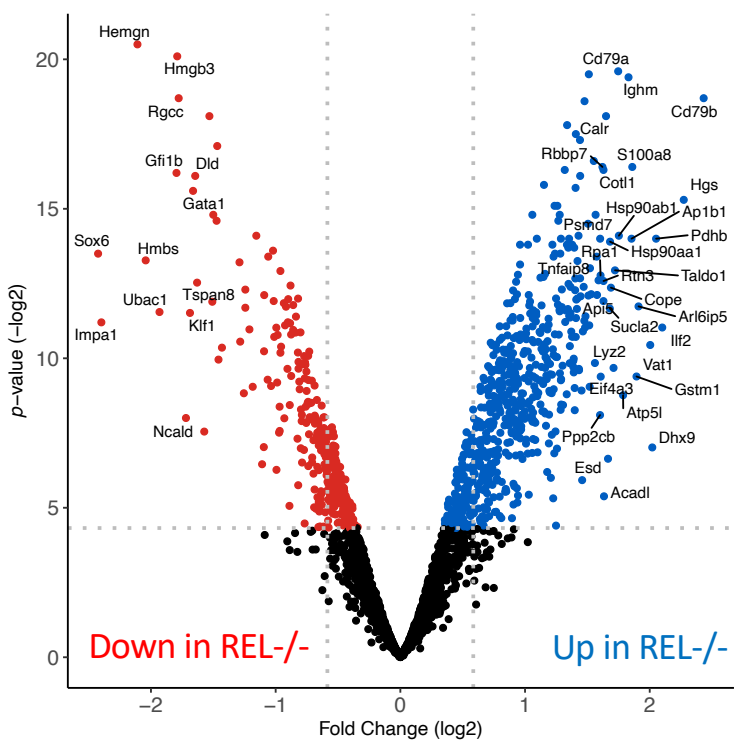

B

Phospho proteome: REL-/- vs REL-/- CHK1i

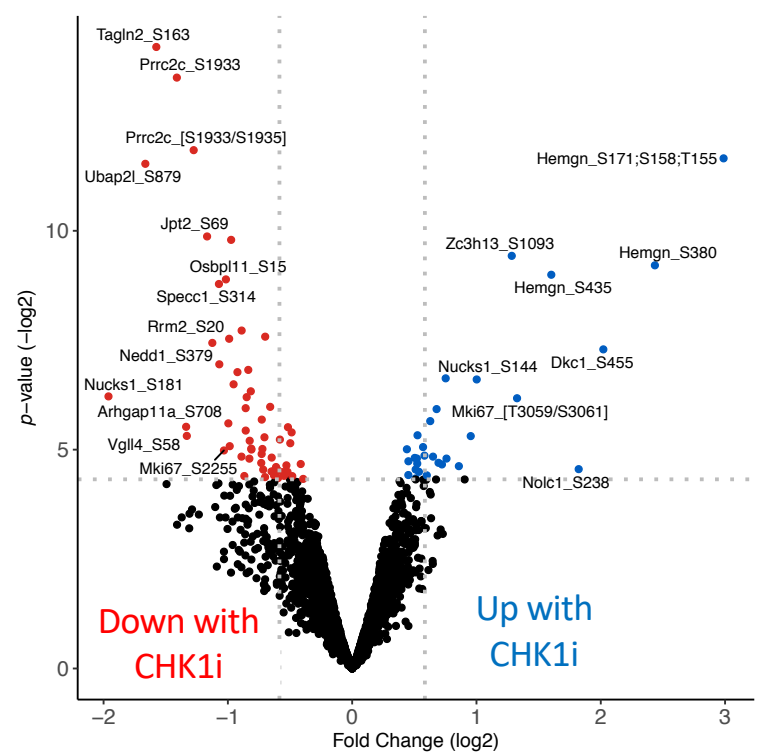

$\mathrm{D}$

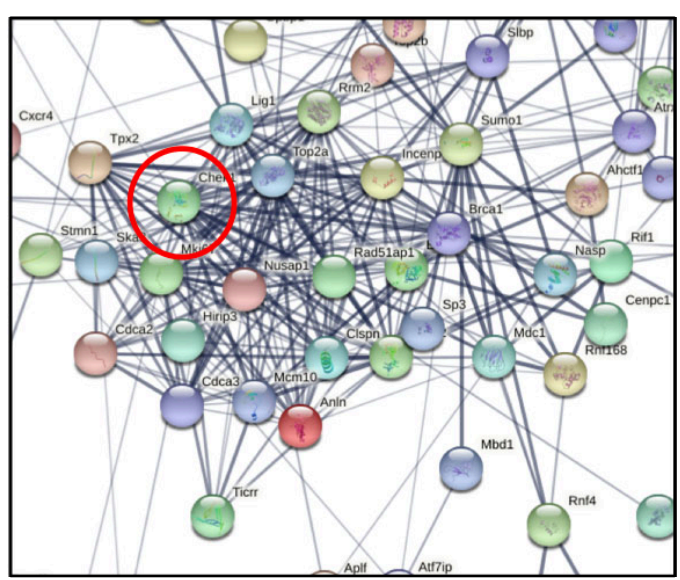

E Phosphosite overlap: Down in REL-/- vs WT

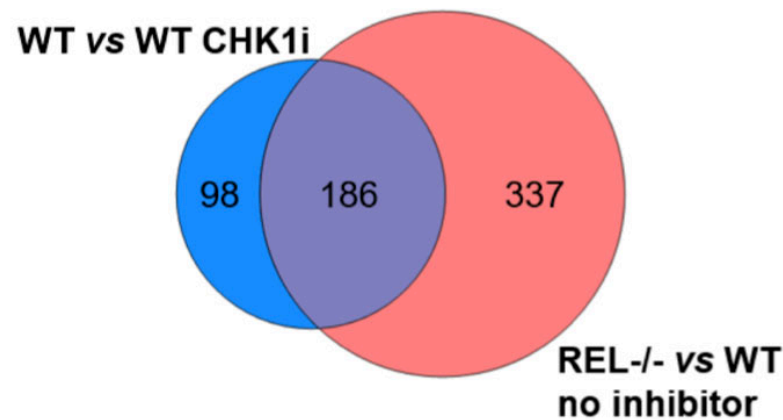

G

Total proteome overlap: Down in REL-/- vs WT

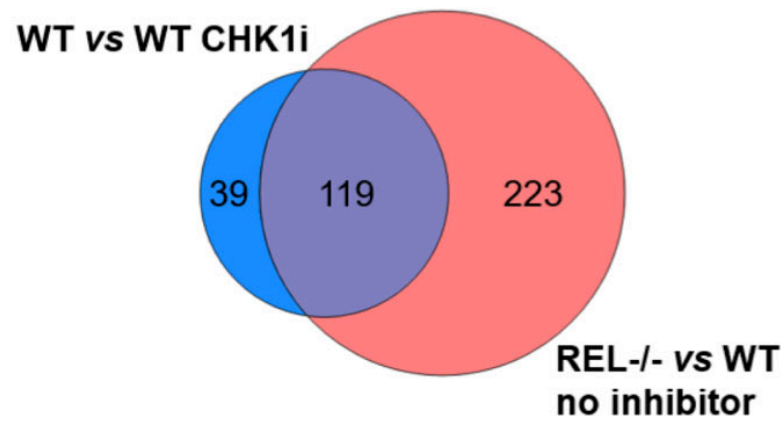


bioRxiv preprint doi: https://doi.org/10.1101/2021.05 26 445425. this version posted May 27 2021. The copyriaht holder for this preprint (which was not certified by peer review) is the author/funder, who has granted bioRxiv a license to display the preprint in perpetuity. It is made available under aCC-BY-NC-ND 4.0 International license.

\section{Hunter et al., Figure 4}

A

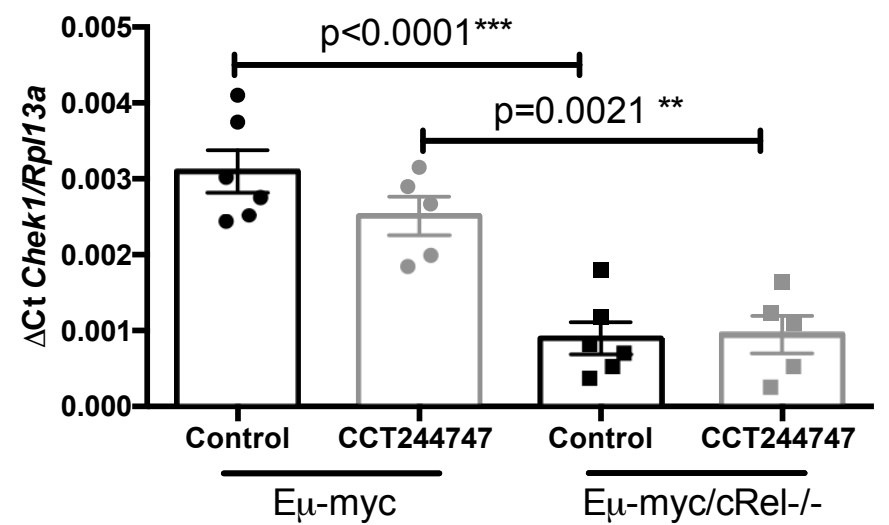

B
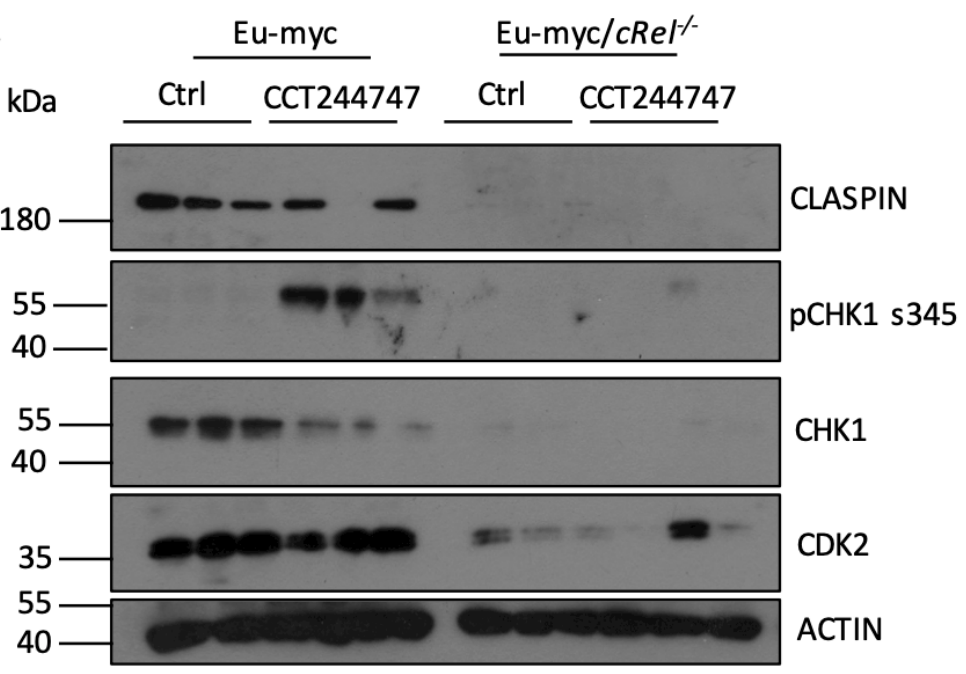

C

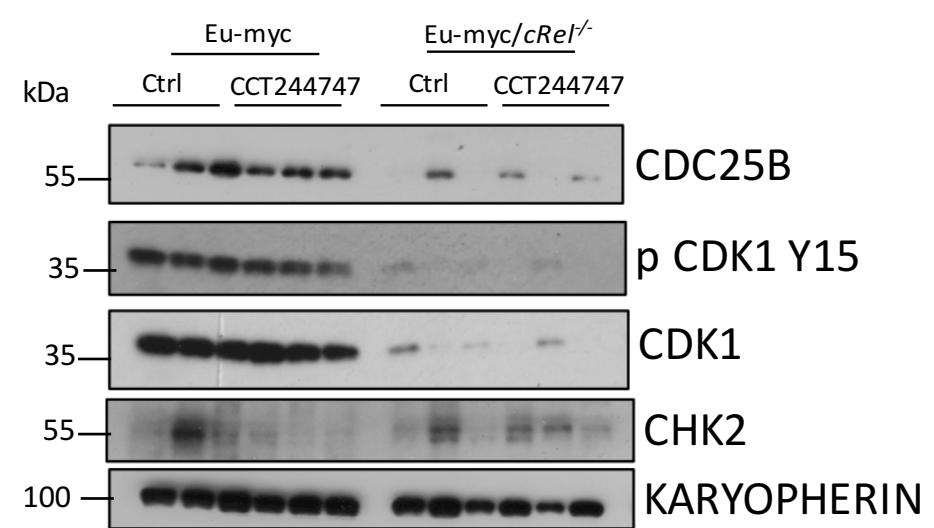


bioRxiv preprint doi: https://doi.org/10.1101/2021.05.26.445425; this version posted May 27, 2021. The copyright holder for this preprint (which was not certified by peer review) is the author/funder, who has granted bioRxiv a license to display the preprint in perpetuity. It is made available under aCC-BY-NC-ND 4.0 International license.

\section{Hunter et al., Figure 5}

A
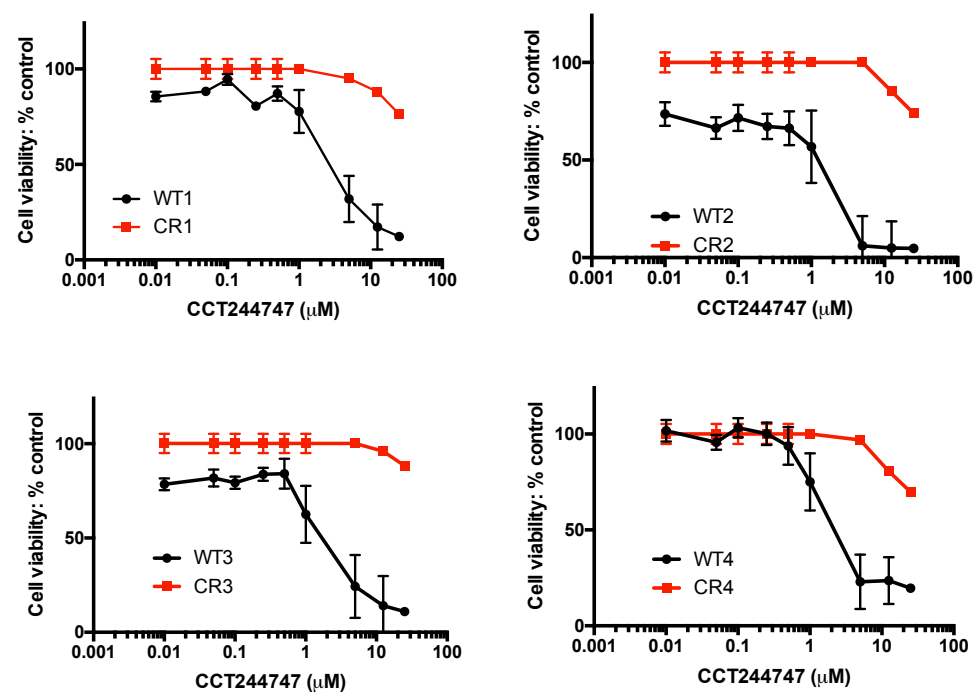

B
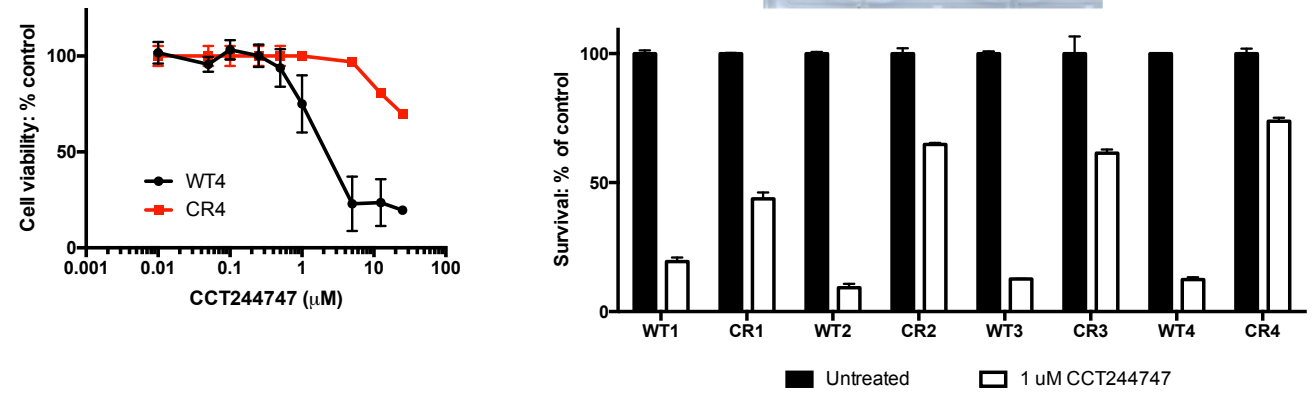

C
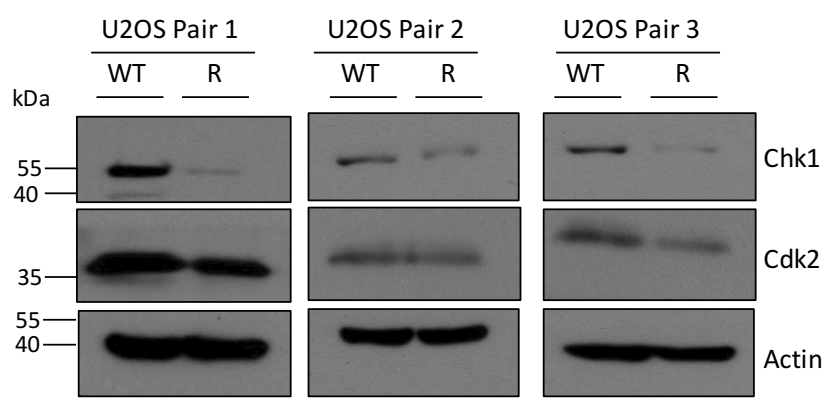

D

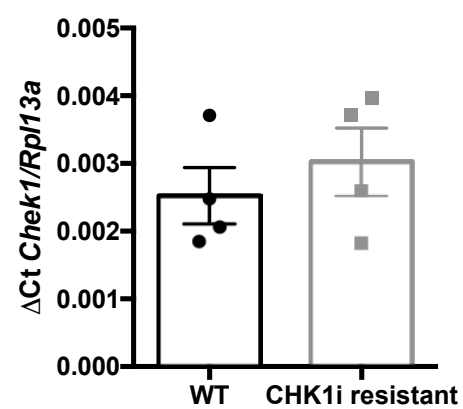

E

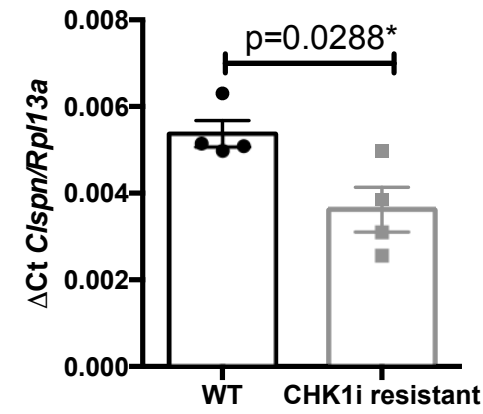


bioRxiv preprint doi: https://doi.org/10.1101/2021.05.26.445425; this version posted May 27, 2021. The copyright holder for this preprint (which was not certified by peer review) is the author/funder, who has granted bioRxiv a license to display the preprint in perpetuity. It is made available under aCC-BY-NC-ND 4.0 International license.

\section{Hunter et al., Figure 6}

A

RNA Seq: REL-/- vs WT

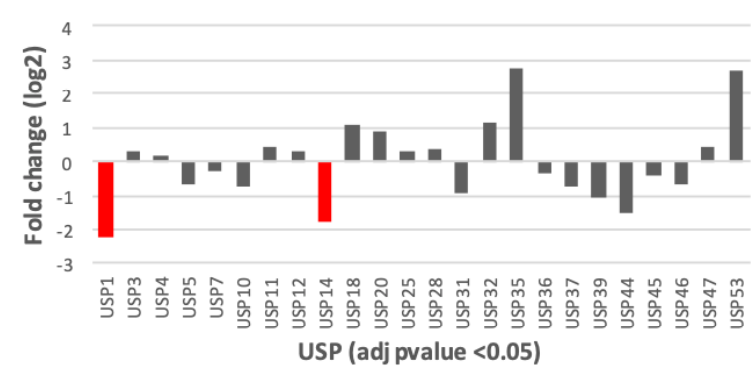

C

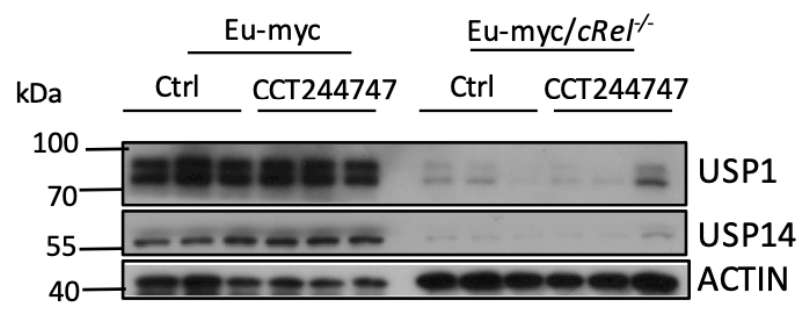

$E$

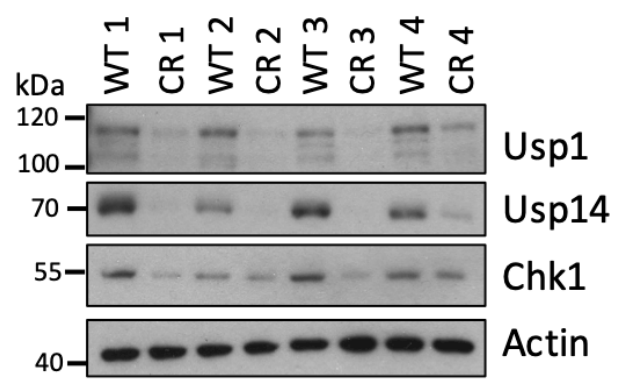

$\mathrm{G}$

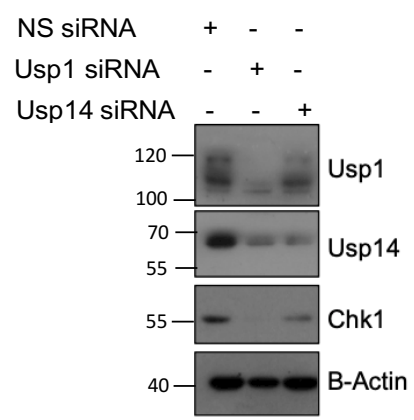

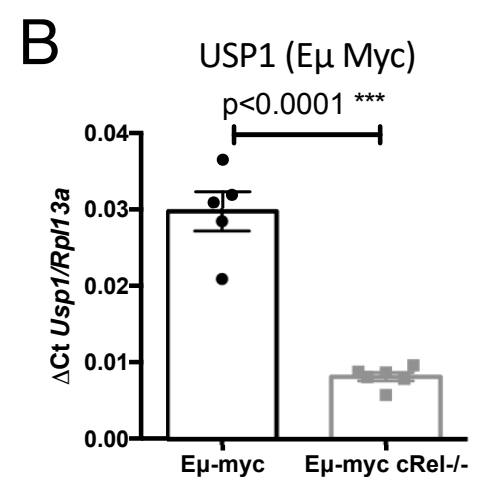

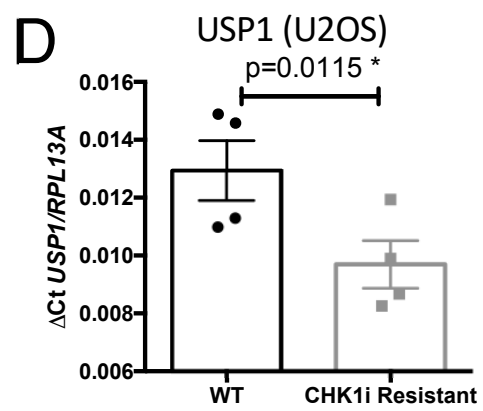

F NS SiRNA + CRel siRNA - +

U2OS
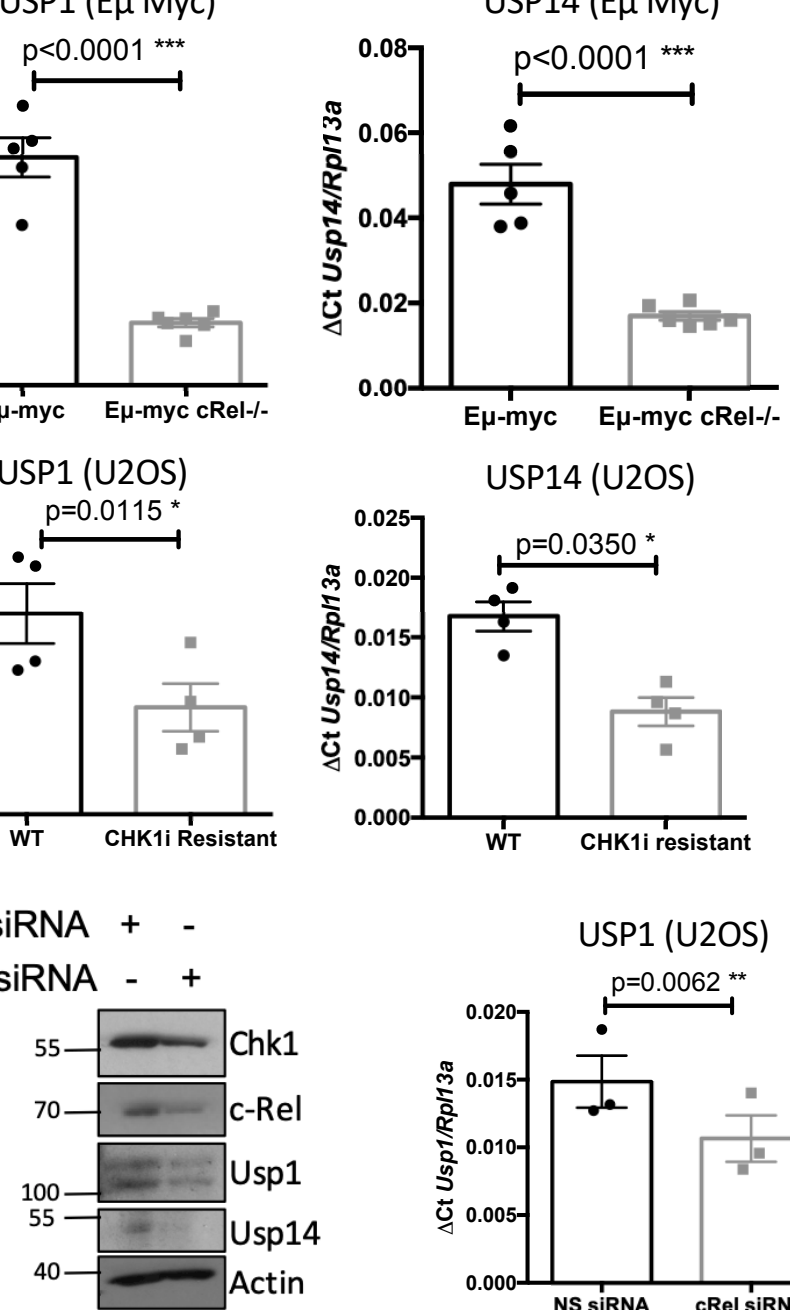

USP1 (U2OS)
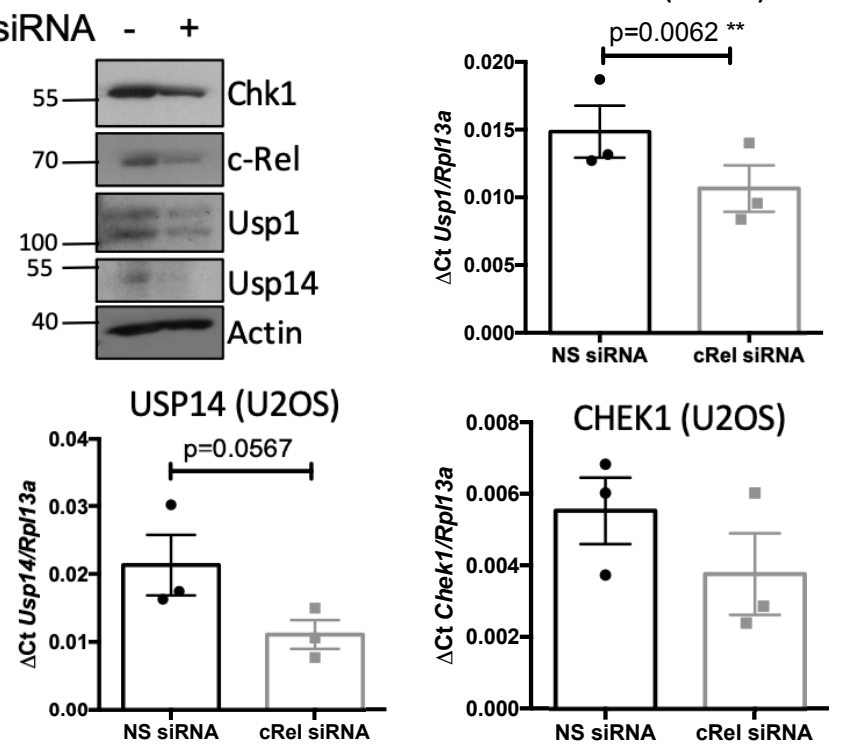

$\mathrm{H}$

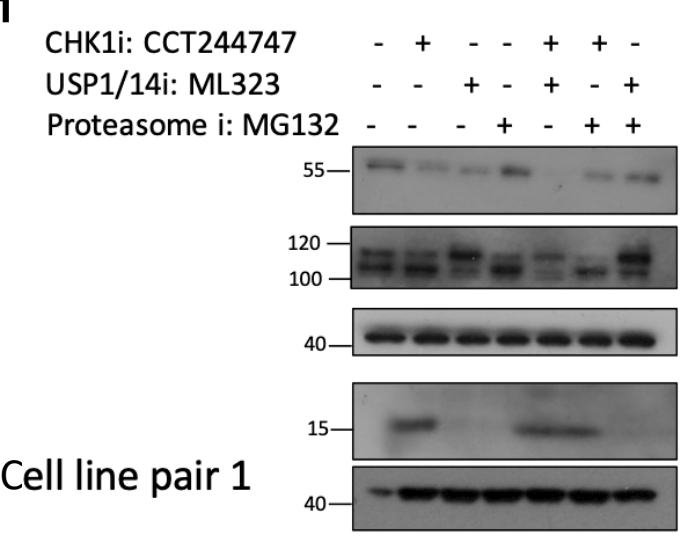

CCT244747 Resistant

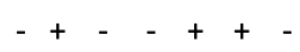

$-+-++$

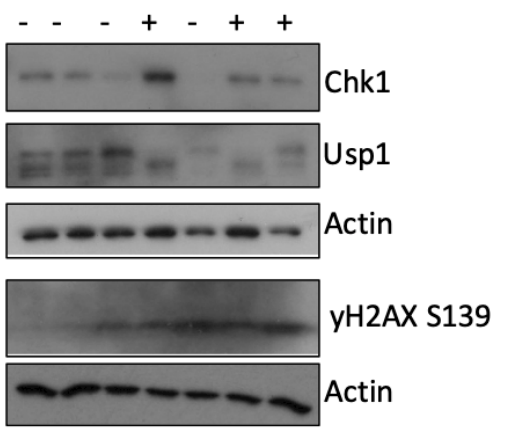

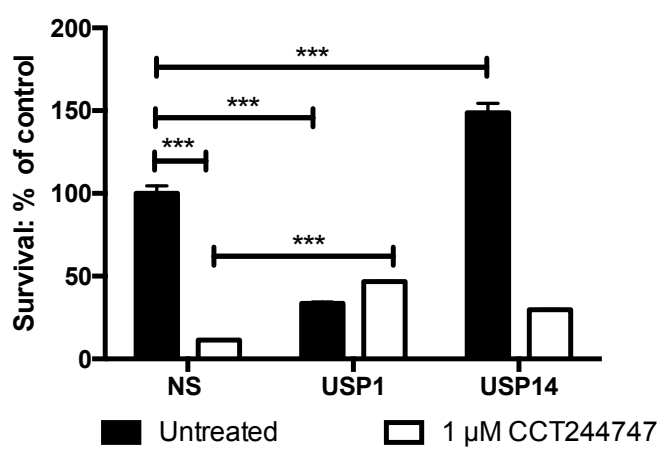


bioRxiv preprint doi: https://doi org/10.1101/2021.05.26 445425. this version posted May 27 2021. The copyriaht holder for this preprint (which was not certified by peer review) is the author/funder, who has granted bioRxiv a license to display the preprint in perpetuity. It is made available under aCC-BY-NC-ND 4.0 International license.

\section{Hunter et al., Figure 7}

A Upregulated phosphosite overlap

\section{Up in REL-I- vs WT}

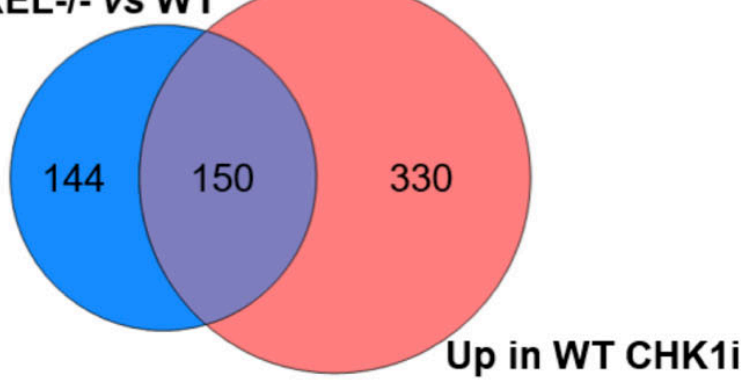

B Upregulated total proteome overlap

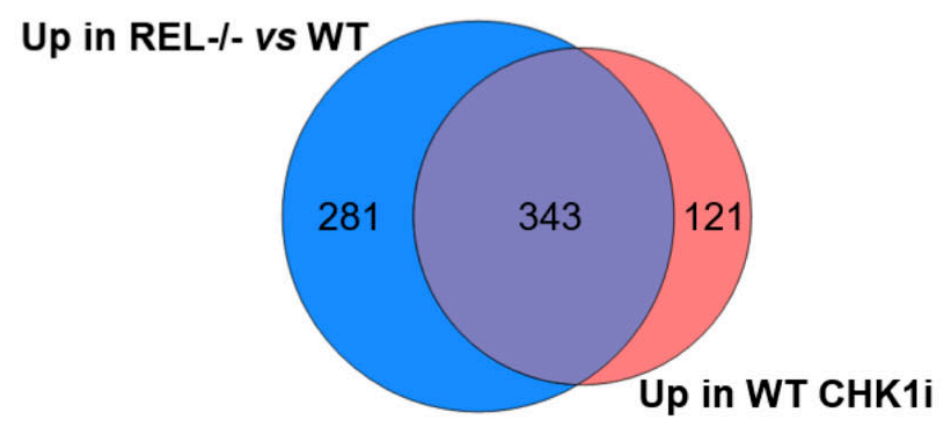

C

$\mathrm{kDa} \quad \mathrm{Ctrl} \quad \mathrm{CCT244747} \quad \mathrm{Ctrl}$ CCT244747

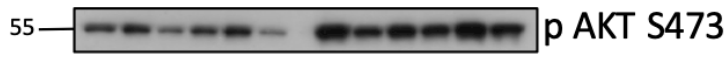

$55-2---\cdots-\cdots$ AKT

40—---2--2ACTIN

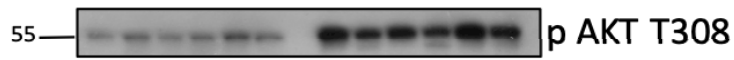

$55-2--------1$ AKT

40-

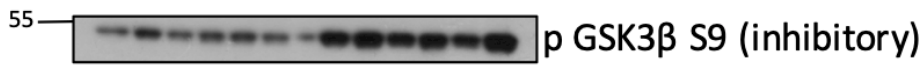

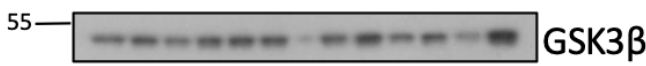

$40-\infty \ldots-\cdots$ ACTIN

$\mathrm{E}$

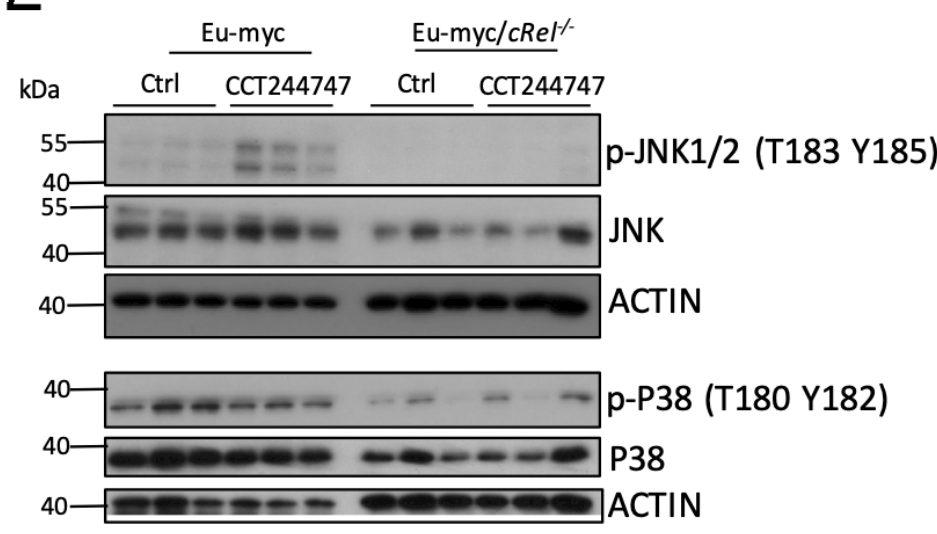


Hunter et al., Figure 8

A

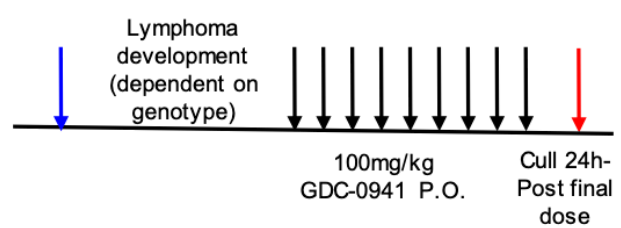

B

WT Tumour 1

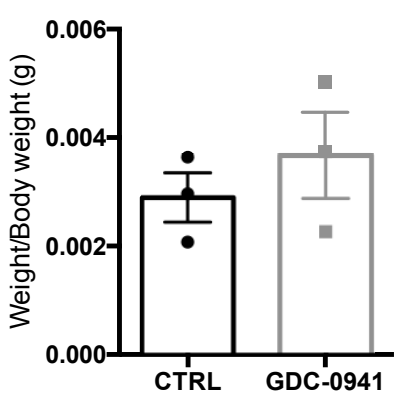

cRel $^{-/-}$Tumour 1

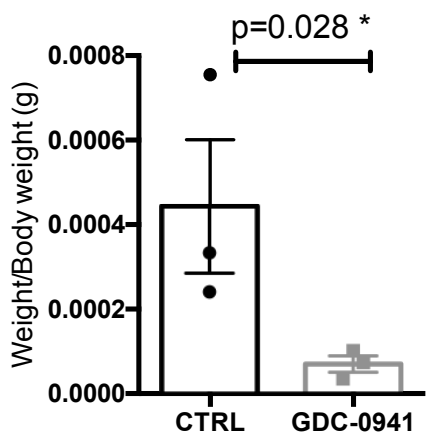

WT Tumour 2

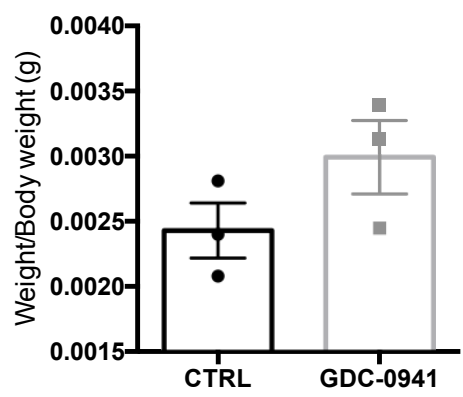

cRel $^{-/-}$Tumour 2

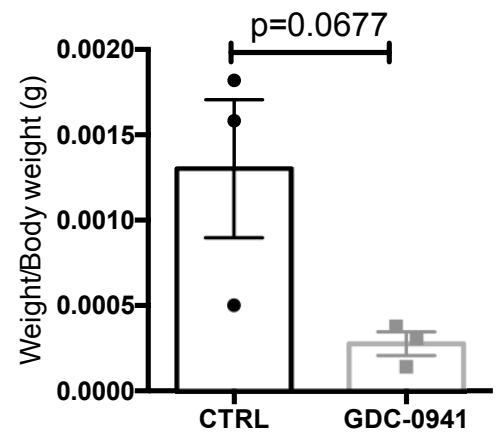

WT Tumour 3

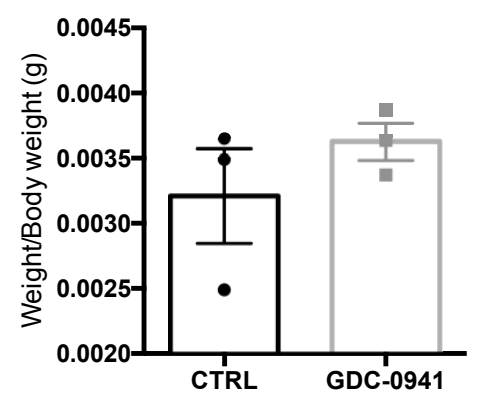

cRel $^{-/-}$Tumour 3

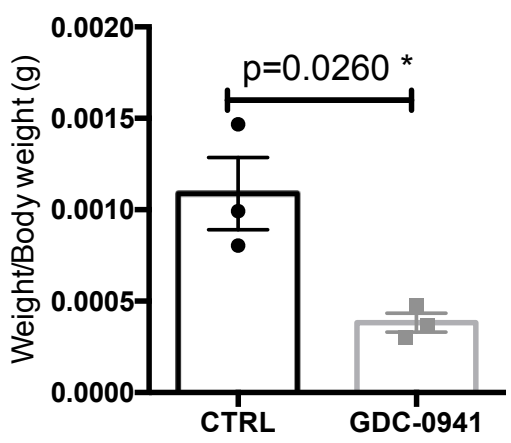

Cervical Lymph node 
Hunter et al., Figure 8

A

c-Rel expression drives USP1 and CLSPN expression, promoting CHK1 activity

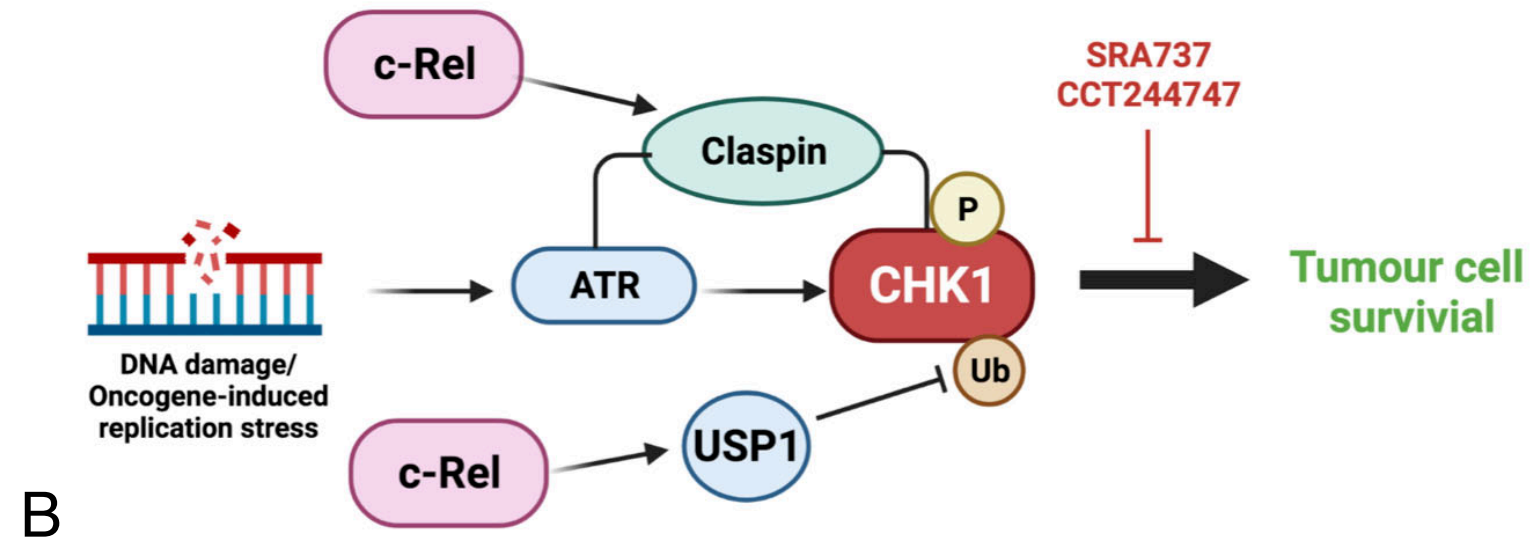

Loss of c-Rel expression results in CHK1 inactivation and upregulation of the PI3K/Akt pathway

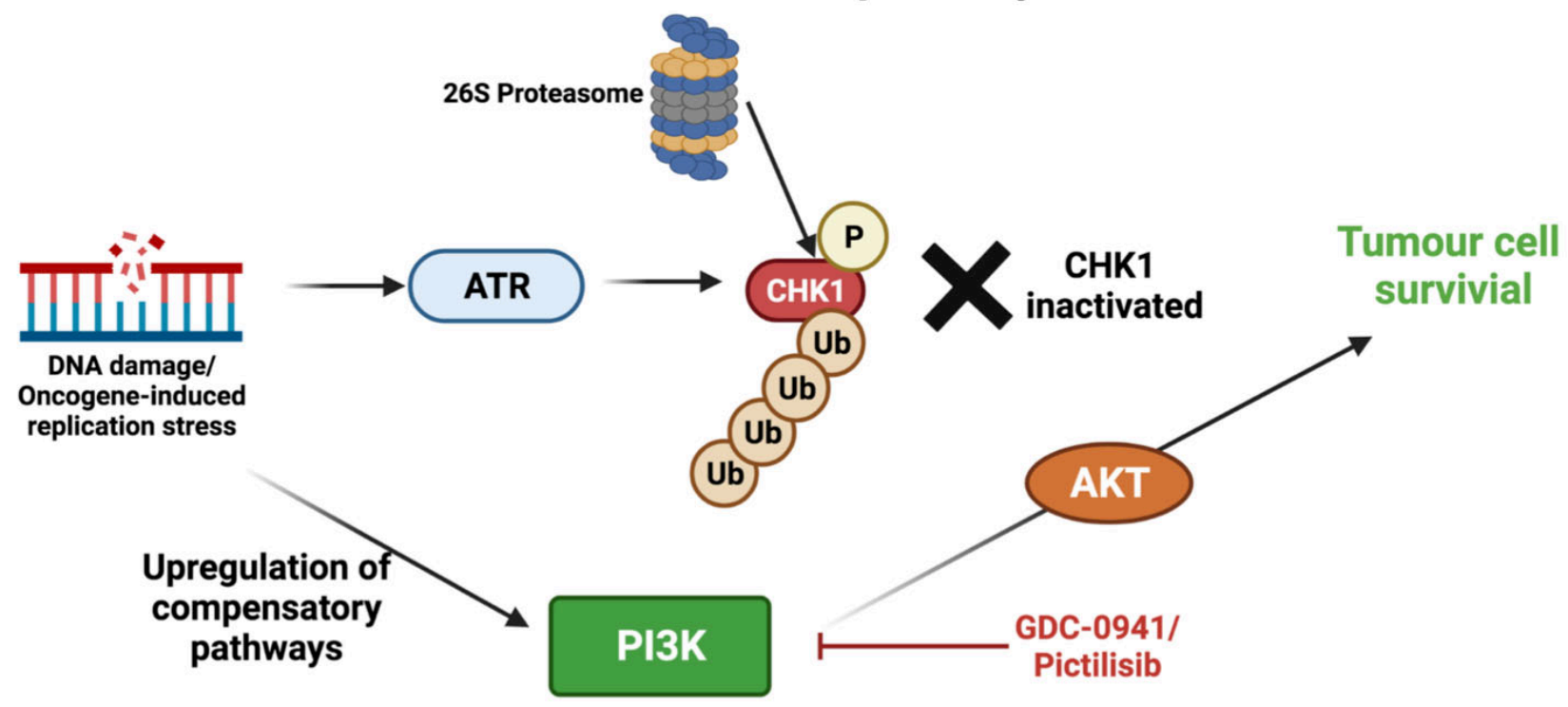


bioRxiv preprint doi: https://doi.org/10.1101/2021.05.26.445425; this version posted May 27, 2021. The copyright holder for this preprint (which was not certified by peer review) is the author/funder, who has granted bioRxiv a license to display the preprint in perpetuity. It is made available under aCC-BY-NC-ND 4.0 International license.

\section{Hunter et al., Supp Figure 1}

A

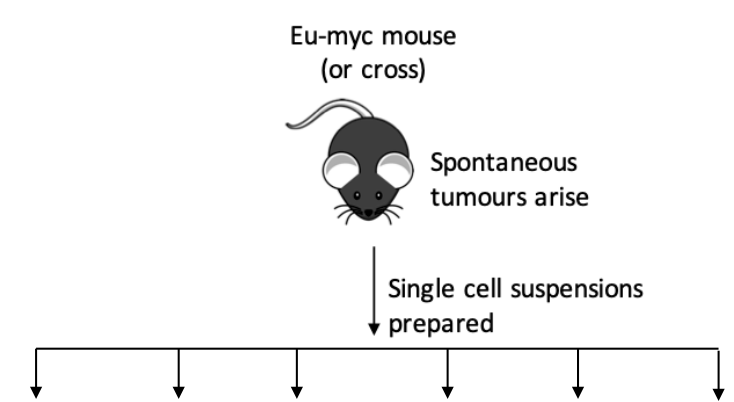

$1 \times 10^{6}$ cells implanted via the lateral tail vein into WT recipients

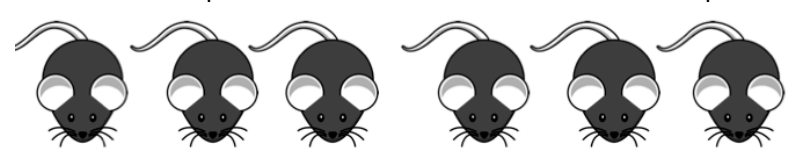

Allow tumours to be become palpable

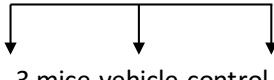

3 mice vehicle control treated

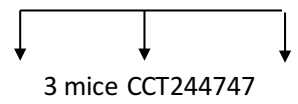

treated
B

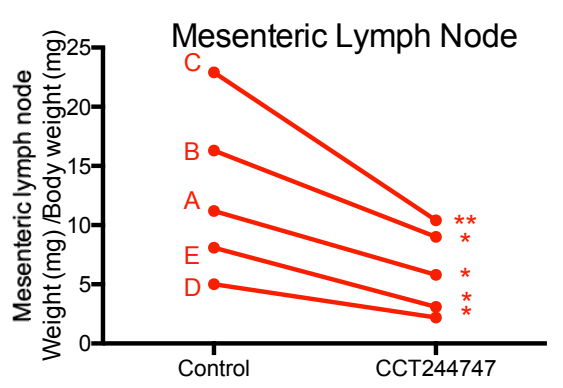

Eu-myc
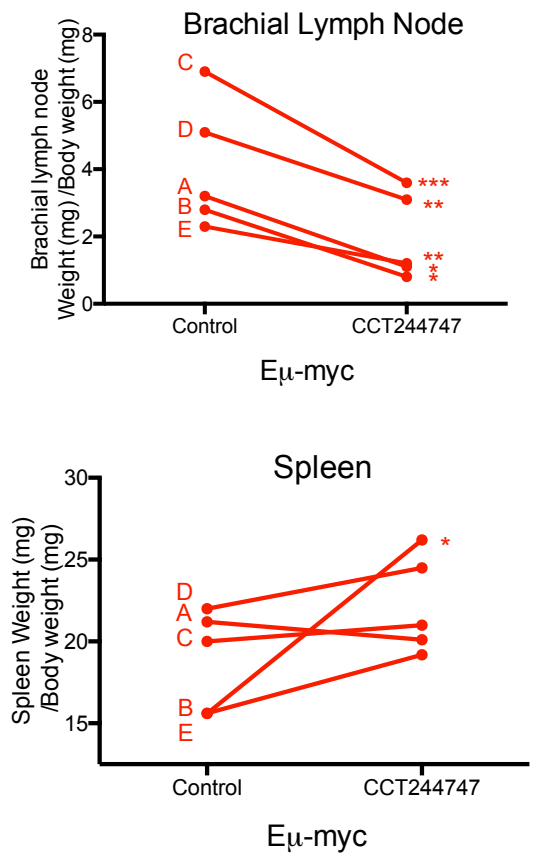

Thymus

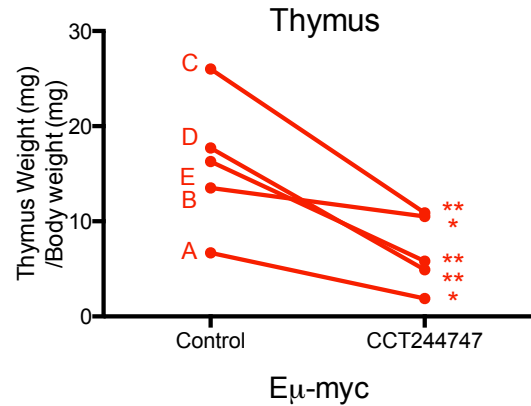

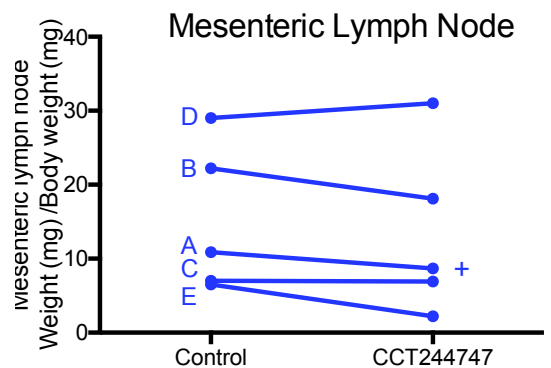

Eu-myc crel-/-

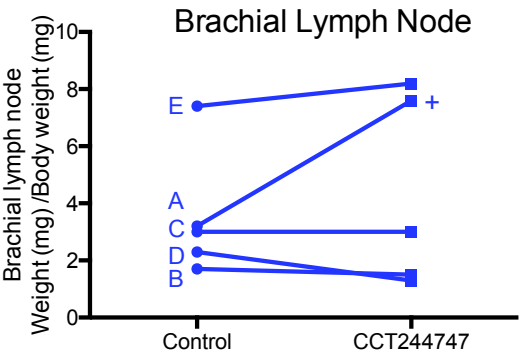

E $\mu$-myc crel-/-

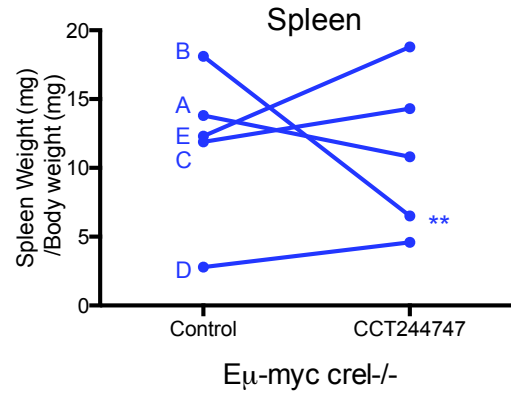

Thymus

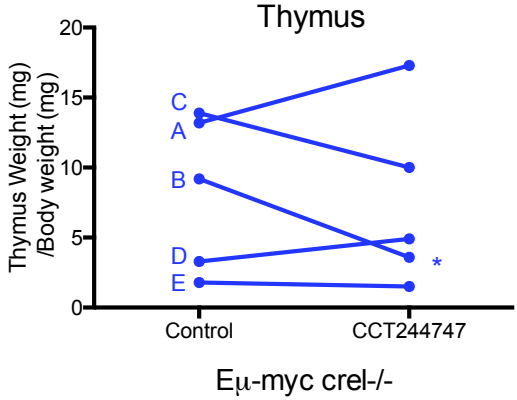

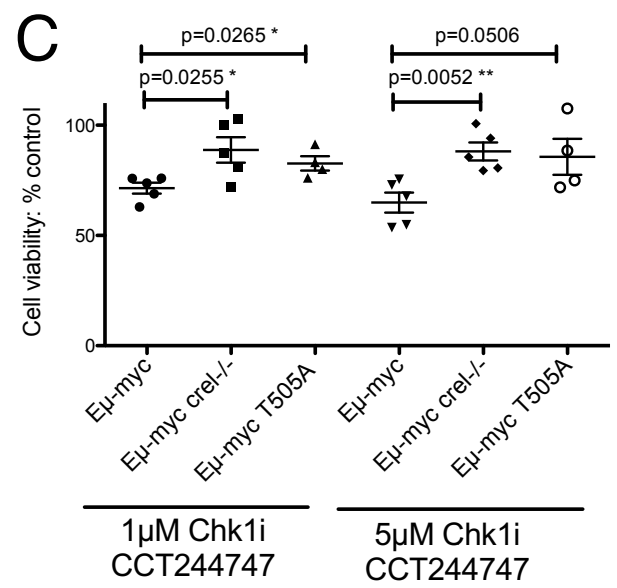

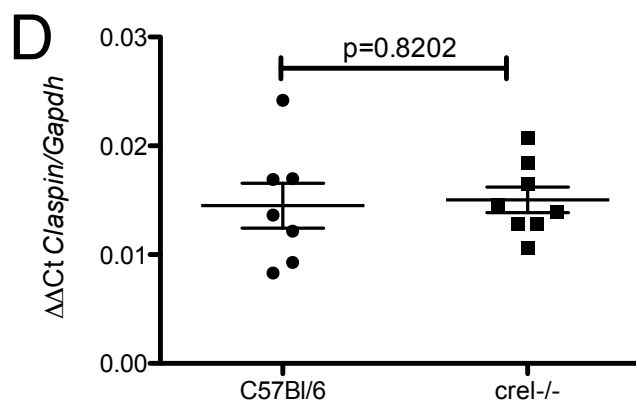

Normal B-cells 
bioRxiv preprint doi: https://doi.org/10.1101/2021.05.26.445425; this version posted May 27, 2021. The copyright holder for this preprint (which was not certified by peer review) is the author/funder, who has granted bioRxiv a license to display the preprint in perpetuity. It is made available under aCC-BY-NC-ND 4.0 International license.

\section{Hunter et al., Supp Figure 2}

A

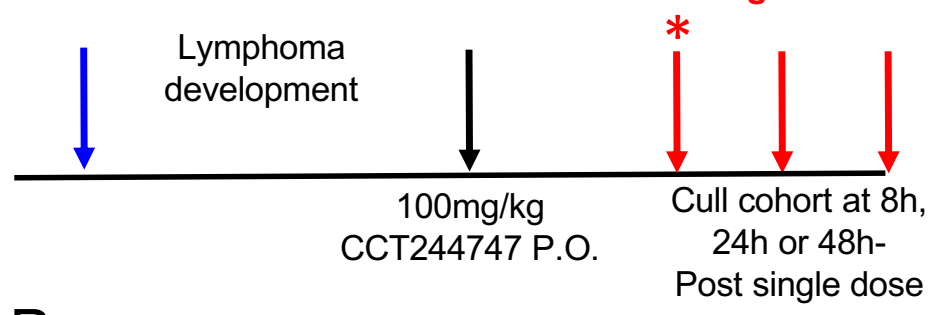

B

Extract Proteins \& Digest

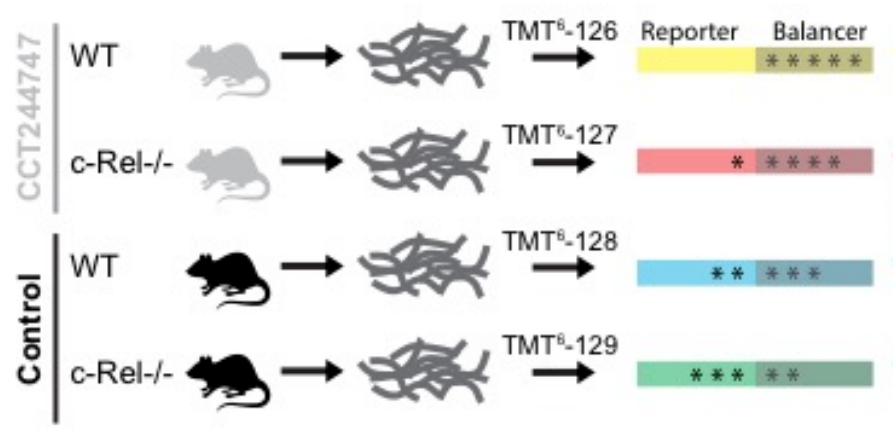

C

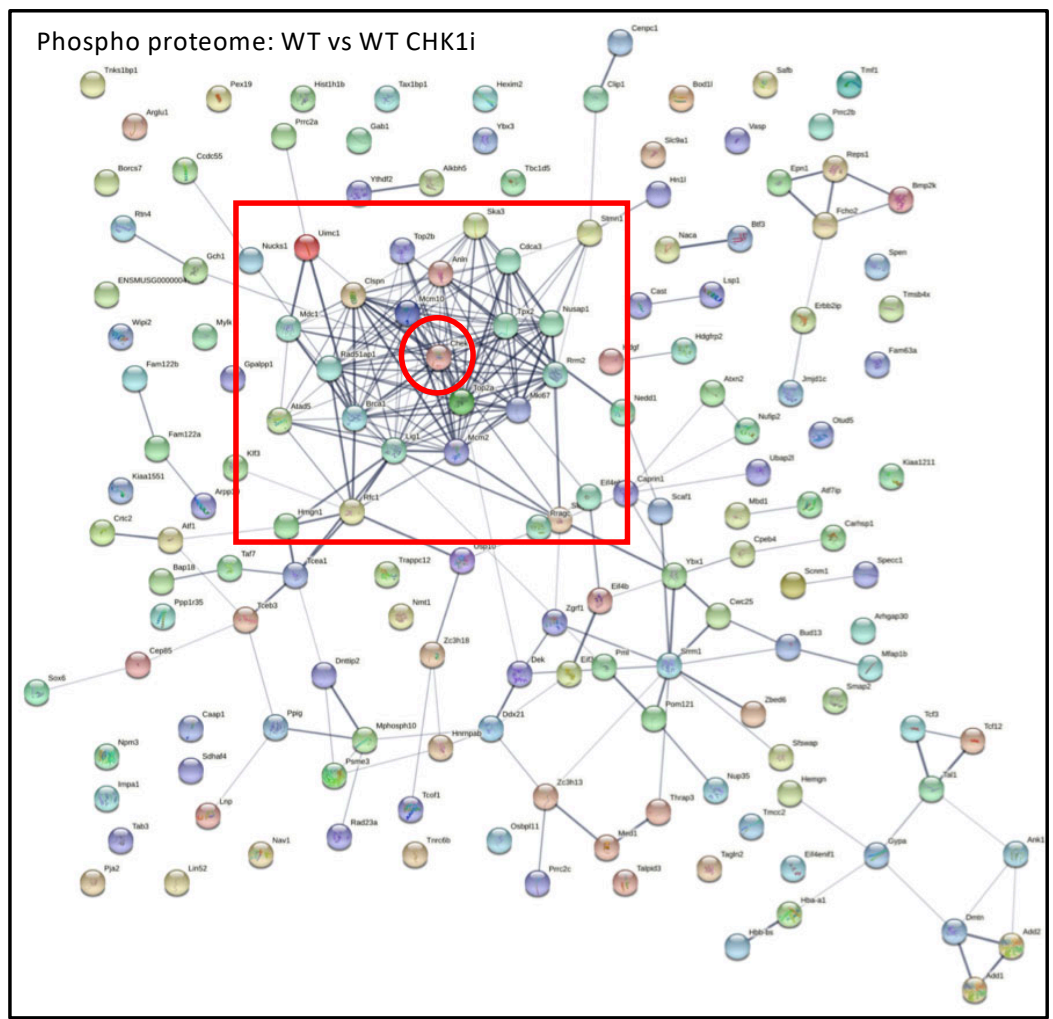

Mix 1:1 Fractionate

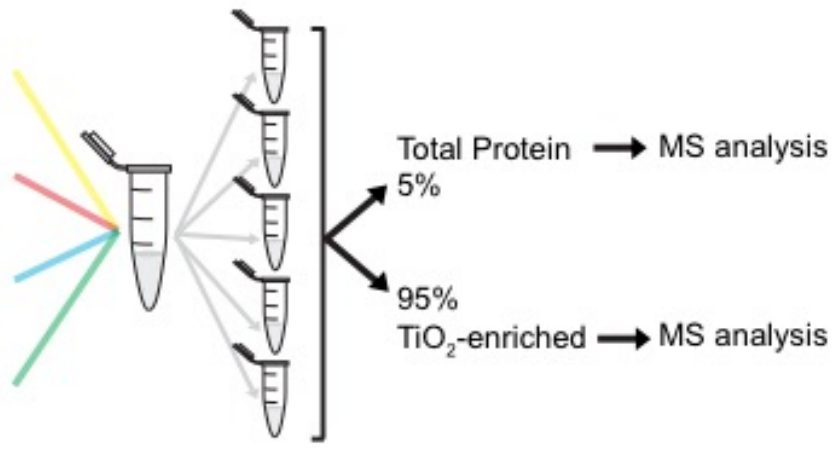

$\mathrm{D}$

\begin{tabular}{|c|c|c|}
\hline symbol & logFC & adj.P.Val \\
\hline Esm1 & -0.711236561 & 0.039222682 \\
\hline Supt3 & -0.38225412 & 0.046437539 \\
\hline Vat1 & 0.391107849 & 0.01114098 \\
\hline Pld3 & 0.422924968 & 0.042563989 \\
\hline Neurl3 & 0.460752568 & 0.031881387 \\
\hline Gas6 & 0.527275369 & 0.039222682 \\
\hline Slc30a1 & 0.596743199 & 0.022712666 \\
\hline Slc7a8 & 0.597998301 & 0.009197544 \\
\hline Hist3h2a & 0.613168446 & 0.003439054 \\
\hline Tsc22d1 & 0.634404018 & 0.022712666 \\
\hline Rasgef1b & 0.664719985 & 0.022712666 \\
\hline Msantd2 & 0.829963543 & 0.023788944 \\
\hline Cd4 & 0.850478722 & 0.0042644 \\
\hline Fam234a & 0.952577539 & 0.022712666 \\
\hline Fads6 & 0.961208608 & 0.046466435 \\
\hline Pou6f1 & 0.986354532 & 0.022712666 \\
\hline Gist1h171 & 1.003370582 & 0.01114098 \\
\hline Gm42653 & 1.14433723 & 0.022712666 \\
\hline
\end{tabular}


bioRxiv preprint doi: https://doi.org/10.1101/2021.05.26.445425. this version posted May 27 2021. The copyriaht holder for this preprint (which was not certified by peer review) is the author/funder, who has granted bioRxiv a license to display the preprint in perpetuity. It is made available under aCC-BY-NC-ND 4.0 International license.

Hunter et al., Supp Figure 3

A

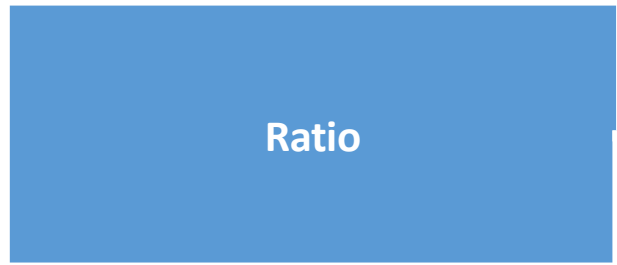

\begin{tabular}{|c|c|c|c|}
\hline \multicolumn{2}{|c|}{$\begin{array}{c}\text { \#Phosphopeptides } \\
\text { significant }\end{array}$} & \multicolumn{2}{|c|}{ \#Proteins significant } \\
\hline p value $\leq 0.05$ & $\begin{array}{c}q \text { value } \leq \\
0.1\end{array}$ & $\begin{array}{c}p \text { value } \leq \\
0.05\end{array}$ & $\begin{array}{c}\text { value } \leq \\
0.1\end{array}$ \\
\hline 625 & 165 & 622 & 0 \\
\hline 89 & 0 & 162 & 0 \\
\hline 1106 & 830 & 966 & 634 \\
\hline 691 & 31 & 943 & 394 \\
\hline
\end{tabular}

B

Phosphositeoverlap

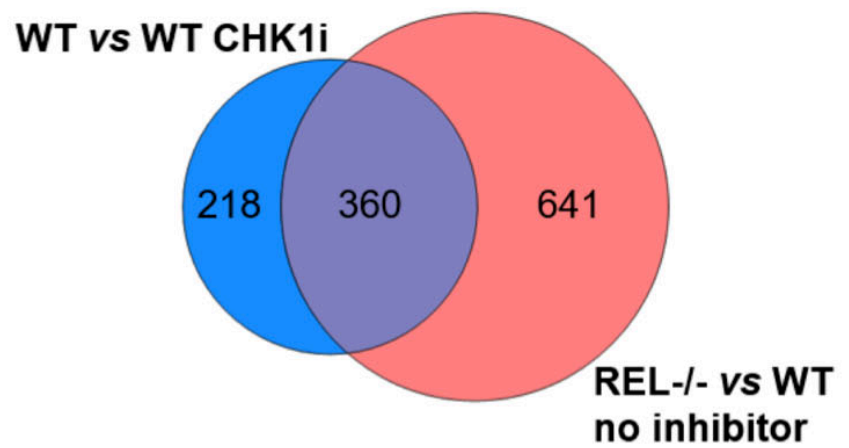

C

Total proteome overlap

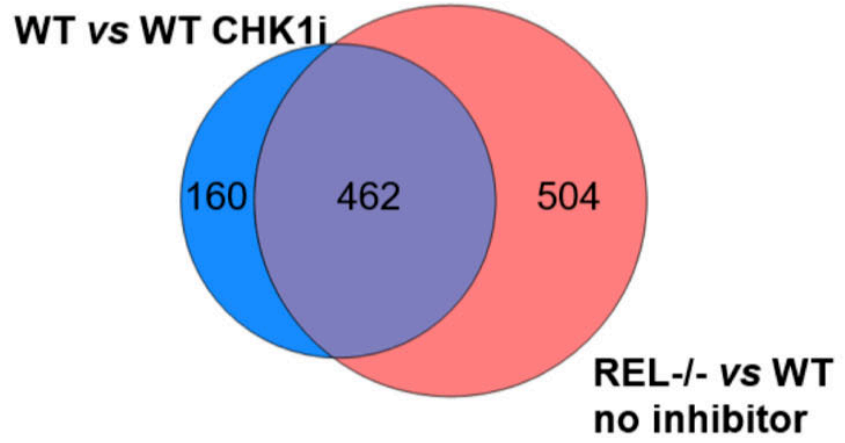

D

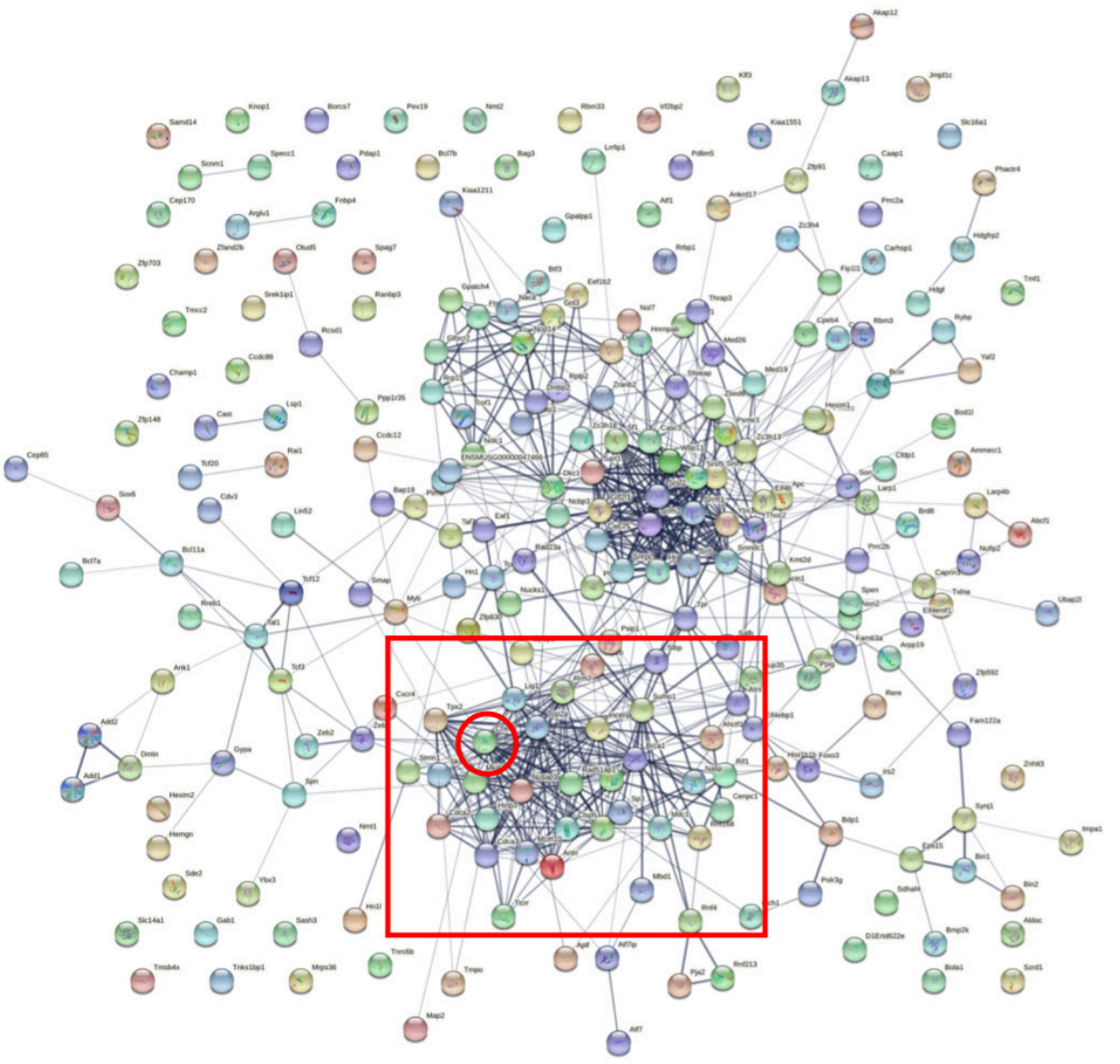


Hunter et al., Supp Figure 4
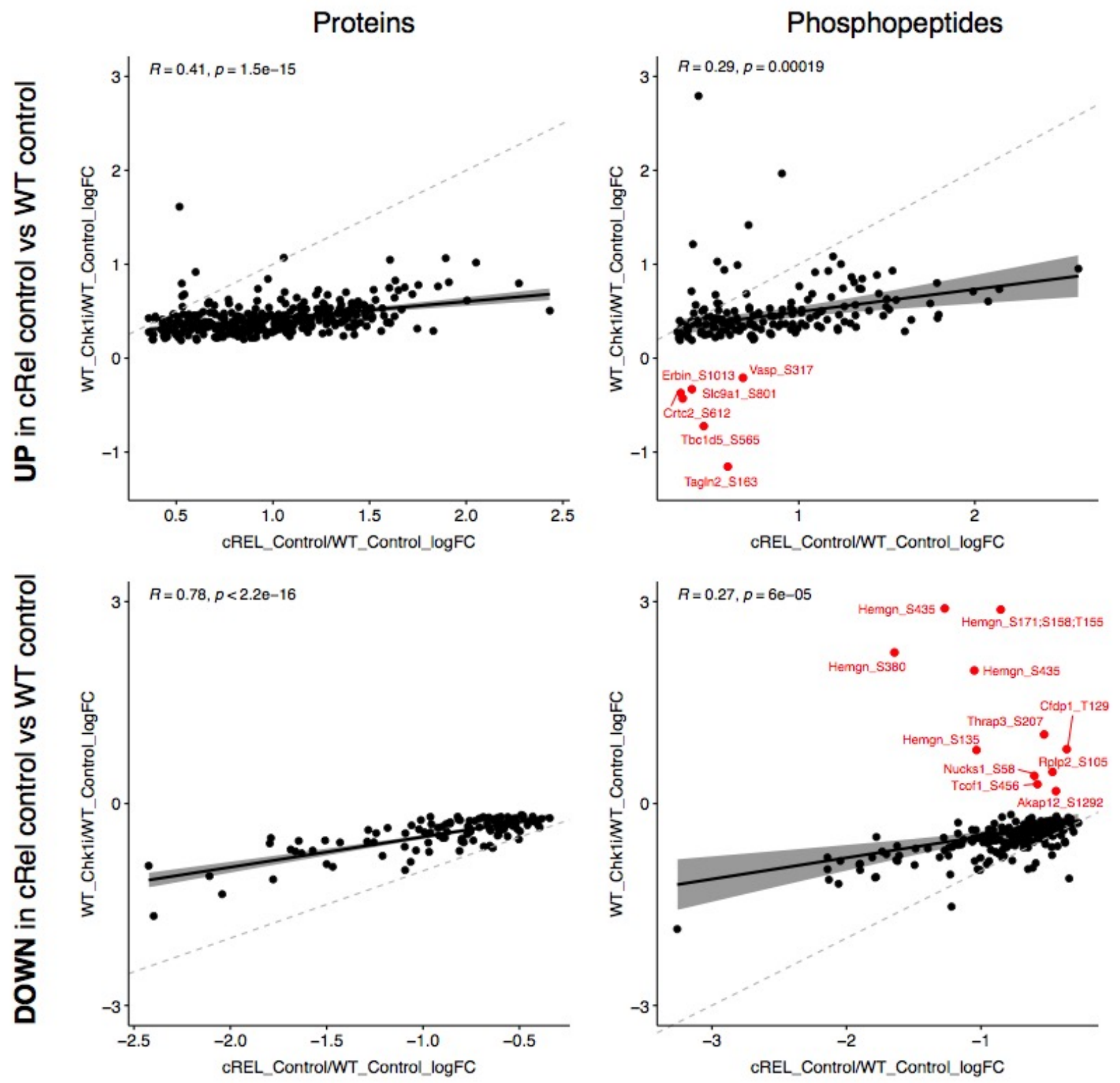

Correlation between phospho peptides and proteins up or down regulated in REL-/- vs WT and WT CHK1i vs WT 
bioRxiv preprint doi: https $/ /$ doi org/10.1101/2021.05 26.445425; this version posted May 27, 2021. The copyright holder for this preprint (which was not certified by peer review) is the author/funder, who has granted bioRxiv a license to display the preprint in perpetuity. It is made available under aCC-BY-NC-ND 4.0 International license.

\section{Hunter et al., Supp Figure 5}

A

\begin{tabular}{|c|c|c|}
\hline $\begin{array}{c}\text { ATR pathway } \\
\text { genes }\end{array}$ & $\begin{array}{c}\text { Fold change } \\
\text { log2 }\end{array}$ & Adj pvalue \\
\hline CDC25C & -2.70 & $1.36403 \mathrm{E}-16$ \\
\hline CHEK1 & -2.20 & $6.594 \mathrm{E}-13$ \\
\hline MCM10 & -2.17 & $2.28421 \mathrm{E}-10$ \\
\hline CDC6 & -2.11 & $9.66523 \mathrm{E}-12$ \\
\hline CLSPN & -2.00 & $8.45403 \mathrm{E}-12$ \\
\hline CDC45 & -1.92 & $6.48256 \mathrm{E}-14$ \\
\hline MCM6 & -1.73 & $2.11556 \mathrm{E}-13$ \\
\hline MCM3 & -1.66 & $8.28725 \mathrm{E}-13$ \\
\hline MCM5 & -1.65 & $3.58692 \mathrm{E}-12$ \\
\hline RFC4 & -1.63 & $4.52474 \mathrm{E}-12$ \\
\hline MCM7 & -1.60 & $1.56684 \mathrm{E}-13$ \\
\hline MCM2 & -1.59 & $8.19789 \mathrm{E}-11$ \\
\hline CDC7 & -1.53 & $2.68592 \mathrm{E}-15$ \\
\hline ORC2 & -1.46 & $1.51114 \mathrm{E}-17$ \\
\hline MCM4 & -1.40 & $1.23948 \mathrm{E}-12$ \\
\hline DBF4 & -1.36 & $4.71863 \mathrm{E}-14$ \\
\hline ORC6 & -1.36 & $5.89705 \mathrm{E}-13$ \\
\hline ORC1 & -1.30 & 0.00853 \\
\hline MCM8 & -1.28 & $8.84119 \mathrm{E}-11$ \\
\hline CDC25A & -1.19 & $3.67803 \mathrm{E}-12$ \\
\hline RFC5 & -1.17 & $1.51509 \mathrm{E}-10$ \\
\hline RPA3 & -1.16 & $1.54334 \mathrm{E}-09$ \\
\hline RPA2 & -1.15 & $1.13117 \mathrm{E}-10$ \\
\hline RFC3 & -1.09 & $8.4964 \mathrm{E}-11$ \\
\hline CDK2 & -1.00 & $2.59781 \mathrm{E}-17$ \\
\hline HUS1 & -0.98 & $7.83871 \mathrm{E}-08$ \\
\hline RFC2 & -0.91 & $3.52178 \mathrm{E}-13$ \\
\hline ORC5 & -0.76 & $1.11968 \mathrm{E}-14$ \\
\hline ORC4 & -0.69 & $3.98262 \mathrm{E}-07$ \\
\hline RPA1 & -0.65 & $4.74165 \mathrm{E}-10$ \\
\hline RAD1 & -0.64 & $1.81826 \mathrm{E}-09$ \\
\hline ATR & -0.59 & $1.24476 \mathrm{E}-08$ \\
\hline & & \\
\hline
\end{tabular}

B

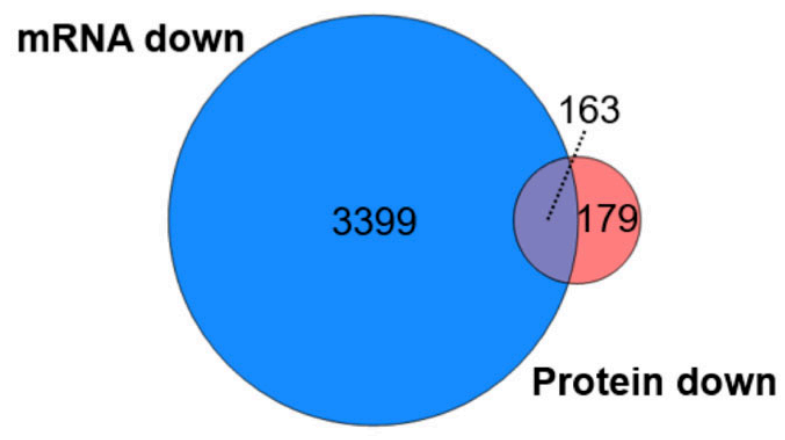

RNA Seq vs total proteome overlap: down in REL-/- vs WT

C

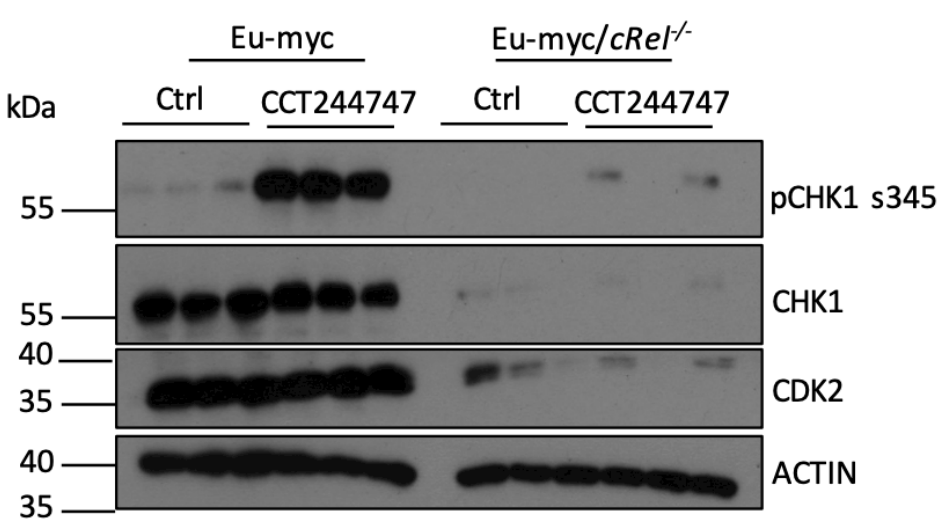


bioRxiv preprint doi: https://doi. org/10.1101/2021.05 26.445425; this version posted May 27,2021 . The copyright holder for this preprint (which was not certified by peer review) is the author/funder, who has granted bioRxiv a license to display the preprint in perpetuity. It is made available under aCC-BY-NC-ND 4.0 International license.

\section{Hunter et al., Suppl Figure 6}

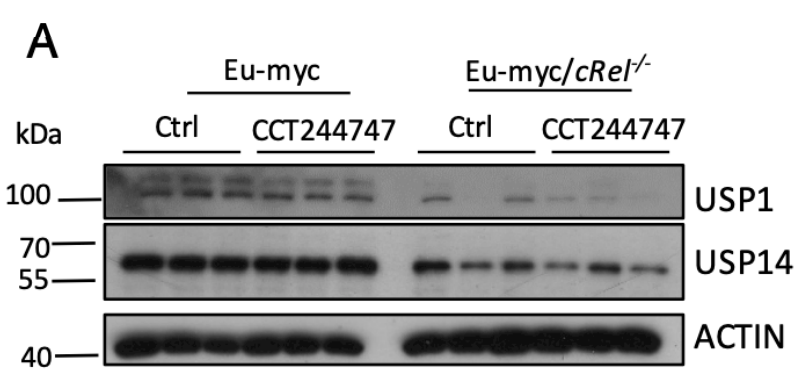

B
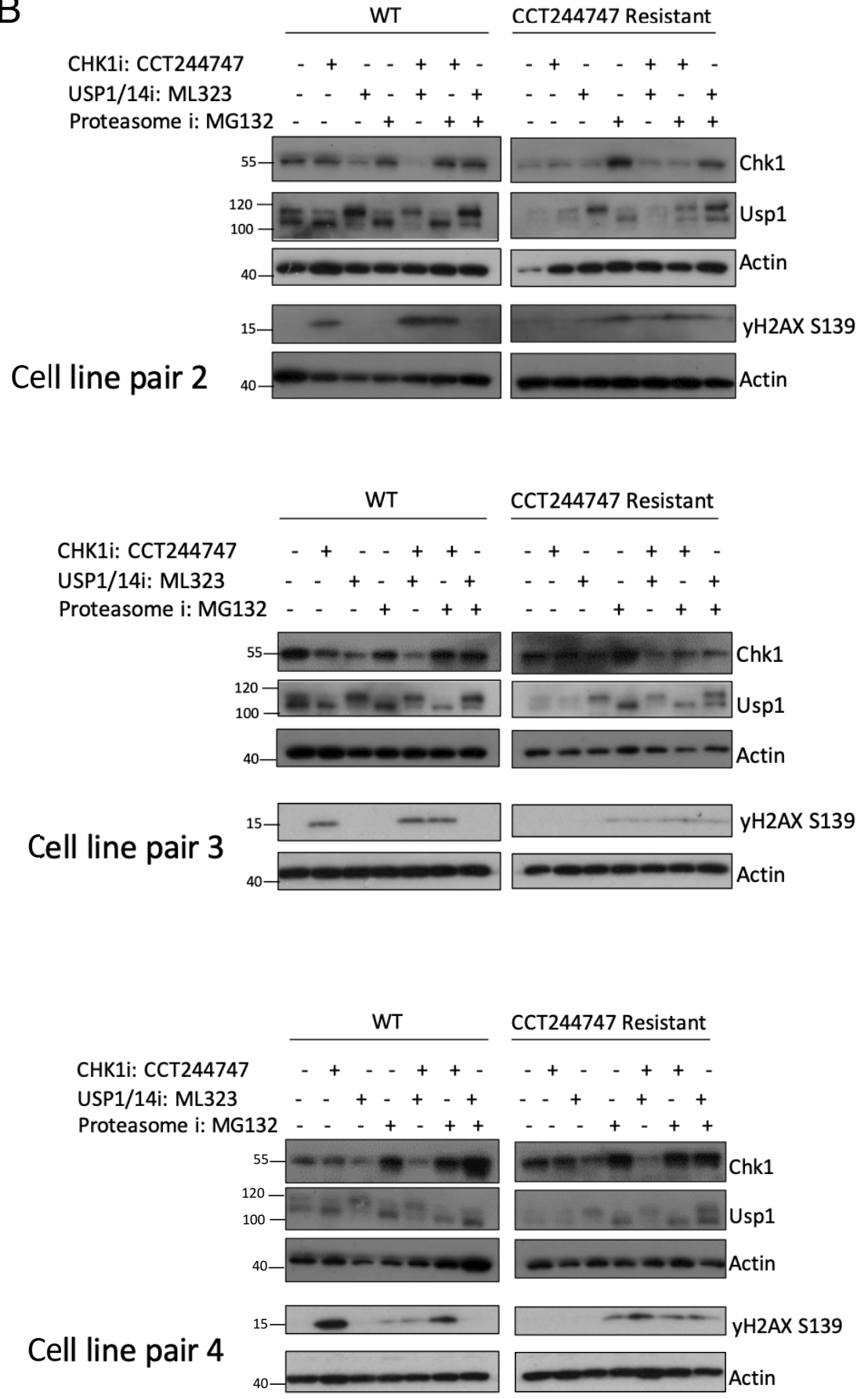
bioRxiv preprint doi: https://doi org/10.1101/2021.0526.445425. this version posted May 27, 2021. The copyright holder for this preprint (which was not certified by peer review) is the author/funder, who has granted bioRxiv a license to display the preprint in perpetuity. It is made available under aCC-BY-NC-ND 4.0 International license.

\section{Hunter et al., Supp Figure 7}

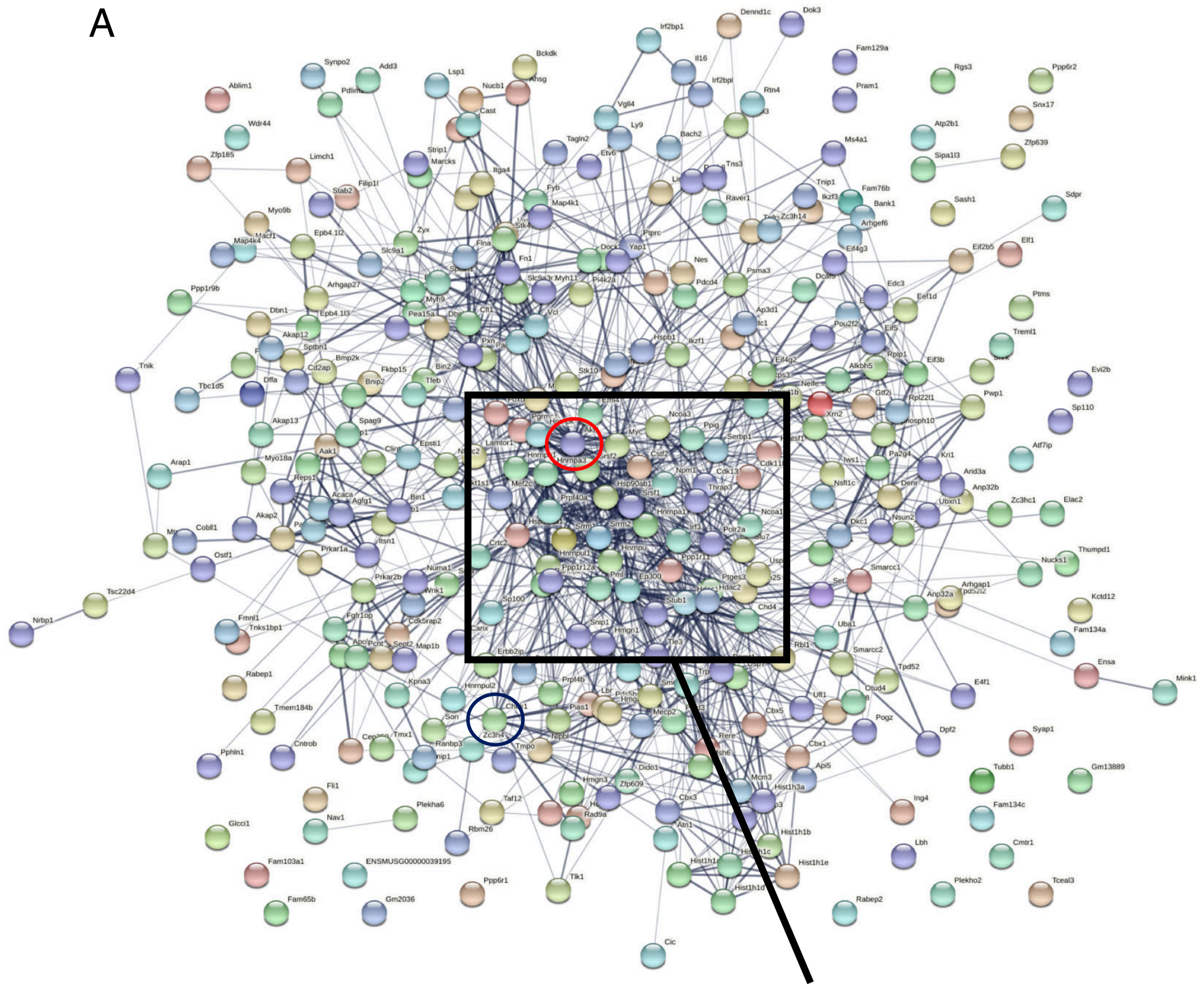

AKT1 linked cluster of phospho proteins (see Table S1) 
bioRxiv preprint doi: https://doi.org/10.1101/2021.05.26.445425; this version posted May 27, 2021. The copyright holder for this preprint (which was not certified by peer review) is the author/funder, who has granted bioRxiv a license to display the preprint in perpetuity. It is made available under aCC-BY-NC-ND 4.0 International license.

\section{Hunter et al., Supp Table 1}

\begin{tabular}{|c|c|c|c|}
\hline \multicolumn{4}{|c|}{$\begin{array}{l}\text { STRING links to proteins with upregulated phosphorylation in } \\
\text { REL-/- cells vs WT }\end{array}$} \\
\hline AKT1 & $\begin{array}{c}\text { ERK1 } \\
\text { (MAPK3) }\end{array}$ & $\begin{array}{l}\text { JNK1 } \\
\text { (MAPK8) }\end{array}$ & $\begin{array}{l}\text { p38 MAPK } \\
\text { (MAPK14) }\end{array}$ \\
\hline Abi1 & Abi1 & Akt1s1 & Arhgap27 \\
\hline Acaca & Akt1 & Atn1 & Bnip2 \\
\hline Acin 1 & Akt1s1 & $\mathrm{Bc} 110$ & $\mathrm{Cfl} 1$ \\
\hline Akt1s1 & Canx & Bin2 & Fn1 \\
\hline Arhgap1 & $\mathrm{Cfl1}$ & Canx & Foxo1 \\
\hline Bach2 & $\mathrm{Cic}$ & $\mathrm{Cfl1}$ & Hdac1 \\
\hline $\mathrm{Bcl} 10$ & Ep300 & Dbnl & Hdac2 \\
\hline Canx & Fn1 & Ep300 & Hnrnpa1 \\
\hline Cast & Foxo1 & Erbb2ip & Hnrnpk \\
\hline Cfl1 & Hdac1 & $\mathrm{Fn} 1$ & Hsp90aa1 \\
\hline Crtc2 & Hdac2 & Foxo1 & Hsp90ab1 \\
\hline Dennd1b & Hnrnpk & Hdac1 & $\mathrm{Hspb1}$ \\
\hline Dnmt1 & Hsp90aa1 & Hdac2 & Irf3 \\
\hline Dock2 & Hsp90ab1 & Hnrnpk & Lcp1 \\
\hline Edc3 & Hspb1 & Hsp90aa1 & Mef2c \\
\hline Eml4 & Irf3 & Hsp90ab1 & Myc \\
\hline Ep300 & Lcp1 & Hspb1 & Ncoa3 \\
\hline Flna & Mef2c & Irf3 & Nfatc2 \\
\hline Fn1 & Myc & Lcp1 & Nfkb1 \\
\hline Foxo1 & Ncoa3 & Map1b & Pea15a \\
\hline Hdac1 & Nes & Myc & Ptprc \\
\hline Hdac2 & Nfkb1 & Ncoa3 & Pxn \\
\hline Hnrnpa1 & Pea15a & Nfatc2 & Slc9a1 \\
\hline Hsp90aa1 & Ppp1r12a & Nfkb1 & Spag9 \\
\hline Hsp90ab1 & Ptges3 & Palld & $\mathrm{Vcl}$ \\
\hline Hspb1 & Ptprc & Ptprc & Yap1 \\
\hline Irf3 & Pxn & Pxn & \\
\hline Iws1 & SIc9a1 & Spag9 & \\
\hline Lamtor1 & Stub1 & Sptan1 & \\
\hline Lbr & Tnfrsf13c & $\mathrm{Vcl}$ & \\
\hline Lcp1 & $\mathrm{Vcl}$ & Yap1 & \\
\hline Map1b & Yap1 & & \\
\hline \multicolumn{4}{|l|}{ Mapk14 } \\
\hline \multicolumn{4}{|l|}{ Marcks } \\
\hline \multicolumn{4}{|l|}{ Mef2c } \\
\hline \multicolumn{4}{|l|}{ Myc } \\
\hline \multicolumn{4}{|l|}{ Myh9 } \\
\hline \multicolumn{4}{|l|}{ Ncoa3 } \\
\hline \multicolumn{4}{|l|}{ Nes } \\
\hline \multicolumn{4}{|l|}{ Nfatc2 } \\
\hline \multicolumn{4}{|l|}{ Nfkb1 } \\
\hline \multicolumn{4}{|l|}{$\mathrm{Npm1}$} \\
\hline Ostf1 & & & \\
\hline $\mathrm{Pa} 2 \mathrm{~g} 4$ & & & \\
\hline Palld & & & \\
\hline Pdcd4 & & & \\
\hline Pea15a & & & \\
\hline Pml & & & \\
\hline Ppig & & & \\
\hline Ptprc & & & \\
\hline Pxn & & & \\
\hline Ranbp3 & & & \\
\hline Rbl1 & & & \\
\hline $\mathrm{Rbm} 25$ & & & \\
\hline Rplp0 & & & \\
\hline Rps3 & & & \\
\hline SIc9a1 & & & \\
\hline SIc9a3r1 & & & \\
\hline Srsf1 & & & \\
\hline Stk4 & & & \\
\hline Stub1 & & & \\
\hline Tfeb & & & \\
\hline Tnfrsf13c & & & \\
\hline Tns3 & & & \\
\hline Trp53bp1 & & & \\
\hline Usp7 & & & \\
\hline Usp8 & & & \\
\hline Vasp & & & \\
\hline $\mathrm{Vcl}$ & & & \\
\hline Yap1 & & & \\
\hline Zyx & & & \\
\hline
\end{tabular}


bioRxiv preprint doi: https://doi org/10.1101/2021.05.26.445425. this version posted May 27 2021. The copyriaht holder for this preprint (which was not certified by peer review) is the author/funder, who has granted bioRxiv a license to display the preprint in perpetuity. It is made available under aCC-BY-NC-ND 4.0 International license.

\section{Hunter et al., Supp Figure 8}

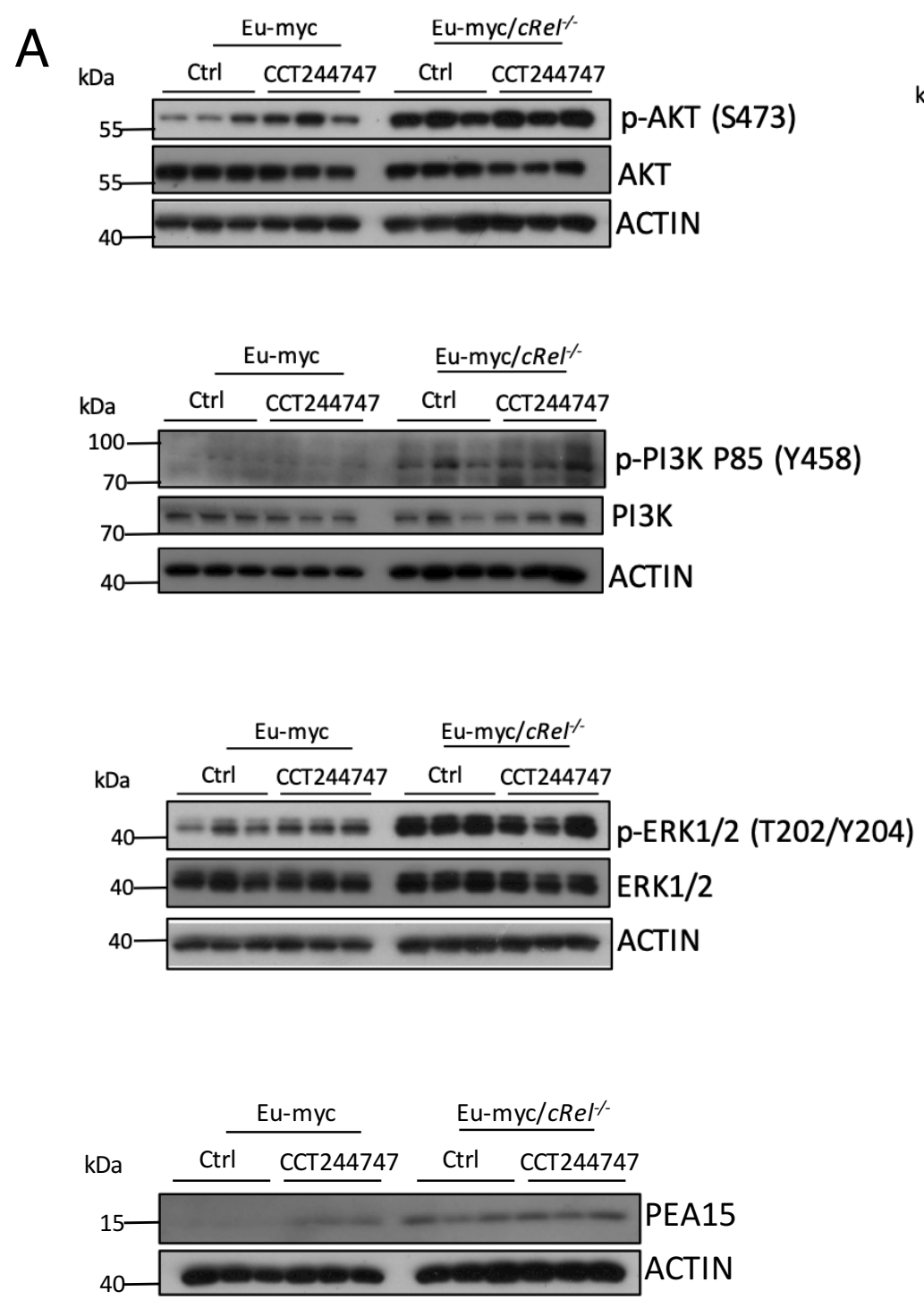

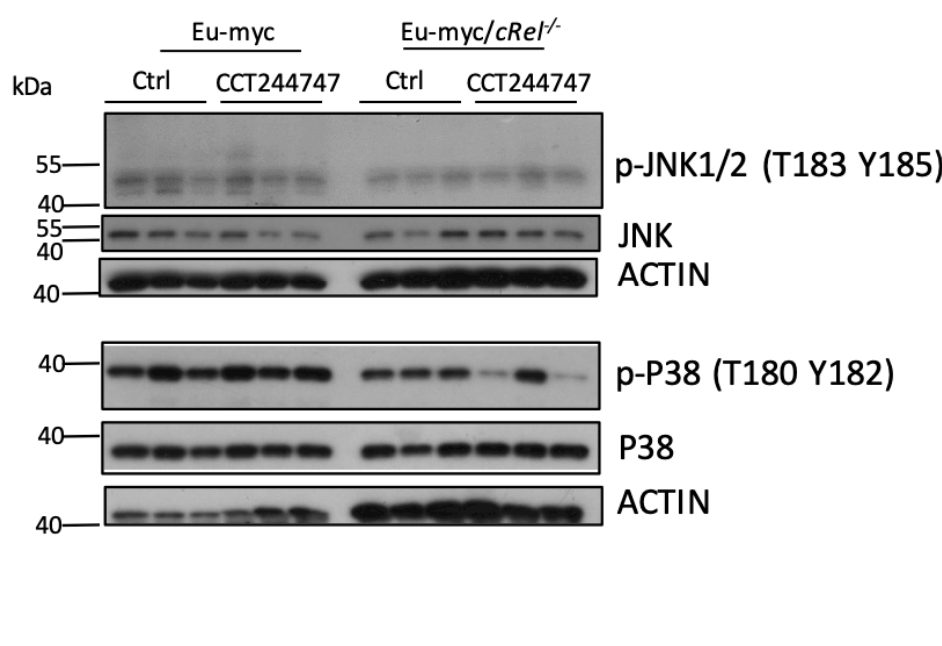


Hunter et al., Suppl Figure 9

WT Tumour 1

A

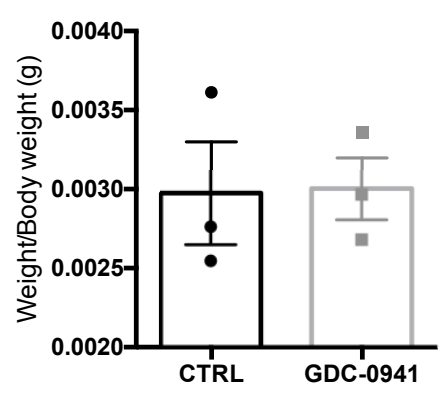

cRel $^{-/-}$Tumour 1

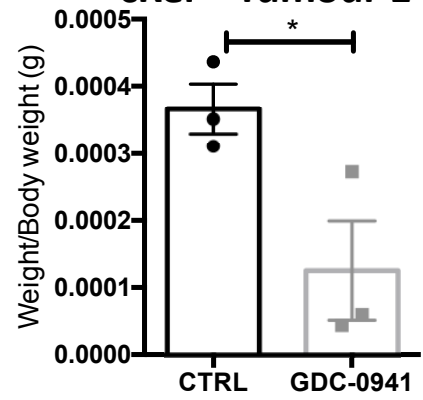

B

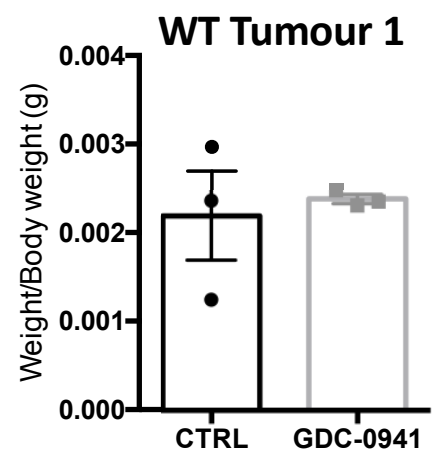

cRel $^{-/-}$Tumour 1

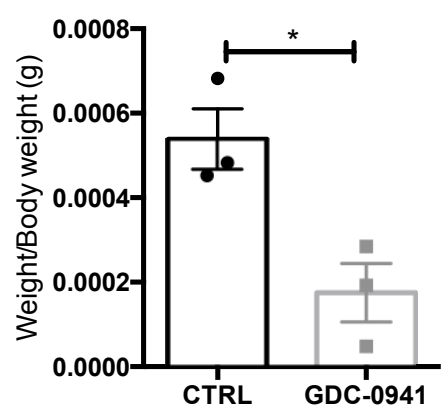

WT Tumour 2

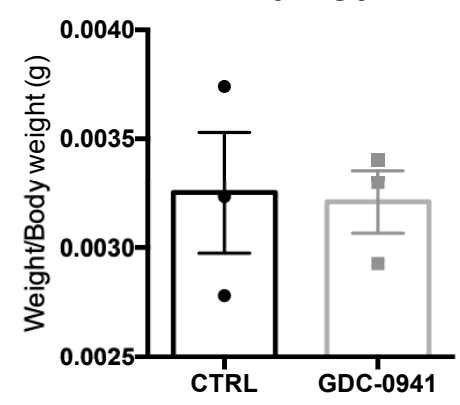

cRel ${ }^{-/-}$Tumour 2

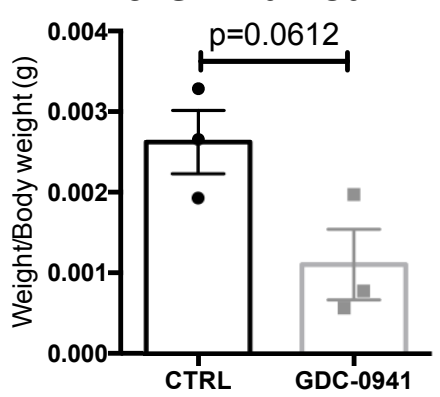

WT Tumour 2

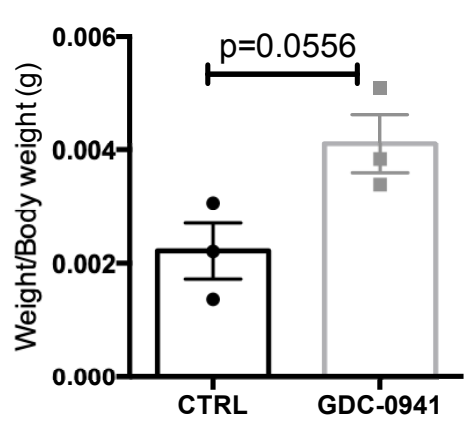

cRel $^{-/-}$Tumour 2

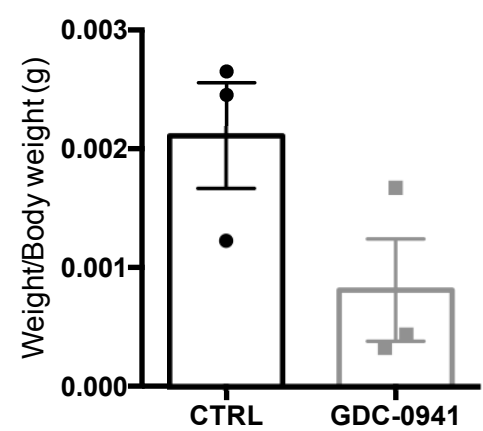

WT Tumour 3

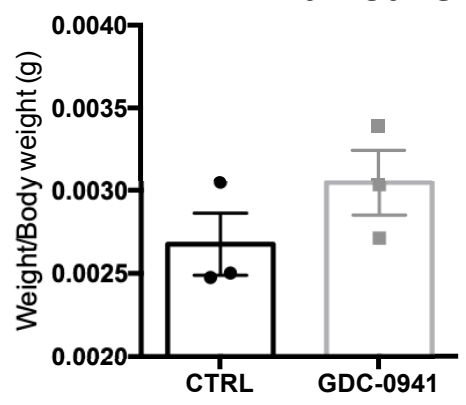

cRel $^{-/-}$Tumour 3

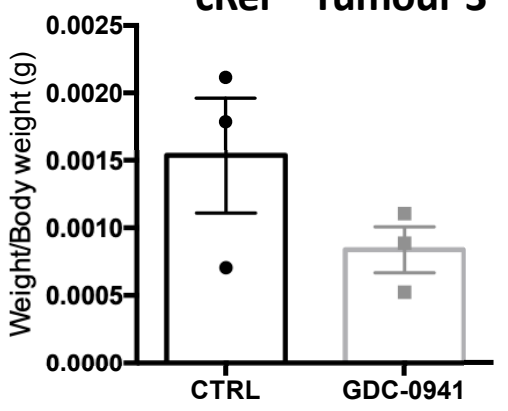

Inguinal Lymph node

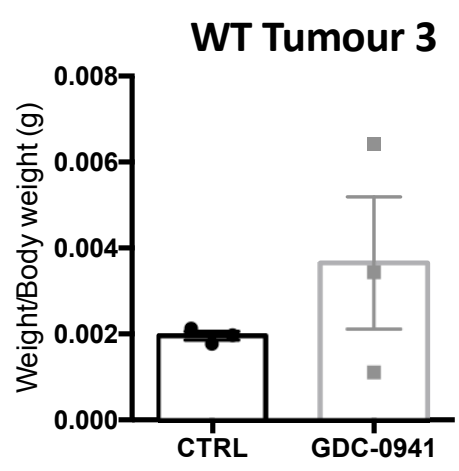

cRel $^{-/-}$Tumour 3

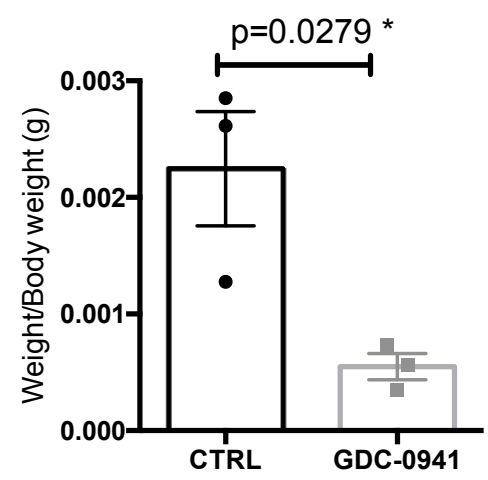


Hunter et al., Suppl Figure 10

A

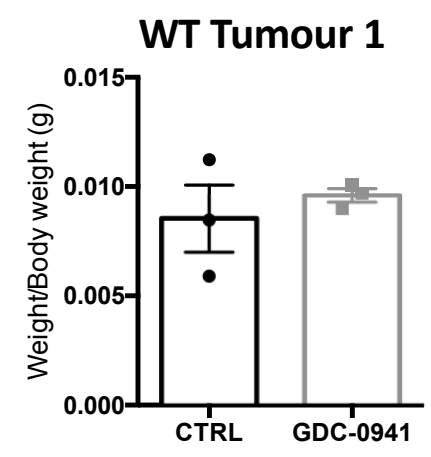

cRel $^{-/-}$Tumour 1

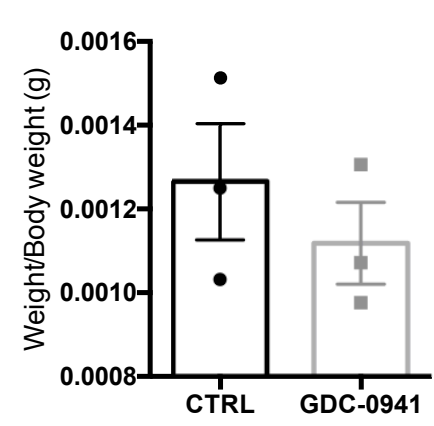

WT Tumour 1

B

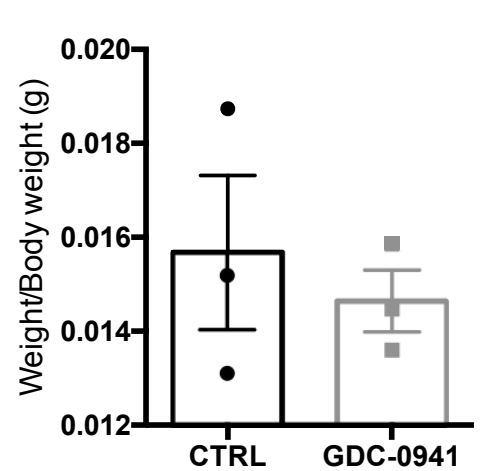

cRel $^{-/-}$Tumour 1

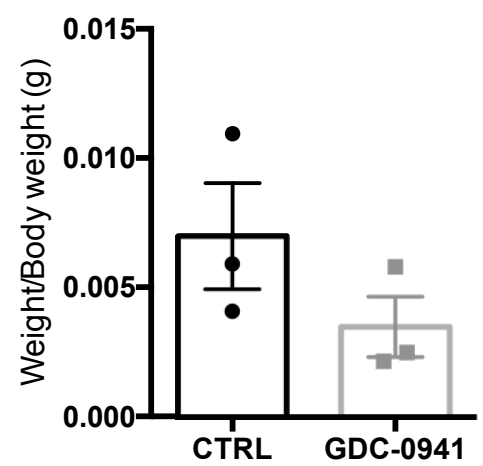

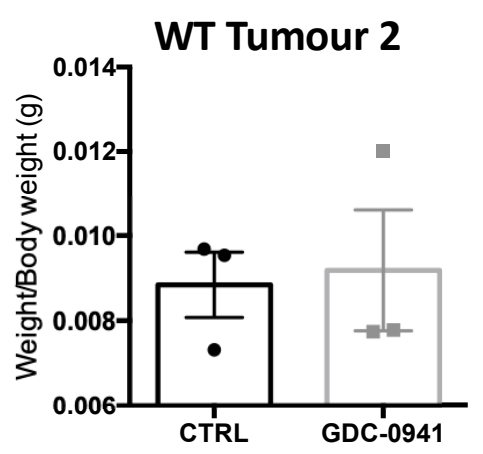

cRel $^{-/-}$Tumour 2

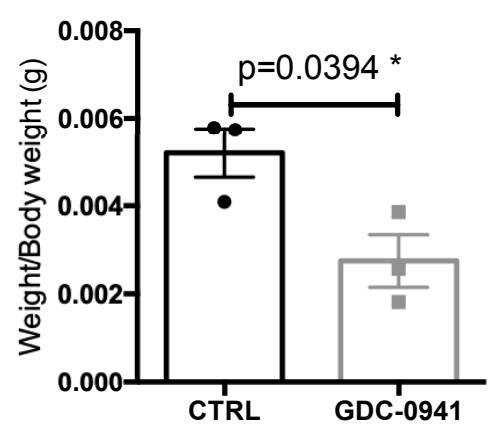

WT Tumour 2

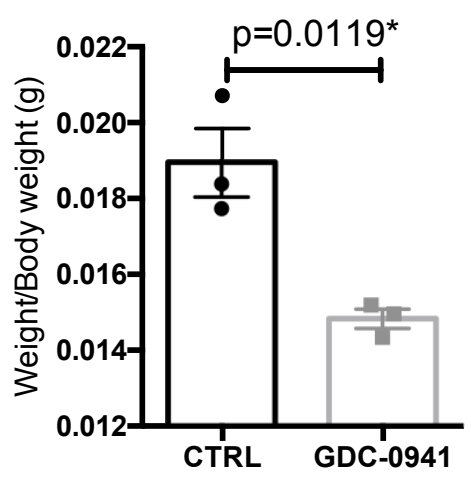

cRel $^{-/-}$Tumour 2

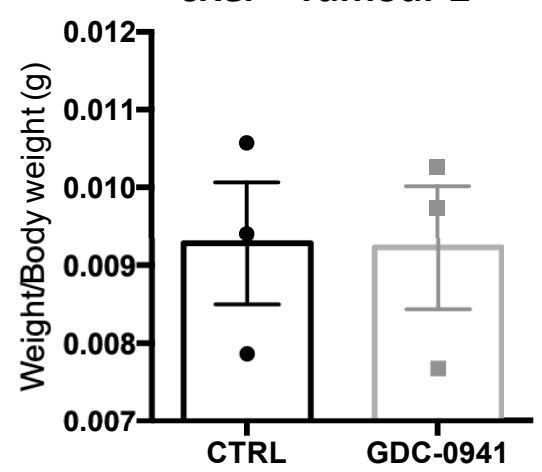

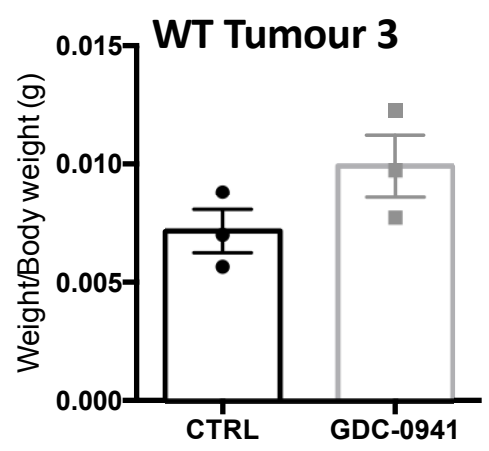

cRel $^{-/-}$Tumour 3

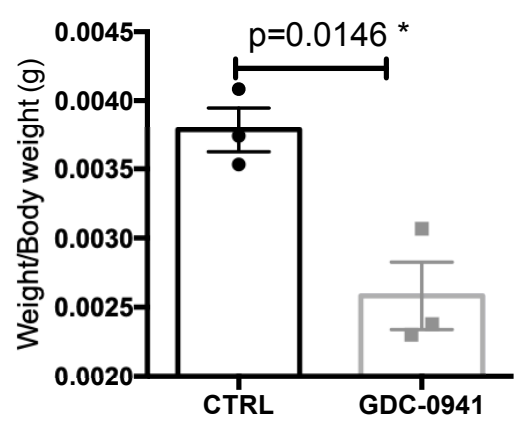

Mesenteric Lymph node

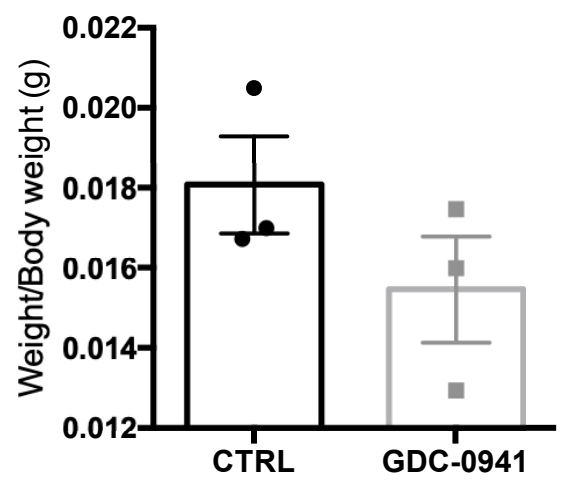

cRel $^{-/-}$Tumour 3

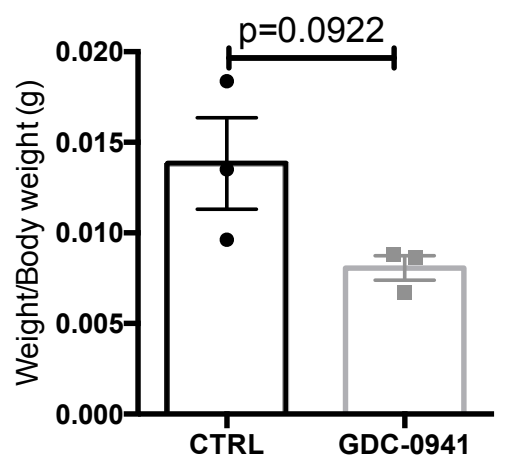

